\title{
MÉTODO PARA ESTIMATIVA DE IRRADIÂNCIA SOLAR GLOBAL ATRAVÉS DE MEDIDAS DE PERIODOS DE INSOLAÇÃO
}

\author{
REKATO CRUZ SIEMA \\ METEOROLOGISTA
}

Orientador: Prof. Dr. Luiz Roberto Angelocci

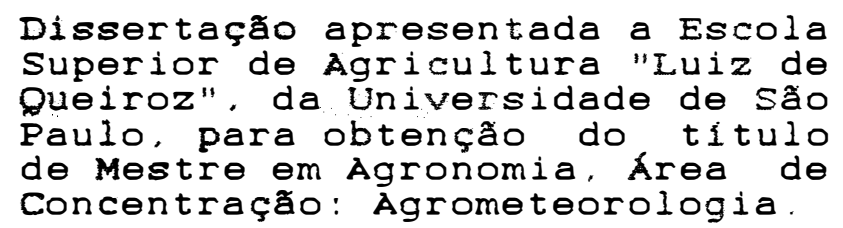

PIRACICABA

Estado de são Paulo - Brasil

Setembro - 1992 
Ficha catalográfica preparada pela Seçao de Livros da Divisao de Biblioteca e Documentaçao - PCAP/USP

\footnotetext{
Senna, Renato Cruz Metodo para estimativa de irradiância solar global atraves de medidas de periodos de insolaczo. Piracicaba, 1992.

Diss. (Mestre) - ESALQ

Bibliografia.

1. Insolaçao - Periodo 2. Radiaçao solar - Estima tiva - Metodo I. Escola Superior de Agricultura Luiz de Queiroz, Piracicaba
} 


\section{MÉTODO PARA ESTIMATIVA DE IRRADIÂNCIA SOLAR GLOBAL ATRAVÉS DE MEDIDAS DE PERIODOS DE INSOLAÇÃO}

Aprovado em 17.09 .92

Comissão julgadora

Prof, Dr, Luiz Roberto Angelocci

ESAIQ USP

Prof. Dr, Marcelo Bento Paes de Camargo

IAC

Prof. Dr, Romisio Geraldo Bouhid André

ECAV/UNESP

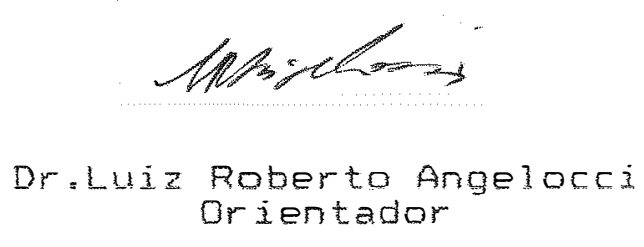




\section{SUMARIO}

Pagina

LISTA DE FIGURAS .........................

LISTA DE TABELAS..............................

LISTA DE SIMBOLOS...........................

RESUMO $\ldots \ldots \ldots \ldots \ldots \ldots \ldots \ldots \ldots \ldots \ldots \ldots \ldots \ldots \ldots \ldots \ldots \ldots \ldots \ldots \ldots$

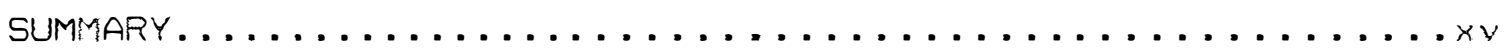

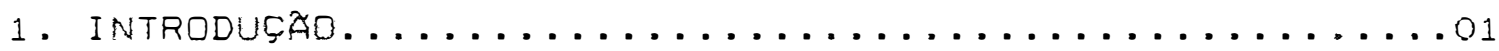

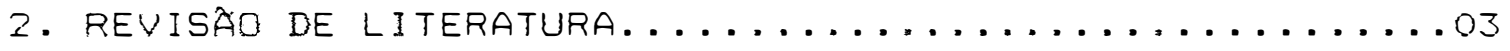

3. MATERIAL E METODOS.........................

3.1. Dados coletados.........................

3.1.1. Irradiância solar global............12

3.1.2. Insolą̧о..........................

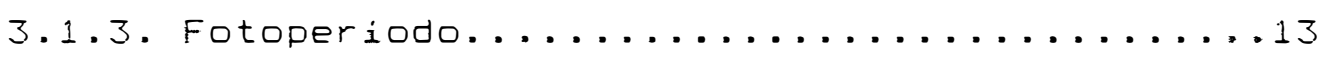

3.1.4. Irradiância solar global na ausência da

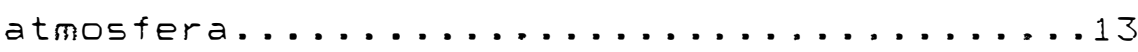

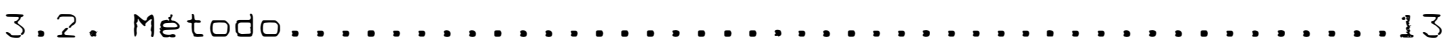

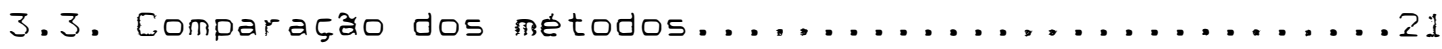

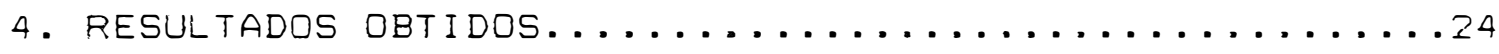

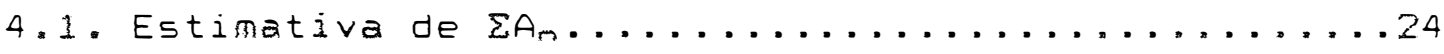

4.2. Estimativa dos coeficientes de transmissividade da atmosfera "Ta" e das nuvens "Tw"...........24

4.3. Estimativa da relaça "Q/Q。" pelo metodo

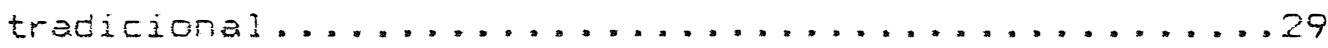

4.4. Estimativa da relaçao " $Q / Q_{0}$ " pelo método

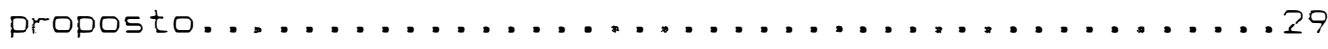

4.5. Resultado dos testes.......................29 
Pagina

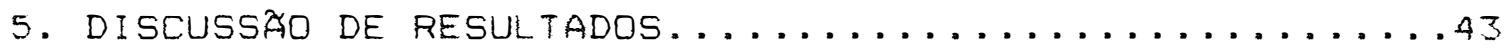

6. conclusues e recomendaçio....................47

REFERENCIAS BIBLIOGRAFICAS.....................

APENDICE................................. 
Figura 1. Distribuiço teorica e real da radiaça solar no limite mais externo da atmosfera e ao nivel da superficie..............

Figura 2. Representaçao esquemática dos periodos

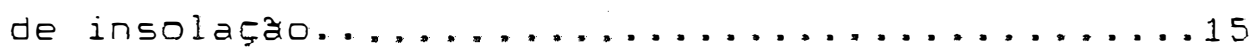

Figura 3. Posiça relativa das nuvens em altitude na atmosfera da Terra.................

Figura 4. Variaçăo da irradiancia solar ao longo do dia sem presença de nuvens.................

Figura 5. Representaça esquematica do modelo proposto...16 Figura 6. Representaçao esquemática da tira

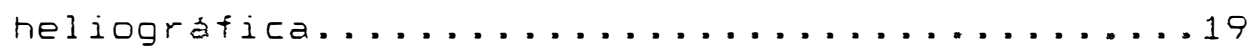

Figura 7a. Teste MBE para o método tradicional de janeiro a juntio..........................

Figura 7b. Teste MBE para o método proposto de janeiro a junto...........................

Figura 8a. Teste MBE para o método tradicional de jultio a dezembro........................

Figura 8b. Teste MBE para o método proposto de

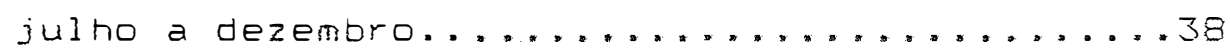

Figura 9a. Teste RMSE para o método tradicional de

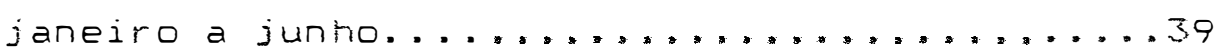

Figura 9b. Teste RMSE para o método proposto de janeiro a junto...................... 
Figura 10a. Teste RMSE para o metodo tradicional de

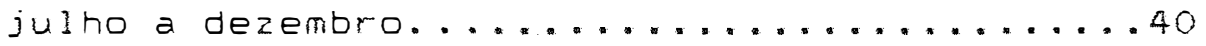

Figura 10b. Teste RMSE para o metodo proposto de

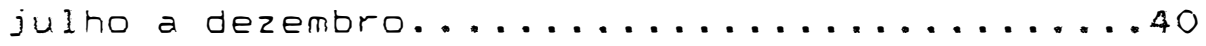

Figura 11 a. Teste MPE para o metodo tradicional de

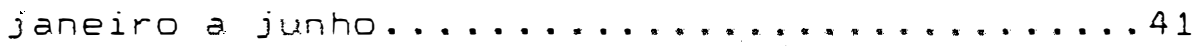

Figura 11b. Teste MPE para o metodo proposto de

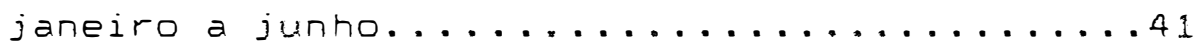

Figura 12a. Teste MPE para o metodo tradicional de

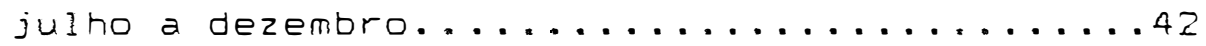

Figura 12b. Teste MPE para o metodo proposto de

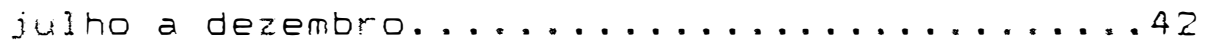




\section{LISTA DE TABELAS}

Pagina

Tabela 1. Composi ̧ăo média da atmosfera limpa...........04

Tabela 2. Correçao dos limites e integraçao da area para um dia hipotético.................

Tabela 3a. Valores máximos observados de $\Sigma A_{n}$ e $Q / Q_{b}$, janeiro e fevereiro...................

Tabela 3b. Valores máximos observados de $\Sigma A_{n} \in Q / Q_{0}$,

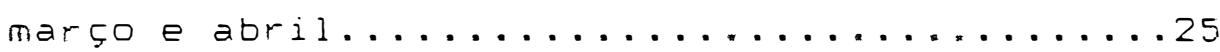

Tabela 3c. Valores máximos observados de $\Sigma A_{n}$ e $Q / Q_{0}$,

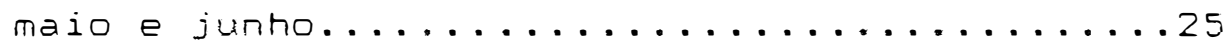

Tabela 3d. Valores máximos observados de $\Sigma A_{n} e Q_{1} Q_{0}$,

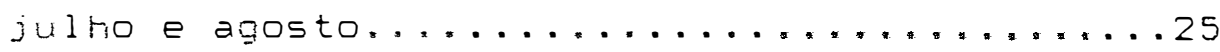

Tabela 3e. Valores máximos observados de $\Sigma A_{n}$ e $Q / Q_{0}$,

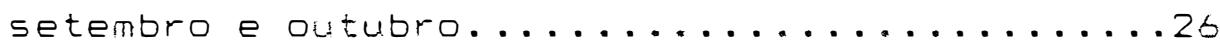

Tabela $3 f$. Valores máximos observados de $\Sigma A_{n} \in Q / Q_{1}$,

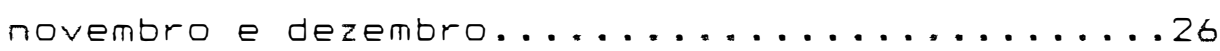

Tabela $4 a$. Valores minimos observados de $\Sigma A_{n}$ e $Q / Q_{o}$, janeiro e fevereiro...................

Tabela 4b. Valores minimos observados de $\sum A_{n}$ e $Q / Q_{0}$,

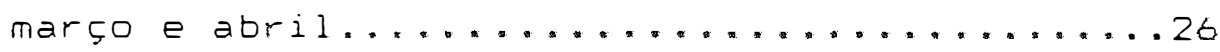

Tabela 4c. Valores minimos observados de $\sum A_{n}$ e $Q / Q_{a}$,

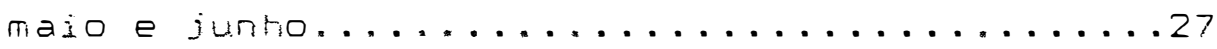

Tabela 4d. Valores minimos observados de $\Sigma A_{m}$ e $Q / Q_{1}$,

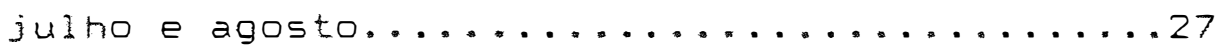

Tabela 4e. Valores minimos observados de $\Sigma A_{n}$ e $Q / Q_{0}$,

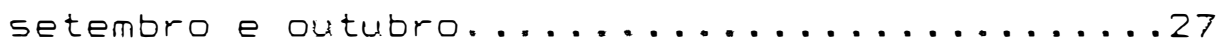


Tabela $4 f$. Valores minimos observados de $\Sigma A_{n} \in Q / Q_{1}$,

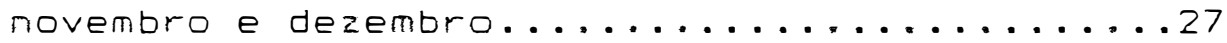

Tabela 5. Valores calculados de "Ta" e "Tr"..........29

Tabela 6. Medias bimestrais dos testes................

Tabela 7. Coeficientes das retas de regressao entre os valores observados e calculados, indice "d"...30

Tabela 8. Estimativas diarias da relaça $Q / Q_{0}$ segundo 0 método tradicional (Q1/Qo)e o método proposto $(Q 2 / Q 0)$, com os resultados dos testes MBE, RMSE e MPE para cada método. Janeiro e fevereiro....31

Tabela 9. Estimativas diarias da relaçăo Q/Qo segundo o método tradicional (Q1/Qo) e o método proposto (Q2;Q0), com os resultados dos testes MBE, RMSE e MPE para cada método. Março e abril........32

Tabela 10. Estimativas diarias da relacao $Q / Q_{0}$ segundo método tradicional $(Q 1 / Q 0)$ e o método proposto $\left(Q 2, Q_{0}\right)$, com os resultados dos testes MBE, RMSE e MPE para cada método. Maio e junho.........33

Tabela 11. Estimativas diárias da relaço $Q / Q_{0}$ segundo 0 método tradicional (Q1/Qo) e o método proposto (Q2/Qo), com os resultados dos testes MBE, RMSE e MPE para cada método. Julho e agosto.......34 Tabela 12. Estimativas diarias da relaça Q/Qo segundo o método tradicional (Q1/Qo) e o método proposto (Q2/Qo), com os resultados dos testes MBE, RMSE e MPE para cada método. Setembro e outubro..... S5 
Página

Tabela 13. Estimativas diárias da relaçao $Q / Q_{0}$ segundo 0 método tradicional $\left(Q 1 / Q_{0}\right)$ e o método proposto $\left(Q 2 / Q_{0}\right)$, com os resultados dos testes MBE, RMSE e MPE para cada método. Novembro e dezembro....36 


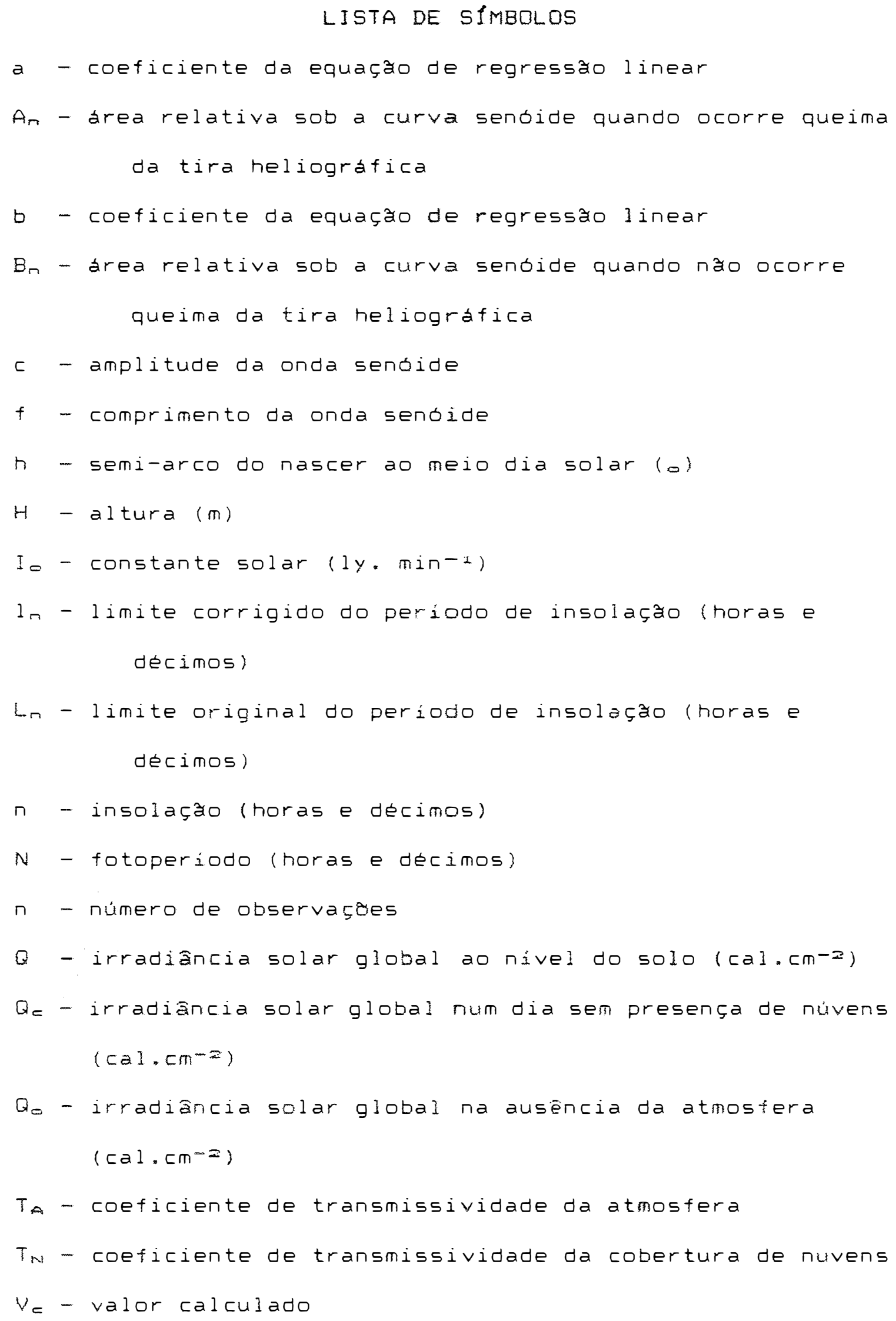




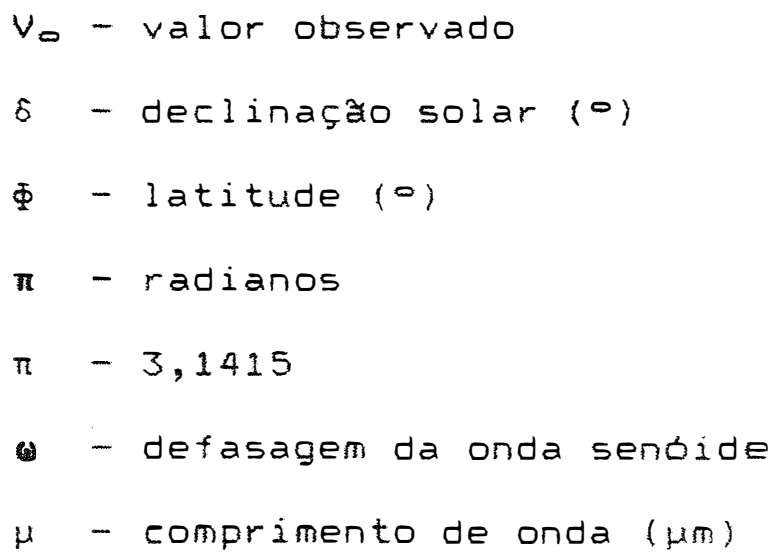


$x i i$

\title{
MÉTODO PARA ESTIMATIVA DE IRRADIÂNCIA SOLAR GLOBAL ATRAVÉS DE MEDIDAS DE PERIODOS DE INSOLAÇÃO
}

\author{
Autor: Renato Cruz Senna \\ Orientador: Prof. Dr. Luiz Roberto Angelocci
}

RESUMO

O presente trabalho trata do desenvolvimento de um método de estimativa da irradiancia global diária através dos periodos de insolação registrados pelo heliografo tipo Campbell-Stokes. O método de estimativa difere do tradicional uma vez que integra os perlodos de insolação através de uma curva senóide empregando os coeficientes de transmissividade atmosferica e da cobertura de nuvens, os quais foram estimados bimestralmente através da média dos valores extremos de irradiancia solar global e da area sob a curva senoide.

Para o desenvolvimento do método utilizou-se dados de irradiancia global medidos pelo piranómetro Eppley padrão, instalado no campus da Escola superior de Agricultura Iuiz de Queiroz, da Universidade de São Paulo, na cidade de Piracicaba llatitude $22^{\circ} 42^{\prime 3} 30^{\prime \prime} \mathrm{S}$ e longitude

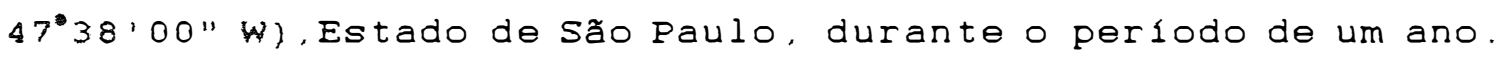

como resultado, obteve-se a equação:

$$
0 / 0_{0}-T_{A}\left[\sum A_{z}+T_{H}\left(I-\sum A_{D}\right)\right]
$$


onde:

$\varnothing$ = irradiancia estimada ao nivel do solo (cal. $\mathrm{cm}^{-2}$ ).

8. = irradiancia na ausancia da atmosfera (cal. $\mathrm{cm}^{-2}$ ).

$T_{\text {: }}$ coeficiente de transmissividade da atmosfera.

$T_{\text {M }}=$ coeficiente de transmissividade da cobertura de nuvens. $A_{a}=$ area integrada sob a curva senóide.

Na comparação com o método tradicional, utilizando-se os coeficientes proposto por Ometto (1968), - metodo proposto revelou-se superior para as estimativas diárias, melhorando os resultados nos meses de inverno local. são feitas sugestões no sentido de testar o método para situações de periodos e locais mais abrangentes que as utilizadas, para uma melhor definição sobre o comportamento do método e sobre a possibilidade de uma aplicação mais generalizada. 


\title{
METHOD FOR ESTIMATTING GLOBAL SOLAR IRRADIANCE THROUGH SUNSHINE BRIGHT PERIODS
}

\author{
Author: Renato Cruz Senna \\ Adviser: Prof. Dr. Iuiz Roberto Angelocci
}

SUMMARY

The present work deals with the development of a method for estimating daily global irradiance through sunshine bright periods recorded on a Campbell-stokes heliograph. The method differs from the traditional for it integrates the sunshine bright periods through a sine curve. By using two monthly periods, the atmospheric transmission coefficient and cloud covering coefficient were estimated from the averege of the extreme data of a global irradiance and area under the sine curve.

The global solar irradiance data utilized to develop this method were measured with a standart Eppley pyranometer at "Escola Superior de Agricultura Luiz de Queiroz", Universidade de Sao Paulo, at Piracicaba llatitude

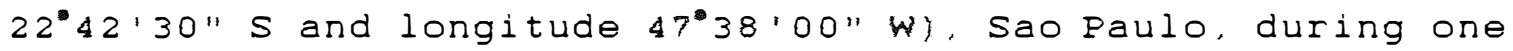
year.

As a result, a general equation was obtained:

$$
0 / Q_{0}-T_{A}\left[\sum A_{2}+T_{3}\left(I-\sum A_{R}\right)\right]
$$


where:

$\&$ = global irradiance estimated at ground level (cal. $\mathrm{cm}^{-2}$ ). Q. = extraterrestrial global irradiance (cal. $\left.\mathrm{cm}^{-2}\right)$.

$T_{1}$ = atmospheric transmissivity coefficient.

$T_{n}=$ cloud cover transmissivity coefficient.

$A_{n}=$ area under the sine curve.

Testing the method against the traditional approach with the coefficients found by ometto (1968), the proposed method gave better daily estimations. Additional tests between the methods should be performed, using on independent data set, in order to know its accuracy and general application. 


\section{INTRODUCATO}

o conhecimento da quantidade de radiaça solar que atinge a superficie da Terra é de suma importancia por ser a fonte da quase totalidade de energia disponivel aos processos que ocorrem no sistema terra-atmosfera. Embora exista uma diversidade muito grande de instrumentos capazes de medir a radiaço global, difusa, liquida, fotossinteticamente ativa ou ainda o espectro da radiaça, o custo do intrumental e de sua manutenço tornam dificil sua utilizaça fora dos centros de pesquisas mais avançados de nosso Pais. Por estas razbes, o heliografo tem sido o equipamento mais frequentemente utilizado, na rede nacional de meteorologia, para estimativa de radiaça solar.

Embora em principio o heliografo registre o número de horas de brilho solar ("insolaça"), năo medindo diretamente a irradiancia global, é possivel associar essas duas grandezas de maneira a permitir a estimativa da segunda. A maioria dos autores buscou correlacionar linearmente o total de horas de insolaça com a irradisncia global numa dada localidade, obtendo relaçes empiricas com bom ajuste para valores médios mensais. Outros partiram para integraçao horária, obtendo equaçós com um grau de ajuste melhor que a 
primeira, porém de dificil utilizaçăo.

Esse método clássico apresenta fontes de erro como, por exemplo, năo levar em consideraçao os horários em que ocorrem os periodos de insolaçao, ou estimar coeficientes de regressao anuais, quando a concentraça de vapor d"água e os sistema de nuvens que os afetam, variam de forma sazonal. Neste trabalino busca-se mostrar a possibilidade da integracao de uma curva sendide desde o nascer até o par do Sol para os periodos de insolaçăo, obtendo-se uma equacăo que evite os erros mais frequentes na estimativa pelo método cíassico. 


\section{REVISAOO DE LITERATURA}

A energia emitida pelo sol torna possivel os processos que mantem a vida no planeta como, por exemplo, a fotossintese, o aquecimento do ar e do solo e a evaporacăo. Na escala de tempo esta energia nao é constante pois a radiaço solar esta sujeita a varios fatores que a fazem variar de forma quali-quantitativa.

A qualidade da radiaça solar deperde principalmente da composicao atmosferica, pois muito embora grande parte de seus constituintes apresentem concentracoes constantes na escala do tempo, alguns elementos extremamente importantes do ponto de vista da absorcao da radiaça solar sao bastante variáveis. A tabela 1 apresenta os principais constituintes da atmosfera. Alem destes, elementos como poeira, polem e emissoes industriais tem sua concentracăo desconhecida.

A atmosfera terrestre apresenta a absorcåo seletiva da radiasăo, ou seja, alguns elementos nåo absorvem a radiacao de uma forma continua em todo seu espectro e sim preferenciajmente determinados comprimentos de onda. O ozônio, por exemplo, absorve grande parte da radiaşo ultravioleta, a qual e de extrema importancia para o planeta 
devido a sua açao germicida. A figura 1 apresenta a distribuicao teorica da radiaça de um corpo negro a temperatura de $6000 \mathrm{k}$, o espectro da radiaça solar ao nável da superficie e os principais constituintes responsaveis pela absor çå.

Tabela 1. Composicăo media da atmosfera limpa. (Smithsonian Meteorological Tables, 1984, p. 389)

\begin{tabular}{|c|c|}
\hline Constituintes & Fraçao molar (\%) \\
\hline Nitrogênio & 78.090 \\
\hline Oxigênio & 20.950 \\
\hline Argônio & 0.930 \\
\hline Dióxido de Carbono* & 0.030 \\
\hline Neônio & $1.8010^{-=}$ \\
\hline Helio & $5.24 \quad 10^{-4}$ \\
\hline Criptônio & $1.0010^{-4}$ \\
\hline Hidrogênio & $5.0010^{-}=$ \\
\hline xenônio & $8.0010^{-t}$ \\
\hline Ozônio* & $1.0010^{-t}$ \\
\hline Radônio* & $6.0010-10$ \\
\hline Vapor d'agua* & 0 a 3 \\
\hline * variável & \\
\hline
\end{tabular}

Além da absorçăo seletiva, o espalhamento pela atmosfera contribui significativamente para a qualidade da radiaço solar, pois determinados comprimentos de onda sao espalhados com maior eficiência do que outros, estando este fenómeno relacionado com a distancia percorrida pela radiaça na atmosfera, modificando assim a relaçăo entre as porcentagens destes comprimentos de onda.

Do ponto de vista quantitativo, de interesse no presente trabalino, vários fatores contribuem para alterar 
a radiaçao solar. O valor médio aceito para a quantidade de energia que atinge uma superficie normal a radiaçao solar na ausência da atmosfera ou seja, a constante solar, é $2 \mathrm{cal} \cdot \mathrm{cm}^{-2} \cdot \mathrm{min}^{-1}$

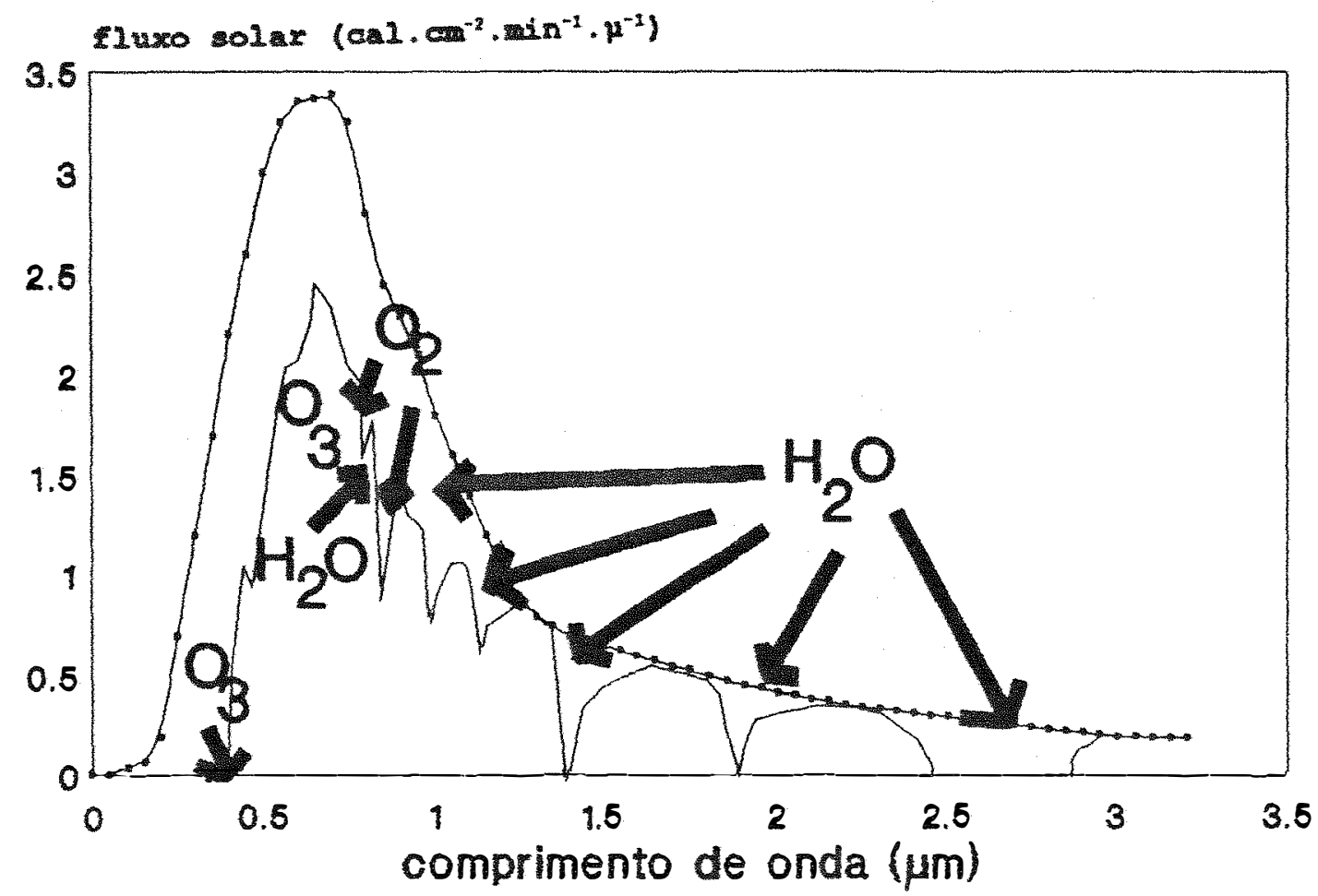

Figura 1. Distribuicao tedrica e real da radiaço soiar na camada mais externa da atmosfera e ao nivel da superficie. Adaptada de Rosenberg (1974).

\section{Para determinar-se a intensidade da radiaça}

solar que atinge um certo local num dado momento necessita-se conhecer a posiçao do sol no ceu. D sol ocupa um dos focos da elipse descrita pela orbita da Terra. O plano que contem a elipse denomina-se "plano ecliptico". A propria Terra gira sobre si mesma em torno de um eixo imaginatio, causando assim a variaçao diurna da quantidade de radiaça que incide sobre dado local, estando o eixo inclinado de aproximadamente 
23,450 em relaça a normal do plano eclíptico. A excentricidade da elipse, responsável pela variaça da distância Terra-Sol, associada a inclinaçă do eixo terrestre altera a quantidade de energia recebida pelos hemisférios do planeta, durante o ano, determinando assim as estaçbes.

Caso se leve em conta apenas o aspecto quantitativo do espalhamento e da absorcăo pela atmosfera, o que determinará uma maior ou menor atenuaça da radiaçăo solar será a posiça relativa do sol no céu, ou seja, a radiaça atravessará um maior ou menor número de massas oticas.

As nuvens sao o fator de maior importäncia no aspecto quantitativo da radiaça solar, porém sua variabilidade quanto a forma, espessura e consequente efeito sobre a radiaçao sao de grande complexidade, tanto que, se por um lado o resultado mais esperado seja a atenuaçăo sobre a radiaçăo, algumas formaçoes podem incrementar a radiaçao que atinge o solo, através de fenómenos de multipla reflexăo. Relaçôs empiricas entre a cobertura de nuvens e a radiaçăo que atinge a superficie tem sido objeto de muitas investigaçes desde o comeco do século. O método primeiramente sugerido por Kimball' e colocado em bases

1 KIMBALL, H.H. Variations in the total and luminous solar radiation with geographical position in the United States. Monthly Weather Review, Boston, 47: 769-93, 1919. 
matemáticas por \&ngströna, ambos citados por COULSON (1975), tem sido largamente utilizado desde entăo. A relaçăo linear entre a irradiância solar global diária (Q) e a porcentagem de insolaçăo possivel ( $/ N$ ) para determinada latitude e data, foi proposta por \&ingstron da seguinte forma:

$$
Q=Q_{c}[a+(1-a) n / M]
$$

onde "Qe" é a irradiância solar global em um dia sem presença de núvens e "a" uma constante determinada empiricamente. Devido ao fato de "Qe" variar com a transmissividade atmosferica, Prescott=, citado por BLACK et al (1954), propos a seguinte modificaça:

\section{$Q-Q_{0}(a+b n / N)$}

onde "Qo" e a irradiancia solar global numa superficie horizontal na ausência da atmosfera, "a" e "b" sao constantes a serem determinadas a partir das medidas.

Um grande número de pesquisadores estimou os coeficientes para os mais diversos locais, cobrindo praticamente todo o globo terrestre, como pode ser encontrado em MARTINEZ-LOZAND et al (1984). Cobrindo praticamente todo - Territorio Nacional, RIBEIRO (1980) estima os coeficiente

\footnotetext{
= SNGSTRON, A.K. Solar and terrestrial radiation. Quarterly Journal of Royal Meteorological Societ, London, 50: $121-5,1924$.

- PRESCOTT, J.A. Evaporation from a water surface in relation to solar radiation. Transactions Royal Society of Science, 64: 114-25, 1940.
} 
"a" e "b", desde Fortaleza no Ceará até Domingos Petroline no Rio Grande do Sul. Além deste pode-se citar CERVELLINI et al (1966) estimando os coeficientes para o estado de sao Paulo, OMETTO (1968) que propós coeficientes para as condiços de Piracicaba (SP), REIS et al (1973) para Recife (PE), $S A$ (1973) para Manducaru (BA), TUBEL is et al (1977) para Botucatu (SP), Lopes et alii (1971) e Mota (1976) para Pelotas (RS), RIBEIRO et al (1980) para as condiçes de Manaus e SANTOS et al (1983) para Jaboticabal (SP).

o estudo da relaço entre a insolaça (n), a irradiância solar global (Q) e a irradiância solar global da superficie na ausência da atmosfera (Qo) foi realizada por BLACK et al (1954). Além de estimar os coeficientes "a" e "b" da equaçao (2), utilizando-se de séries de valores médios, os autores observaram uma relaço entre a jatitude da estaça e os coeficientes estimados. Para tal estudo Black e seus colaboradores se utilizaram das series de 32 estaças cobrindo desde a Austrália até o Alaska.

Com o aumento do número de estudos, algumas deficiências começaram a ficar evidentes, entre elas podendose citar a ineficacia do heliografo para registrar a insolacao para pequenas elevaçes do sol, conforme observou MATEER (1955); grandes erros nas estimativas ocorriam durante - inverno no Canadá, quando o Sol permanecia muito tempo com uma elevaça inferior a 50. Alem desta, outras razbes para o coeficiente de correlaça năo ser muito elevado foram 
descritas por Baker \& Haines ${ }^{4}$ citados por COULSON (1975) e MART INEZ-LOZANO et al (1984):

(1) algumas vezes a irradiancia el al ta com o céu parcialmente encoberto, devido à reflexao das nuvens,

(2) as condiçoes atmosfericas variam muito,

(3) alquns erros nao detectados na calibraçao dos intrumentos e na avaliaça dos dados podem ocorrer.

Utilizando-se dos dados de seis estaçes localizadas no oeste da Africa, entre as latitudes de 6,50M E 13,50N, DAVIES (1965) testou diversos periodos para relacionar os dados. Sua conclusao foi que a correlaça mensal seria a mais correta. Davies tamben enumerou razoes que impedem a perfeita correlacao entre os dados:

(a) o heligorafo Campbell subestima a insolasao por nao registrar a radiaçao difusa sob condiçaes de nebulosidade ou a radiaçao direta quando a altura solar é baixa,

(b) a existência de um erro de grandeza desconhecida nas medidas de insolaçao, falhas ne calibrasao dos instrumentos e inexatidáo dos metodos para reduçao dos dados.

Dutra conclusao importante obtida por Davies foi a existencia de uma correlaço inversa entre os coeficientes, mostrando que a cada decrescimo no valor de "b", em funça do aumento da nebulosidade correspondia um

4 BACKER, D. \& HAINES, D. Solar Radiation and sunstiine duration relationship in the North-Central region and Alaska. 5.1., University of Minnesota, Agricultural Experiment. Technical Bulletin, 262, 1969. 
incremento no valor mensal de "a" devido ao aumento da reflexao da radiaço solar pelas múvens. Resultados semelhantes foram encontrados por SANTOS et al (1983); determinando os coeficientes da equaço (2), para as condiçBes de Jaboticaba\} (SP), os autores mostraram variaços sazonais significativas, entretanto a soma dos coeficientes permaneceu constante indicando uma transmissividade atmosferica proxima a $75 \%$.

A revisao bibliografica sobre a evoluço historica da equa̧ăo de Angstron e suas modifiças, realizada por MARTINEZ-LOZANO et al (1984), coloca de maneira geral os fatores que influenciam os coeficientes "a" e "b":

(1) latitude,

(2) altitude da estaço,

(3) albedo da superficie,

(4) altitude média solar,

(5) concentraçao de vapor d’água,

(b) concentracăo dos poluentes naturais e artificiais.

Alguns destes fatores já haviam sido estudados individualmente. Para a latitude por exemplo, GLOVER e MCCULLOCH (1958 b) estabeleceram a seguinte equaça:

$$
a=0,01+0,27 \cdot \cos \phi
$$

onde $\phi$ é a latitude, enquanto o valor de "b" permanece praticamente constante. Anteriormente, GLOVER e MCCULLOCH (1958a) haviam observado uma relaço inversa entre estes coeficientes de tal forma que a soma dos dois permanecia 
constante e em torno de 0,82 .

Recentemente tentou-se relacionar "a" e "b" a um maior numero de fatores, buscando uma meinor aproximaço, como a sugerida por GOPINATTAN (1988), cujas equacoes expressam os coeficientes da regressao em termos da latitude $(\boldsymbol{\phi})$, altitude $(H)$ e porcentagem da insolaça media mensal (n/N), como segue:

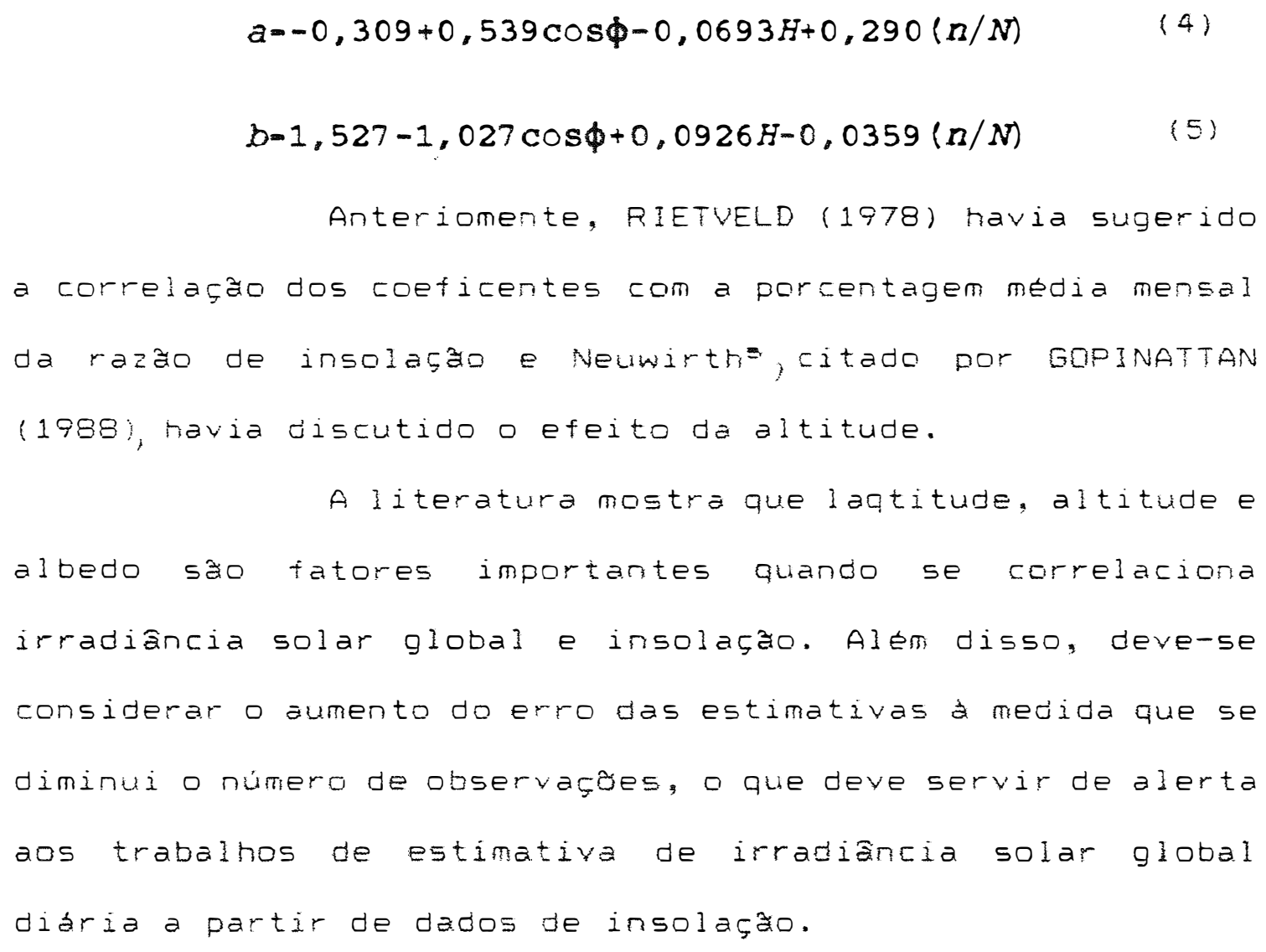$$
a=-0,309+0,539 \cos \phi-0,0693 H+0,290(n / N)
$$$$
b=1,527-1,027 \cos \phi+0,0926 H-0,0359(n / N)
$$$$
\text { Anteriomente, RIETVELD (1978) havia sugerido }
$$

s NEWRITH, F. The estimation on global and sky radiation in Austria, Solar Energy, Oxford, 24: 421, 1980. 


\section{MATERIAL E METODOS}

\subsection{Dados Coletados}

Os dados básicos do trabal ho foram obtidos das medidas realizadas pelo Departamento de Fisica e Meteorologia da Escola Superior de "Agricultura Luiz de Queiroz", da Universidade de Sao Paulo, situada em Piracicaba l latitude

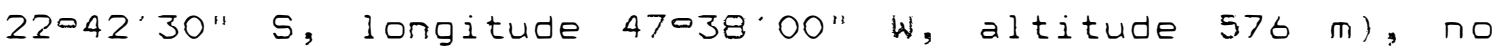
periodo de setembro de 1966 a agosto de 1967 (Ometto, 1968).

\subsubsection{Irradiancia Solar Global}

A irradiáncia solar global (Q) foi medida atraves de um piranometro Eppley, construido por "The Eppley Laboratory", número de serie 2876, modelo de dez juncoes, constante de calibraçăo de $2,84 \mathrm{mv} / \mathrm{cal}$.cm2.min, instalado a 17,4 metros de altura em horizonte completamente aberto ligado a um sistema de registradores.

\subsubsection{Insolaçao}

Os dados de insolaça (n) foram obtidos atraves de um heliografo tipo Campbell-stokes, instalado na estaça meteorologica do Departamento de Fisica e Meteorologia da Escola Superior de Agricultura Luiz de 
Queiroz. Estes dados foram cotados neste trabalho da maneira explicada no item denominado "Metodo".

\subsubsection{Fotoperiodo}

o fotoperiodo (N), funcăo do mês e latitude, foi obtido do Anuário do Observatorio de Sao Paulo (1967).

\subsubsection{Irradiancia Solar Global na Ausência da Atmosfera}

A equaço (b) foi utilizada para obter-se os valores diários de irradiância solar na ausência da atmosfera $\left(Q_{0}\right)$ no periodo considerado, conforme Ometto (1968).

$$
Q_{0}=\left(1440 \cdot I_{0} / R^{2} \cdot \pi\right) \cdot(\operatorname{sen} \phi \cdot \operatorname{sen} 8 \cdot h+\cos \phi \cdot \cos 8 \cdot \operatorname{sen} h)
$$

onde:

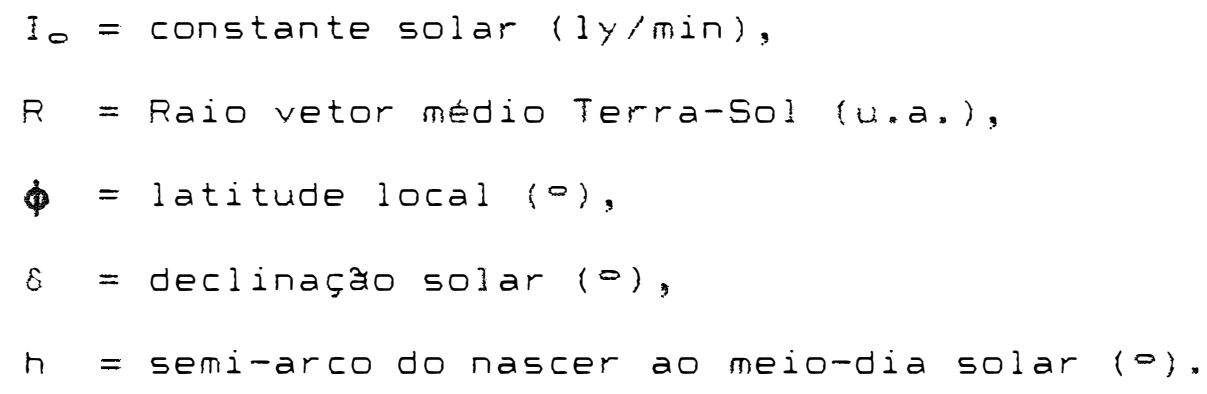

\subsection{Método}

Na ausência da atmostera, a irradiância solar global na superficie do planeta $\left(Q_{0}\right)$ é funcão somente do ângulo de incidência entre o fluxo de radiaçăo a normal a superficie. O modelo aqui proposto assume a presença de uma atmosfera completamente homogênea, com transmissividade constante ao longo do dia, sem influencia da massa otica 
atravessada, de tal forma que a radiaça que atinge o solo no periodo de ausência das nuvens, aqui considerado aquele em que há queima da tira heliográfica, também é funçao apenas do ângulo de incidência, obedecendo a lei de Lambert. Assim pode-se corrigir algumas falhas apresentadas pelo metodo proposto por angströn, quando estima a mesma quantidade de energia para iguais periodos de insolaça sem levar em conta se os mesmos ocorreram em horarios diferentes.

Para um dia qualquer (figura 2) as áreas $A_{n}$ representam os periodos sem nuvens, enquanto que as areas $B_{n}$ os periodos com presença de nuvens e sem queima da tira heliografica. Somando todas as áreas e multiplicando pelo fator da transmissividade atmosferica e das nuvens, respectivamente, obter-se-á a porcentagem da irradiância solar global que atinge a superficie (Q), da seguinte forma:

$$
Q-Q_{0} \cdot T_{A} \cdot\left[\Sigma A_{n}+\left(T_{N} \cdot \Sigma B_{n}\right)\right]
$$

o fator $T_{N}$ aparece aqui multiplicado por Ta devido ao fato da radiaça ja ter atravessado grande parte da atmosfera terrestre, quando ela comeca a sofrer a atenuaça pelas nuvens, pois estas se encontram na camada da atmosfera mais proxima ao solo (figura 3 ).

Para o caso de um dia com ausência absoluta de nuvens a variaça temporal da irradiância solar global ao nivel do solo pode ser representada pela figura 4. 


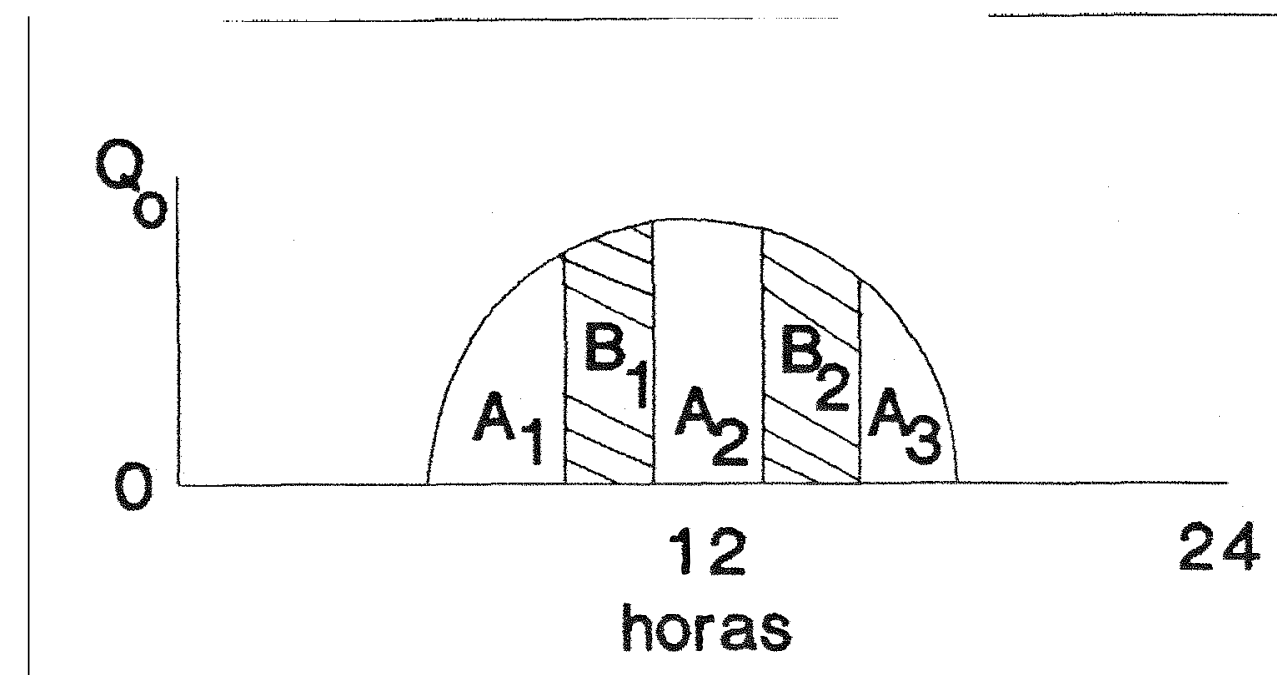

Figura 2. Representacăo esquematica dos periodos de insolacao.
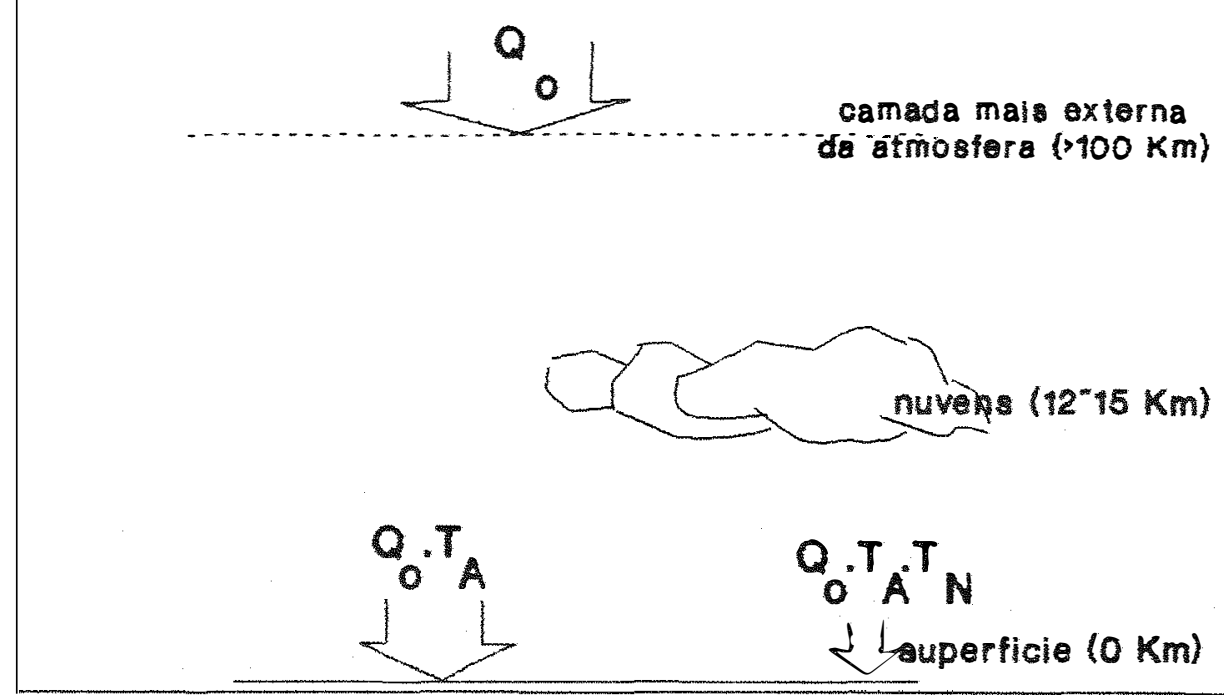

Figura 3. Posicáo relativa das nuvens em altitude ra atmosfera da Terra.

Sob tais circurstäncias pode-se representar uma curva generica, descrita pela equacao (8) (figura 5 ). 


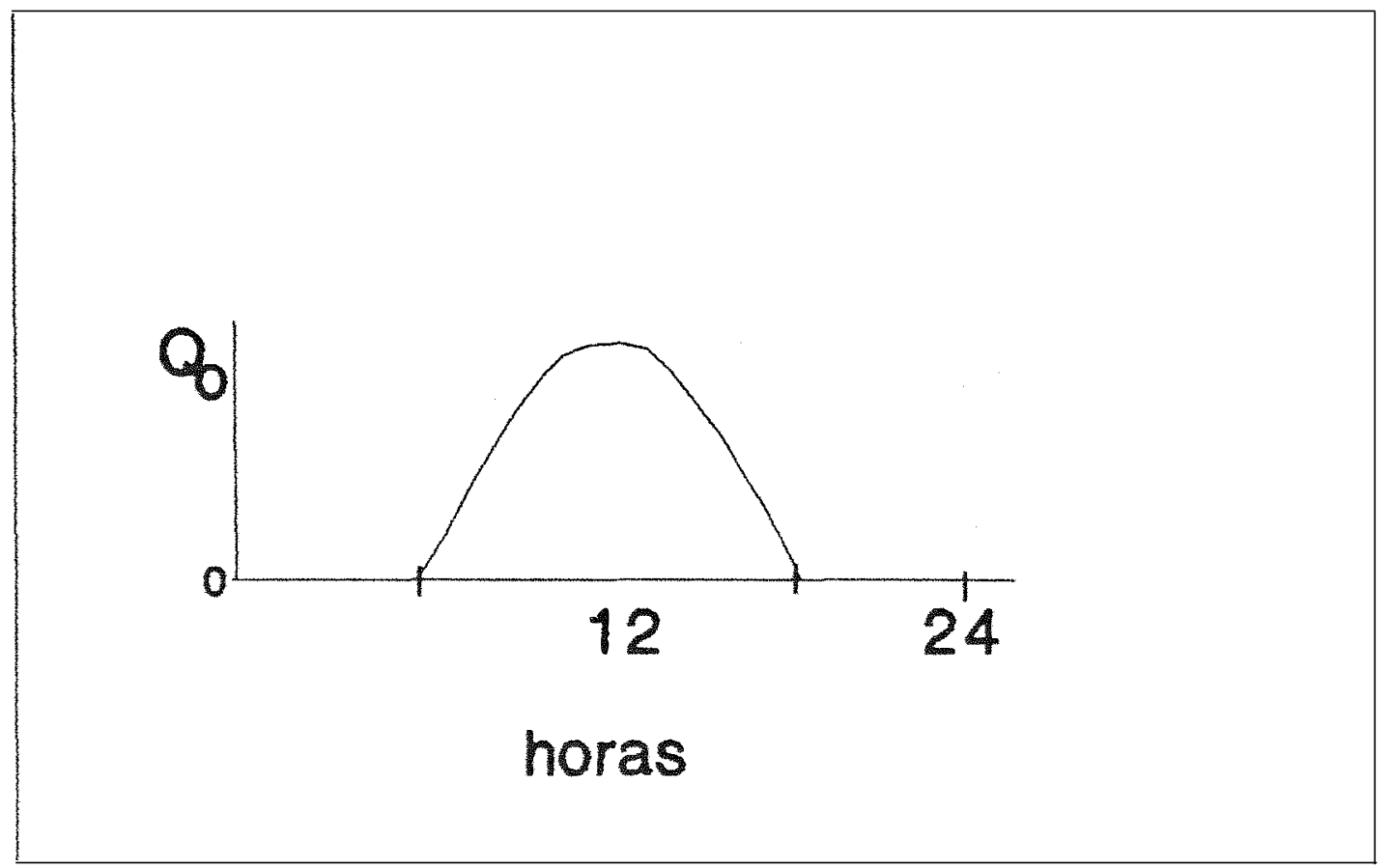

Figura 4. Distribuicao de radiagáo solar ao longo do dia sem presença de nuvens.

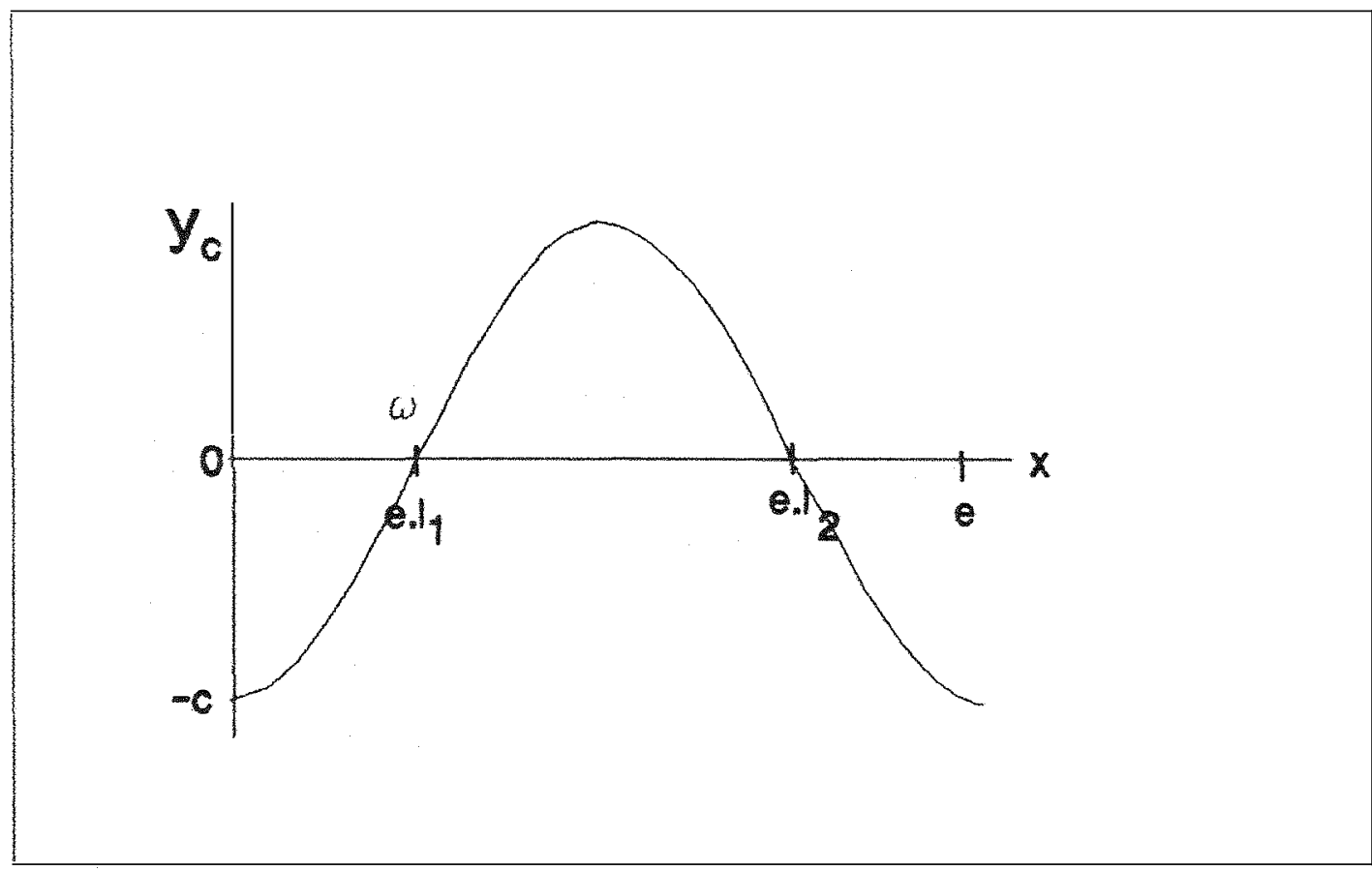

Figura 5. Representaça esquemática do modelo proposto. 
Desta maneira, conhecendo-se a funcăo, basta integrar a area abaixo da curva entre os limites de interesse. Sob condiç̋es de ausência de nuvens, $\Sigma B_{n}=0$ e $\sum A_{n}=1$, de modo que a equacao (7) resume-se a:

$$
Q-Q_{0} \cdot T_{A} \cdot \sum A_{B}
$$

ou seja, a energia que chega ao solo num dia que náo ocorre a presensa de muvens e influenciada apenas pela transmissividade atmosférica.

É necessário conhecer-se os coeficientes "c", "e" e "o". Para tanto, afim de simplificar a integraço, utilizar-se-a os seguintes artificios:

(a) Para que a onda complete uma revoluça (e ou $2 \pi$ ) seráo necessarios dois fotoperiodos ( $2 N$ ). Na realidade tal situaçao so ocorre quando $N=12$ horas e $2 N=24$ horas, entretanto esta aproximaço é possivel, uma vez que utilizar-se-á somente a parte positiva da curva. Desta forma $e=\pi / N$

(b) A curva manterá uma defasagem (a) constante de $\pi / 2$ durante todo o ano, ou seja, o nascer e o por do sol, $L_{1}$ e $L=$ respectivamente, ocorrem quando a curva corta o eixo " $x$ ", desta forma, "eli" e "elz" representam os valores $\pi / 2$ e $3 \pi / 2$ respectivamente. Para que estas condicaes sejam satisfeitas os limites "Lz" e "Lz", ou de modo geral Ln , precisam ser corrigidos pela equacao (11), onde "In" é o novo limite:

$$
I_{n}-L_{n} \cdot[(2 A-2 N) / 2]
$$


Por exemplo, num dia qualquer onde $N=10,6$ tem-se $e=\pi / 10,6$. Assumindo 12 horas locais como sendo 0 meio dia solar, o nascer do sol ocorrerá às 6,7 horas, o pôr do sol as 17,3 horas. Realizando as correçoes, os novos limites $l_{1}$ e $l_{\text {a }}$ correspondem a 5,3 horas e 15,9 horas e ell e ela sao $\pi / 2$ e $3 \pi / 2$ respectivamente. Da mesma forma săo corrigidos valores iguais ou maiores que 12 horas e assim, ajusta-se a curva para qualquer valor de "N".

observando as propriedades da funçao seno, pode-se escrever:

$y-c \cdot(\operatorname{senex} \cdot \cos \omega-\operatorname{cosex} \cdot \operatorname{sen} \omega)$

Resta agora descobrir o valor de "c". Isto sera possivel atraves da integracăo desde o nascer até o por do sol da equaçáo $(11)$, como seque:

$\int_{11}^{12} y d x-c \cdot\left(\int_{11}^{12} \operatorname{senex} \cdot \cos \omega d x-\int_{11}^{12} \operatorname{cosex} \cdot \operatorname{sen} \omega d x\right) \quad(12)$
Sabe-se que $\theta=\pi / 2$, logo $\operatorname{sen} \omega=1$,
$\cos \delta=0$ e a equaça anterior resulta em:

$\sum A_{1}-\int_{13}^{12} y d x--c \int_{11}^{12} \operatorname{cosex} d x$

$\sum A_{n}=-(c / \theta) \cdot[\operatorname{sen} \theta x] \frac{12}{11}$

$\sum A_{n}=(c / e) \cdot(\operatorname{sene} 11-\operatorname{sene} 12)$ 
Para $\Sigma A_{n}=1$, el $1=\pi / 2$ e el $2=3 \pi / 2$. Desta forma a razao (c/e) é igual a 0,5. De uma forma generica, para limites 11, podemos escrever:

$$
\sum A_{n}=0.5 \cdot \sum_{1}^{n}[\operatorname{sen}(e 1 i)-\operatorname{sen}(e l i+1)]
$$

Durante um dia qualquer podem ocorrer periodos de insolaça alternados com periodos de nebulosidade, identificados pelos registros do helidgrafo e calculados pela equaço anteriormente descrita, ou seja, em vez de tratá-ios como uma relaçao entre insolaçao e fotoperiodo $(\mathrm{n} / \mathrm{N})$, considera-se os dados da tira heliográfica em limites de brilho solar, em horas e décimos. Observe-se como exemplo a figura (6), para um dia qualquer onde $N=13,2$ horas e $n=$ 6,5 horas. Para utilizar-se o metodo agora proposto é necessário determinar-se os limites, que no caso sao os apresentados na tabela 2 .

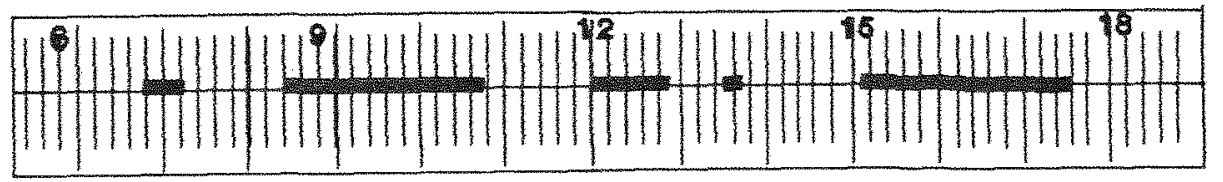

Figura 6. Representaçao esquemática de uma tira heliográfica.

A diferença "1 - $\Sigma A_{n}$ " representa o intervalo onde a radiaçao esta sendo atenuada pelas múvens $\left(\Sigma B_{n}\right)$. 
Tabela 2. Correçao dos limites e integraça da area, para um dia hipotético.

$\begin{array}{rrrrc}\text { L1 } & \text { L2 } & 11 & 12 & \text { An } \\ 6,8 & 7,2 & 8,0 & 8,4 & 0,0177 \\ 8,4 & 10,8 & 9,6 & 12,0 & 0,2370 \\ 12,0 & 12,9 & 13,2 & 14,1 & 0,1063 \\ 13,5 & 13,7 & 14,7 & 14,9 & 0,0221 \\ 15,1 & 17,7 & 16,3 & 18,9 & 0,1522\end{array}$

Para calcular-se a quantidade de energia que alcança o solo necessita-se conhecer os fatores ta e $T_{\text {M. }}$. Estes valores serło calculados a partir dos dados observados. Foram selecionados, para cada conjunto de dois meses, os dez (10) maiores e os dez (10) menores valores de $\sum_{A_{n}}$ e estabeleceu-se duas equaçoes entre as medias destes valores e as medias de $\left(Q / Q_{0}\right)$ da seguinte forma:

$$
0 / Q_{\text {max }}-T_{A} \cdot\left[\Sigma A_{\max }+T_{N}\left(1-\Sigma A_{\text {maxix }}\right)\right]
$$

$$
0 / Q_{\text {conin }}-T_{A} \cdot\left[\Sigma A_{\text {zanin }}+T_{N^{*}}\left(1-\Sigma A_{\text {ranin }}\right)\right]
$$

A partir de um valor pré-estipulado de $T_{M}$ $(0,20\}$ substitui-se na equaça (17) onde Tru apresenta um menor efeito, pois o mesmo estará multiplicado pelo menor coeficiente da equaça, desta forma encontra-se o valor de $T_{A}$. Este valor substituido em (18), da mesma maneira que $T_{m}$ na equacăo anterior ta é agora multiplicado pelo menor coeficiente, determinando-se o novo $T_{\text {ma }}$ e assim 
sucessivamente, até encontrar-se os valores de Ta e Th com uma precisao de três casas decimais.

\subsection{COMPARASAO DOS METODOS}

O método proposto foi comparado ao tradicional através dos testes descritos pelas equacaes 19,20 e 21 , sugeridas por Gopinattan (1988):

$$
M B E-\left[\sum\left(V_{C}-V_{O}\right)\right] / N
$$

$$
\left.R M S E-\sqrt{[\Sigma}\left(V_{c}-V_{0}\right)^{2} / n\right]
$$

$$
M P E-\left[\Sigma\left(\mid V_{0}-V d X 100 / V_{0}\right)\right] / \Omega
$$

onde $V_{c}=$ valor calculado;

$v_{0}=$ valor observado, a partir do piranómetro;

$n$ = número de observaçes.

O teste denominado MBE ("mean bias error"), da

a tendência do erro médio. Quando o resultado é um valor positivo, isto indica uma tendência do modelo de superestimar os calculos, enquanto a situasăo inversa (valor negativo) mostra tendência a subestimar estes cálculos. O segundo teste, RMSE ("root mean square error") mostra como os modelos se ajustam: quanto menor o valor encontrado (proximo a zero), melhor o ajuste. O MPE ("mean percentage error") negligencia - sinal do erro para estimar a variacão média dos valores calculados en relaçăo aos observados. 


\begin{abstract}
Para o metodo tradicional utilizou-se os coeficientes para Piracicaba, propostos por Ometto (1968), como descritos na equaça (21):
\end{abstract}

\title{
$8 / Q_{0}-0,26+0,51 \mathrm{n} / \mathrm{N}$
}

Calculos preliminares indicaram que o uso dos coeficientes sazonais propostos por Ometto (1968) nao alteraram significativamente o resultado dos testes. Ometto (1968), utilizando testes estatisticos conclui que as retas representadas pelos coeficientes sazonais nao diferem significativamente e podem ser agrupadas numa única reta de coeficientes anuais.

Alem dos testes, descritos anteriormente, estabeleceu-se retas de regressao do tipo "y = a + bx" entre as razoes $Q / Q_{0}$ observadas e estimadas pejos dois métodos onde - valor observado e a variaves independente e o vajor estimado a variável dependente, obtendo-se assim um coeficiente "R=" para cada metodo. Determinou-se também o "indice $d "$, conforme sugerido por willmott (1981), que pode ser expresso por:

$$
\begin{gathered}
d=1-\left[\sum\left(V_{c}-V_{0}\right)^{2}\right] /\left[\sum\left(V v_{c}+V v_{0}\right)^{2}\right. \\
\left.v v_{c}-\mid v_{c}-\bar{V}\right] \\
\left.v v_{0}-\mid v_{0}-\bar{V}\right]
\end{gathered}
$$


Assim como "Rz", o valor de "d"varia entre $O$ e 1, quanto maior o valor assumido melhores sao os resultados estimados pelos modelos. 


\section{RESULtADOS OBTIDOS}

\subsection{Estimativa de $\Sigma A_{n}$}

A primeira etapa do trabalno resumiu-se a identificar os " $n$ " periodos de insolaço para cada dia, segundo a metodologia descrita anteriormente. Estes dados encontram-se nos apêndices 1 a 12. Com base nestes dados foi possivel determinar os valores de $\Sigma A_{n}$, conforme apresentados nas tabelas 8 a 13 sob a denominaço de "U". Os demais dados apresentados nessas tabelas foram retirados de Ometto (1968).

4.2. Estimativa dos coeficientes de transmissividade da atmosfera $\left(T_{A}\right)$ e das nuvens $\left(T_{P, H}\right)$.

$$
\text { Conforme a metodologia proposta, os }
$$

coeficientes "TA" e "Th" foram determinados atraves da seleça dos dez (10) valores máximos e dos dez (10) valores minimos de $\sum A_{n}$ (U) com os respectivos valores da relacăo "Q/Qo" (tabelas $3 a$ a $3 f$ e $4 a$ a $4 f$ ). 


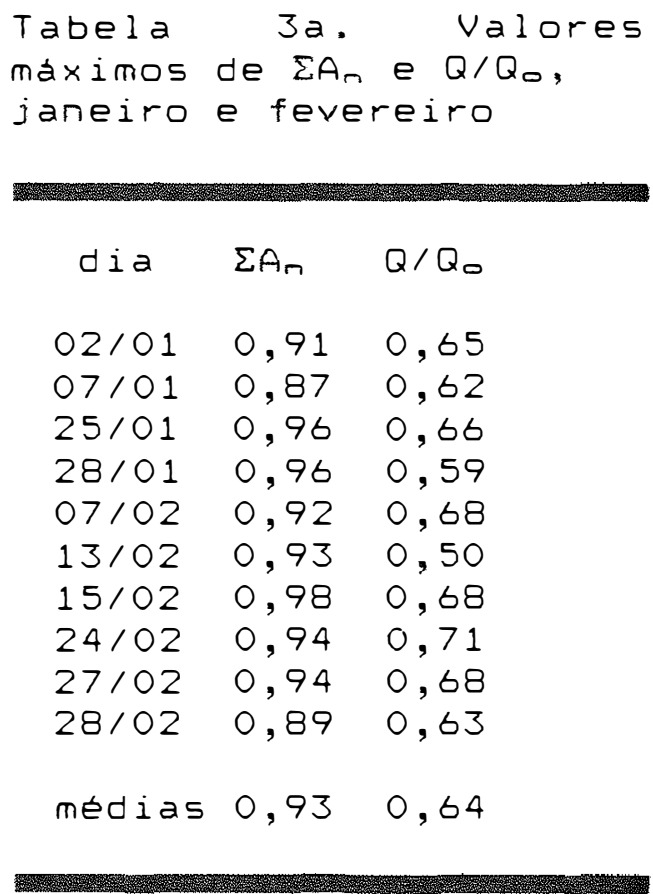

Tabela 3c. Valores máximos de $\Sigma A_{n}$ e $Q / Q_{0}$, maio e juntio

$\begin{array}{ccc}\text { dia } & \sum A_{n} & Q / Q_{0} \\ 07 / 05 & 0,97 & 0,67 \\ 09 / 05 & 0,98 & 0,71 \\ 12 / 05 & 0,96 & 0,70 \\ 24 / 05 & 0,97 & 0,68 \\ 27 / 05 & 0,97 & 0,73 \\ 31 / 05 & 0,96 & 0,65 \\ 19 / 06 & 0,97 & 0,74 \\ 20 / 06 & 0,97 & 0,73 \\ 21 / 06 & 0,96 & 0,73 \\ 23 / 06 & 0,98 & 0,74 \\ \text { medias } & 0,97 & 0,71 \\ \end{array}$

Tabela 3b. Valores máximos de $\Sigma A_{n}$ e $Q / Q_{0}$, março e abril.

$\begin{array}{ccc}\text { dia } & \sum A_{n} & Q / Q_{0} \\ & & \\ 23 / 03 & 0,97 & 0,69 \\ 01 / 04 & 0,98 & 0,66 \\ 02 / 04 & 0,98 & 0,68 \\ 03 / 04 & 0,97 & 0,72 \\ 06 / 04 & 0,99 & 0,71 \\ 07 / 04 & 0,98 & 0,70 \\ 09 / 04 & 0,98 & 0,68 \\ 17 / 04 & 0,99 & 0,70 \\ 18 / 04 & 0,97 & 0,71 \\ 19 / 04 & 0,98 & 0,70 \\ \text { media } & 0,98 & 0,69\end{array}$

Tabela 3d. Valores máximos de $\Sigma A_{n}$ e $Q / Q_{0}$, jultio e agosto

$\begin{array}{ccc}\text { dia } & \sum A_{n} & Q / Q_{0} \\ 17 / 07 & 0,96 & 0,73 \\ 18 / 07 & 0,97 & 0,73 \\ 19 / 07 & 0,98 & 0,74 \\ 20 / 07 & 0,97 & 0,75 \\ 28 / 07 & 0,97 & 0,72 \\ 29 / 07 & 0,97 & 0,65 \\ 30 / 07 & 0,97 & 0,72 \\ 19 / 08 & 0,96 & 0,69 \\ 20 / 08 & 0,96 & 0,69 \\ 31 / 08 & 0,96 & 0,64 \\ \text { medias } & 0,97 & 0,71\end{array}$




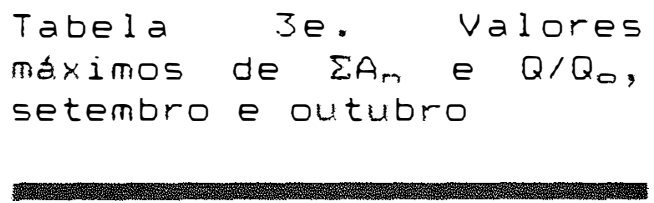

$$
\text { dia } \Sigma A_{n} \quad Q / Q_{0}
$$

$\begin{array}{lll}07 / 09 & 0,98 & 0,66 \\ 18 / 09 & 0,99 & 0,77 \\ 23 / 09 & 0,98 & 0,74 \\ 10,10 & 0,98 & 0,70 \\ 14 / 10 & 0,98 & 0,70 \\ 16 / 10 & 0,99 & 0,69 \\ 20 / 10 & 1,00 & 0,71 \\ 24 / 10 & 0,99 & 0,72 \\ 25 / 10 & 0,99 & 0,74 \\ 26 / 10 & 1,00 & 0,73 \\ \text { medias } & 0,99 & 0,72\end{array}$

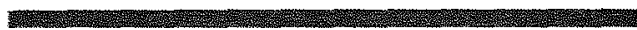

Tabela $4 a$. Valores
minimos de EA e Q/Qo,
janeiro e fevereiro

$\begin{array}{ccc}\text { dia } & \sum A_{m} & Q / Q_{0} \\ 05 / 01 & 0,09 & 0,23 \\ 11 / 01 & 0,09 & 0,31 \\ 12 / 01 & 0,12 & 0,26 \\ 31 / 01 & 0,02 & 0,27 \\ 01 / 02 & 0,07 & 0,24 \\ 04 / 02 & 0,04 & 0,32 \\ 05 / 02 & 0,00 & 0,28 \\ 06 / 02 & 0,11 & 0,26 \\ 19 / 02 & 0,05 & 0,36 \\ 20 / 02 & 0,02 & 0,24 \\ \text { medias } & 0,06 & 0,28 \\ \end{array}$

Tabela $3 f$ valores máximos de $\sum A_{n}$ e $Q / Q_{\infty}$, novembro e dezembro

$\begin{array}{ccc}\text { dia } & \sum A_{n} & Q / Q_{0} \\ 07 / 11 & 0,99 & 0,71 \\ 19 / 11 & 0,99 & 0,74 \\ 21 / 11 & 0,98 & 0,70 \\ 24 / 11 & 0,98 & 0,68 \\ 26 / 11 & 0,99 & 0,69 \\ 29 / 11 & 0,97 & 0,68 \\ 09 / 12 & 0,97 & 0,69 \\ 29 / 12 & 0,98 & 0,62 \\ 30 / 12 & 0,99 & 0,65 \\ 31 / 12 & 0,99 & 0,66 \\ \text { medias } & 0,98 & 0,68\end{array}$

Tabela 4b. Valores minimos de $\Sigma A_{n} e Q / Q_{\infty}$, marco e abril

$\begin{array}{ccc}\text { dia } & \sum A_{n} & Q / Q_{0} \\ 07 / 03 & 0,16 & 0,30 \\ 08 / 03 & 0,19 & 0,33 \\ 09 / 03 & 0,31 & 0,36 \\ 12 / 03 & 0,36 & 0,45 \\ 13 / 03 & 0,10 & 0,28 \\ 14 / 03 & 0,01 & 0,29 \\ 15 / 03 & 0,16 & 0,35 \\ 18 / 03 & 0,14 & 0,28 \\ 16 / 04 & 0,20 & 0,40 \\ 24 / 04 & 0,07 & 0,25 \\ \text { medias } & 0,17 & 0,33\end{array}$

2010 
$\begin{array}{lll}\text { Tabela } & \text { Uc. Valores } \\ \text { minimos de } \sum A_{n} \text { e } Q / Q_{0}\end{array}$ maio e junho

$\begin{array}{ccc}\text { dia } & \sum A_{n} & Q / Q_{0} \\ 03 / 06 & 0,13 & 0,30 \\ 05 / 06 & 0,00 & 0,11 \\ 06 / 06 & 0,00 & 0,12 \\ 07 / 06 & 0,00 & 0,35 \\ 11 / 06 & 0,10 & 0,22 \\ 12 / 06 & 0,02 & 0,19 \\ 13 / 06 & 0,08 & 0,28 \\ 14 / 06 & 0,00 & 0,31 \\ 25 / 06 & 0,09 & 0,41 \\ 27 / 06 & 0,10 & 0,45 \\ \text { medias } & 0,05 & 0,27 \\ \end{array}$

Tabela 4 e. Valores
minimos de EAn e Q/Qo,
setembro e outubro

dia $\quad \sum A_{n} \quad Q / Q_{0}$

$01 / 09 \quad 0,05 \quad 0,20$

$02109 \quad 0,00 \quad 0,04$

$03 / 09 \quad 0,00 \quad 0,13$

$\begin{array}{lll}16 / 09 & 0,07 & 0,27\end{array}$

$20 / 09 \quad 0,00 \quad 0,12$

$28 / 090,00 \quad 0,06$

$23 / 10 \quad 0,150,19$

$28 / 100,020,20$

$30 / 10 \quad 0,00 \quad 0,14$

$31 / 100,00 \quad 0,13$

medias $0,03 \quad 0,15$
Tabela 4d. Valores minimos de $\Sigma A_{n}$ e $Q / Q_{0}$, jultho e agosto

$\begin{array}{ccc}\text { dia } & \sum A_{n} & Q / Q_{0} \\ 11 / 07 & 0,00 & 0,14 \\ 12 / 07 & 0,16 & 0,41 \\ 14 / 07 & 0,30 & 0,42 \\ 15 / 07 & 0,25 & 0,42 \\ 22 / 07 & 0,00 & 0,11 \\ 24 / 07 & 0,29 & 0,48 \\ 12 / 08 & 0,39 & 0,42 \\ 13 / 08 & 0,31 & 0,43 \\ 16 / 08 & 0,60 & 0,47 \\ 18 / 08 & 0,55 & 0,54 \\ \text { medias } & 0,29 & 0,38\end{array}$

Tabela $4 f$ valores minimos de $\Sigma A_{n}$ e $Q / Q_{\varnothing}$, novembro e dezembro

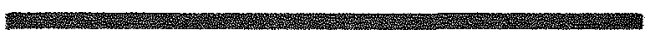

dia $\sum A_{n} \quad Q / Q_{0}$

$11 / 110,210,45$

$12 / 110,20 \quad 0,23$

$14 / 110,180,31$

$17 / 11 \quad 0,220,36$

$20 / 120,020,31$

$21 / 120,00 \quad 0,14$

$22 / 120,00 \quad 0,14$

$23 / 120,00 \quad 0,21$

$24 / 120,020,35$

$27 / 120,00 \quad 0,16$

medias $0,090,27$ 
A partir dos valores medios montou-se seis sistemas de duas equaçes e duas incognitas, descritas de (26a) a (31b). Para a primeira equacao de cada sistema adotou-se o valor de $T_{N}$ como sendo "0,200" e atraves de sucessivas substituiģoes encontrou-se os valores verdadeiros de "Ta" e "TN":

$$
\begin{aligned}
& 0,64-T_{A}\left[0,93+T_{N}(0,07)\right] \\
& 0,28-T_{A}\left[0,06+T_{N}(0,94)\right] \\
& 0,69-T_{A}\left[0,98+T_{N}(0,02)\right] \\
& 0,33-T_{A}\left[0,17+T_{N}(0,83)\right] \\
& 0,71-T_{A}\left[0,97+T_{N}(0,03)\right] \\
& 0,27-T_{A}\left[0,05+T_{N}(0,95)\right] \\
& 0,71-T_{A}\left[0,97+T_{N}(0,03)\right] \\
& 0,38-T_{A}\left[0,29+T_{N}(0,71)\right] \\
& 0,72-T_{A}\left[0,99+T_{N}(0,01)\right] \\
& 0,15-T_{A}\left[0,03+T_{N}(0,97)\right] \\
& 0,68-T_{A}\left[0,98+T_{N}(0,02)\right] \\
& 0,27-T_{A}\left[0,09+T_{N}(0,91)\right]
\end{aligned}
$$


Os valores calculados de Ta e Tw sao mostrados na tabela 5.

\begin{tabular}{|c|c|c|}
\hline periodo & $T_{A}$ & $T_{P N}$ \\
\hline jan/fev & 0,669 & 0,381 \\
\hline marlabr & 0,699 & 0.364 \\
\hline mai/jun & 0,724 & 0,340 \\
\hline jul/ago & 0,725 & 0,330 \\
\hline set/out & 0,726 & 0,182 \\
\hline nov/dez & 0,689 & 0,332 \\
\hline
\end{tabular}

4.3. Estimativa da relaçăo "Q/Q。" pelo método tradicional. - valores estimados da relacáo "Q/Qo" segundo a equaça proposta por Ometto (1968) encontram-se nas tabelas de (8) a (13), sob a designaรan "Q1/Q0".

\begin{abstract}
4.4. Estimativa da relaçăo "Q/Qo" pelo método proposto. os valores da relacalo "Q/Q0", pelo metodo proposto, utilizando-se dos valores de "TA" e "Th" mostrados na tabela 5, encontram-se nas tabelas (B) a (13) sob a designasao "Q2/Q0".
\end{abstract}

4.5. Resultados dos Testes.

Os resultados dos testes representados pelas equaçes (19), (20) e (21), encontram-se nas tabelas (8) a (13). Para una fácil visualizacáa destes resulados, os 
mesmos sao apresentados nas figuras (8a) a (13b) e resumidos na tabela 6 .
Tabela 6. Medias bimestrais dos testes. TRAD = tradicional; PROP = proposto

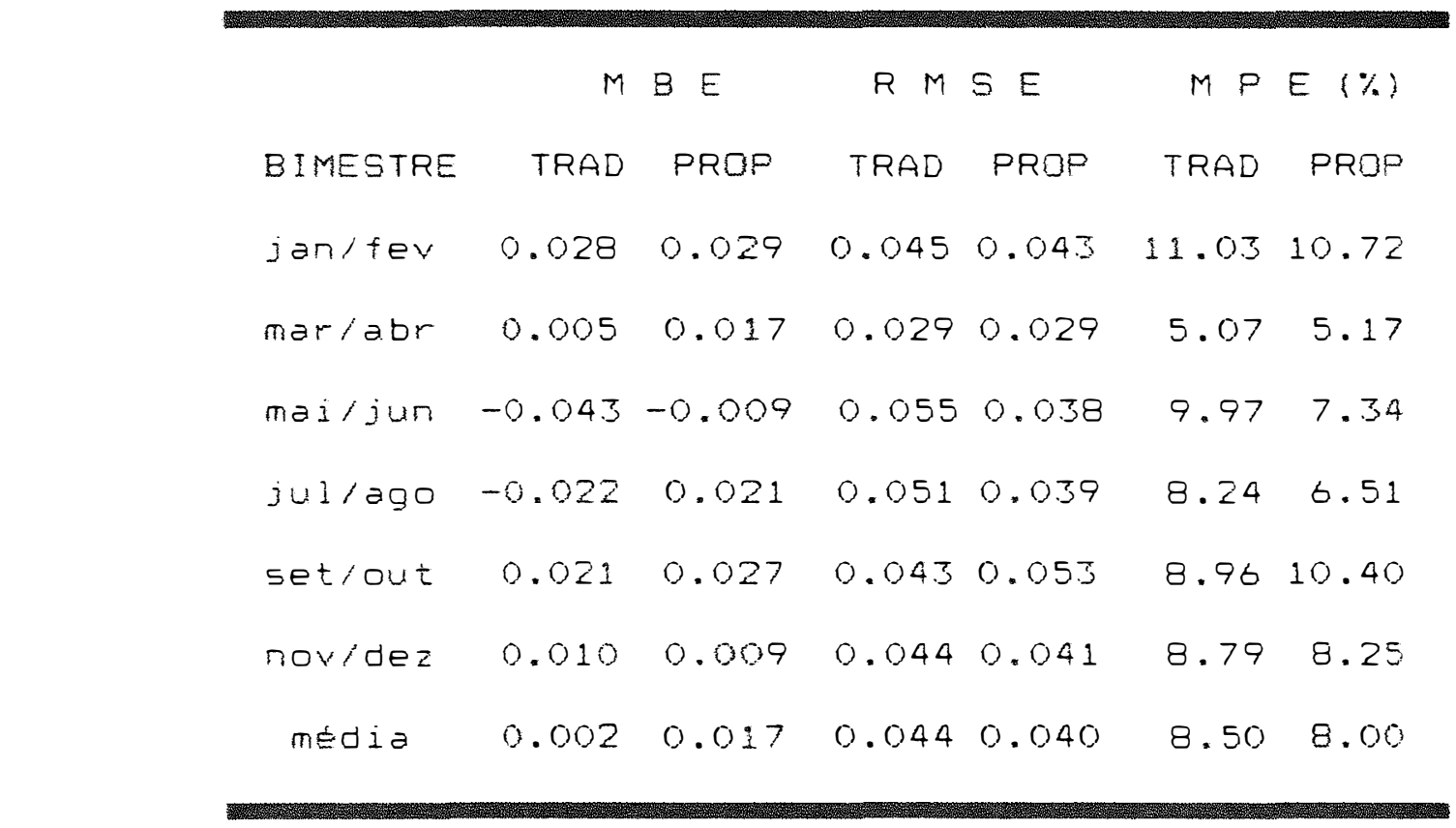

Os coeficientes das retas de regressao e 0 "indice d" apresentaram os resultados mostrados na Tabela 7.

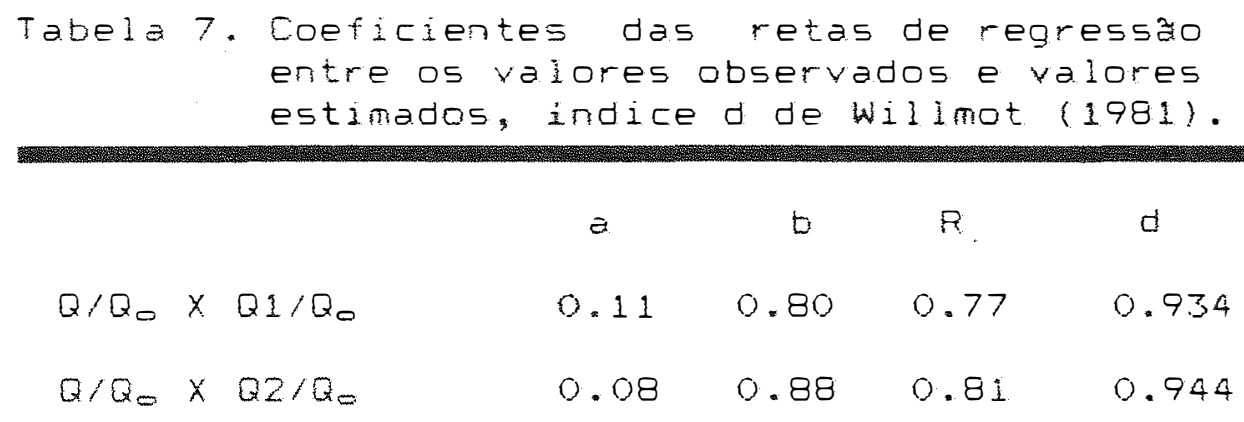


Tabela 8. Estiantivas diarias da relacao Q/Go sequndo o netodo tradicional (a1/Bo\} e netodo proposto (G2/Q0), resultados dos testes RAE, RMGE e MPE para cade eletodo. laneiro e fevereiro

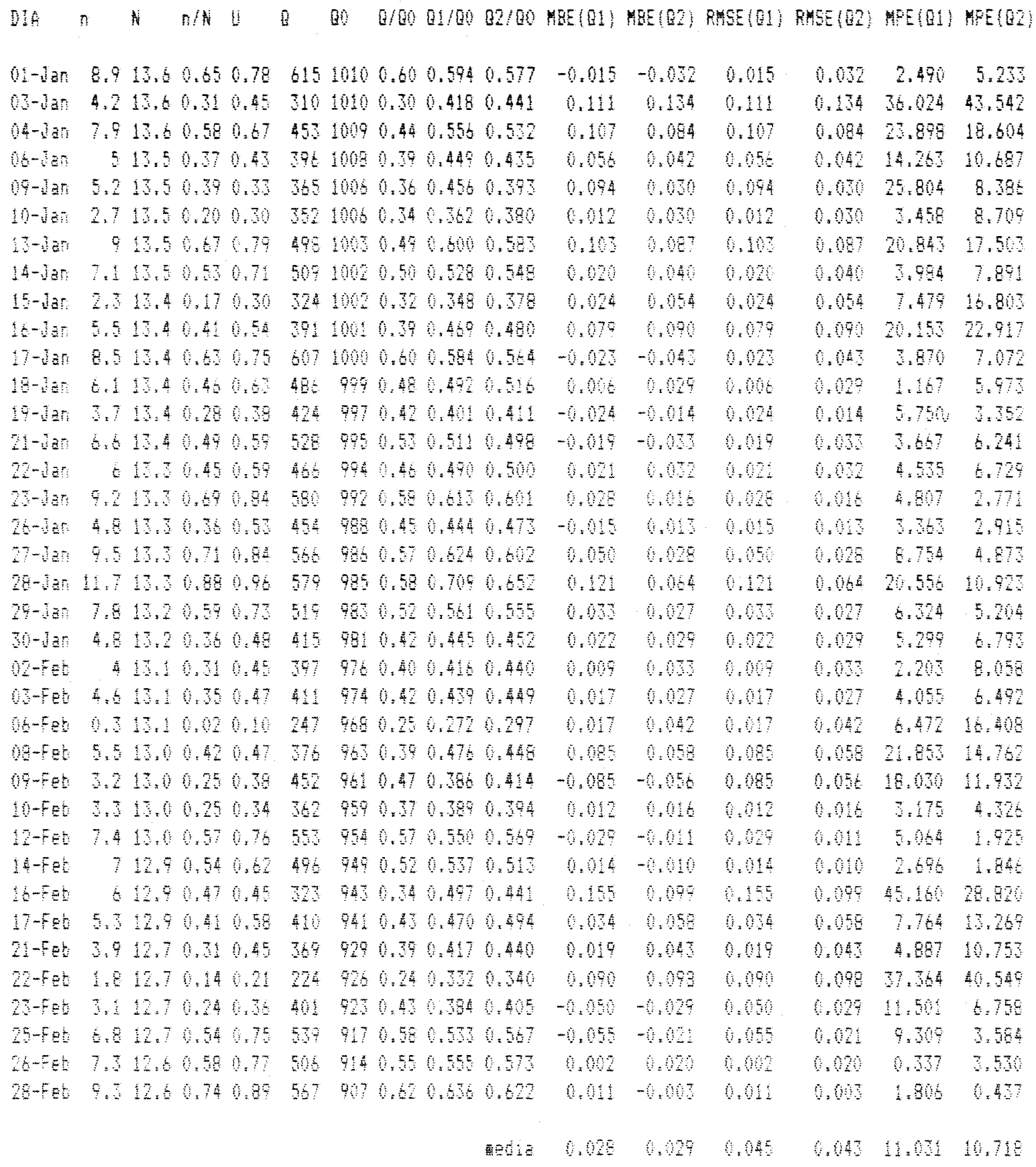




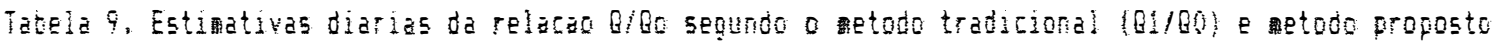

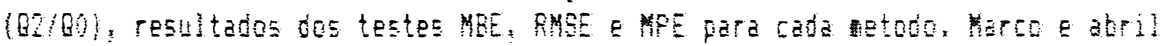

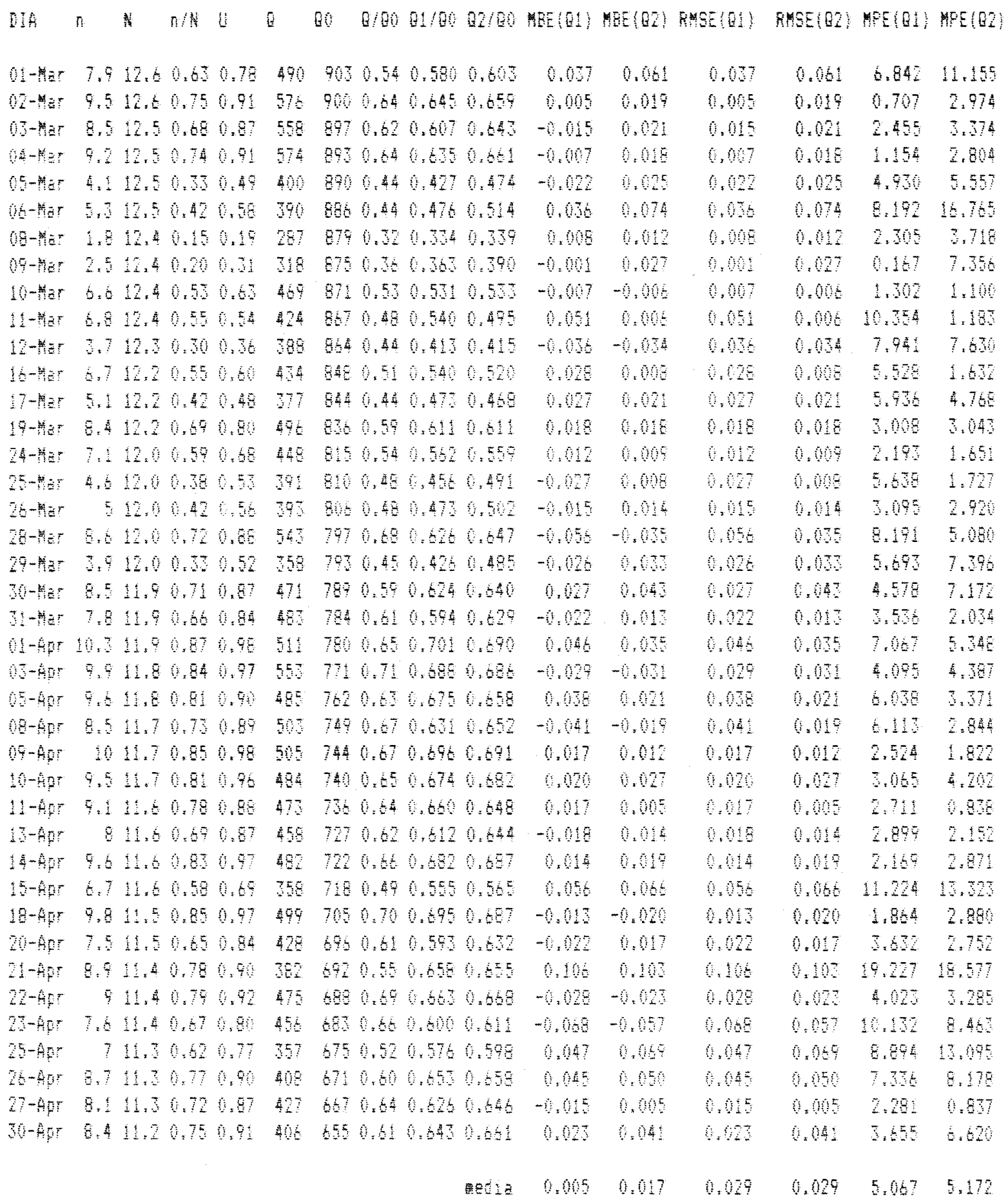




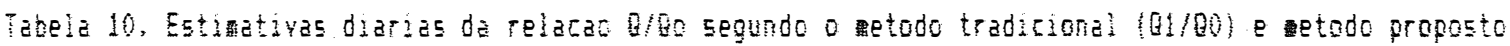

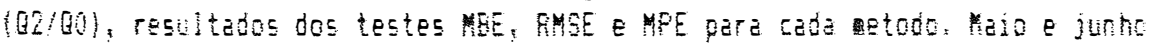

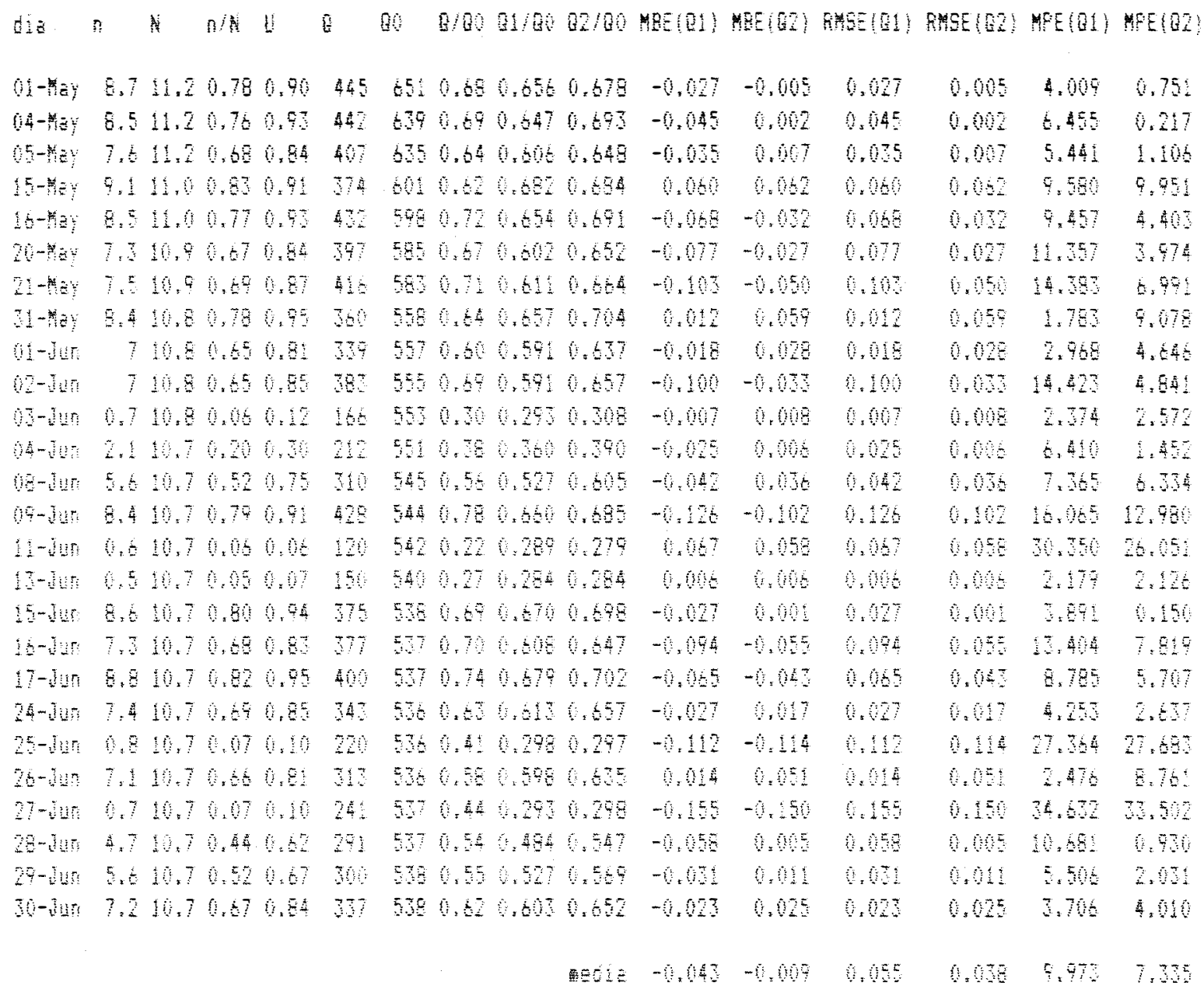




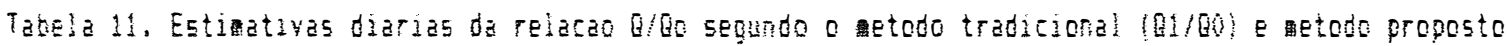

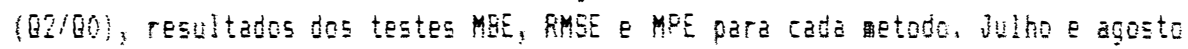

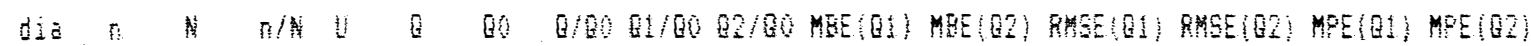

\begin{tabular}{|c|c|c|c|c|c|c|c|c|c|c|c|c|}
\hline $01-$-Ju1 & 6.310 .7 & 0.59 & 0.75 & 315 & 5390.50 & 0.5600 .607 & $-0,024$ & 0.026 & 0.024 & 0.023 & 4.130 & 3.919 \\
\hline 9-Jul & 6.710 .7 & 0.63 & 0.78 & $34 !$ & 5400.02 & $0,5790,622$ & $-0,050$ & $-0,008$ & 0.050 & 0.008 & 7.985 & 1.23 \\
\hline $08-341$ & 5.310 .7 & 0.50 & 0.73 & 334 & 5410.6 & 5130,598 & -0.105 & -1019 & $0.10^{5}$ & .019 & 16.968 & 158 \\
\hline & .710 .7 & $f_{2} c$ & 0.75 & 38 & 5420.61 & 0.540 .605 & -0.079 & -0.05 & .079 & 015 & 12.697 & 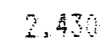 \\
\hline$(5-\sqrt[3]{n}$ & 810.7 & 0,75 & 0.91 & 364 & 5430.67 & 0.6410 .680 & -0.029 & 0.015 & .129 & 015 & 4.372 & 704 \\
\hline tit & 8.710 .7 & 0.78 & 0.90 & 77 & 5440.69 & 0.6560 .64 & $-6,134$ & 0,005 & 05 & 60 & 4.89 & 0.607 \\
\hline & 4.610 .7 & 6.47 & $1, b$ & 99 & $60 \times 5$ & 14790505 & $-4 i c$ & -115 & .158 & 013 & 12.48 & 5 \\
\hline & $5,810,7$ & 1,5 & 0.72 & 25 & 5470.59 & 580.59 & -0.050 & $-6,62$ & .65 & 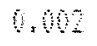 & 9.712 & 87 \\
\hline & 7.410 .7 & 0.69 & 0.87 & 358 & 5.970 .85 & 410.852 & $-0,07$ & 0.0 & .89 & & 6.60 & 5.8 \\
\hline & 5.810 .7 & $x_{1}=4$ & 0.71 & 279 & 550,5 & .580 .989 & $0.0 \%$ & 0.62 & .029 & 82 & 575 & .018 \\
\hline & 7.510 .8 & 1.70 & 0.8 & 36 & $=1.4$ & 6.619055 & -6.130 & $0,0 \mathrm{c}$ & 08 & 68 & 4.598 & 768 \\
\hline & $\div, 10.8$ & 0.16 & 0.30 & 23 & $7: \frac{1}{4}$ & 340.797 & -0.076 & $-0,0$ & 07 & $n$ & 18.34 & 7,15 \\
\hline & 8.810 .8 & 1.77 & 1.97 & 42 & 10.75 & 0.620 .692 & $-0,100$ & $-0,06$ & 10 & & 13.943 & 8.652 \\
\hline & 8.610 .8 & 0.80 & 0.95 & 411 & 307 & $66,79^{8}$ & $-6,63^{2}$ & -4 & $60^{\frac{2}{4}}$ & 8 & 8.754 & 3.017 \\
\hline & 52 & 1.48 & 1.6 & 37 & 26.5 & 0.51 & $-1 \mathrm{E}$ & $-10 \mathrm{~s}$ & 105 & 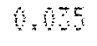 & 17.05 & 84 \\
\hline & $5=10 \times 9$ & 0.5 & 0.74 & 201 & 76.45 & 0.62 & 0,05 & $\eta+1$ & .87 & $\times 15$ & 12,958 & 23.70 \\
\hline & $6,910,9$ & 0.6 & 1.8 & 35 & 50306 & $D, t 0$ & -1.07 & & 0.19 & & 3.191 & 6.145 \\
\hline & 8,6 & 0.79 & 19 & 3 & 500,01 & 0.600 .679 & 0.143 & & An? & & 0.91 & 9.54 \\
\hline & 8.7 & 0.8 & 0.91 & 47 & 580 ०. & 0.6070 .69 & -4.139 & $-1,13$ & 3 & 13 & $\$ 6.723$ & $2.80 t$ \\
\hline & 9.11 .0 & 0.85 & $\pi \%$ & 360 & 59405 & 6.6960 .707 & $6_{2} 043$ & 0,05 & OAH & 80 & 6.525 & 285 \\
\hline & 9.511 .0 & 0.85 & 0.97 & 93 & 597.7 & 7001.712 & -0.016 & -0.00 & $=016$ & 1 & 2.296 & 0.75 \\
\hline & 9.111 .0 & 1.87 & 0.95 & 42 & 6006 & 6.692 1.702 & -0.08 & 0 & 10 & - & 2.51 & 0.35 \\
\hline & 8.9 & 0.75 & 0.91 & 17 & 400,68 & 0.6410682 & -0.042 & & 42 & & $5 \times 181$ & 9 \\
\hline & $7.9 \pm 3.1$ & 0.70 & 6.8 & 38 & 170.2 & $0,618,0=7$ & $-1,007$ & 0.072 & .007 & $m$ & 1.15 & 5.091 \\
\hline ws & 5.711 & 0.5 & 0.73 & 37 & 200, & 4.520 .597 & -408 & $-0,0$ & 1.109 & 0,014 & 14,625 & 5 \\
\hline & 911.1 & 0.81 & 9.95 & 424 & 640.67 & $0.6740 \times 700$ & -0.006 & 0,01 & 0,006 & 0.021 & 0.979 & 3.09 \\
\hline & 9.5 & 0.77 & 0.89 & 368 & 070 & 0.650057 & $\because b$ & & 0.64 & 87 & 1589 & \\
\hline & 8.6 & 0.7 & 0.92 & 401 & 810 & 50.688 & 0.00 & 5 & 0.00 & 5 & 3.09 & 19 \\
\hline $1-40$ & 6.811 .2 & 0.65 & 0.85 & 415 & 380.6 & $0,500,60$ & -0.08 & 0.603 & $0.08:$ & 0.005 & 12.42 & 0.396 \\
\hline & 7.511 .2 & 1.6 & 0.8 & $39=$ & 040.60 & $0.620,5=0$ & -0.60 & 6.12 & .10 & 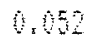 & 0.917 & $9.5 \mathrm{E}$ \\
\hline & 1.2 & 0,71 & 0.85 & 372 & 650.50 & 6.6240 .656 & 4,05 & & 0.655 & $8 \mathrm{~s}$ & 9,580 & 16,071 \\
\hline & 8.611 .5 & 0.76 & 0.71 & 30 & 6019.50 & 0.600 .692 & 0.60 & 0 & 0.065 & 100 & $1+278$ & $17 \times 15$ \\
\hline & 9.711 .4 & 0.82 & 0.95 & 57 & 670.63 & 4.6760701 & 0.041 & $0.06 t$ & 0.041 & .066 & 6.459 & 10.34 \\
\hline & 711.4 & 0.79 & 0.8 & $4 \mathrm{~B}$ & 690.61 & 0.6070 .55 & 0.02 & 0.64 & 605 & 6,013 & 9. 274 & 7.09 \\
\hline & 9.711 .4 & 1,82 & 0.98 & 37 & 685,5 & M.670,94 & 0.102 & 0.120 & 0.102 & 0.120 & 17.88 & 20.880 \\
\hline & $7.511,5$ & 1.6 & 6.84 & 40 & 689.59 & 0.594049 & 6.011 & 0.007 & 1,01 & 0.67 & 1,82 & 11.428 \\
\hline & $8.711 \times 5$ & 0.7 & 0.91 & 442 & $69: 63$ & 0.450 .696 & 0.608 & 0,048 & 1.00 & 0.048 & 1.257 & 7.58 \\
\hline $2 b-A+5$ & $7 \times 711 \times 5$ & 6.6 & 0.8 & 44 & 690,65 & 0.6110 .67 & -0.01 & 6,14 & $10 \mathrm{~B}$ & 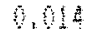 & 4.938 & 2.23 \\
\hline & 5.811 .5 & 0.59 & 6.74 & 45 & 706064 & 0.5620 .602 & -8.07 & $-6 \times 38$ & 0.975 & $0.0 \mathrm{t}$ & $12.28 \mathrm{~B}$ & 5.895 \\
\hline $27-40$ & $6,011,5$ & 0.59 & 0.8 & 432 & 7100,60 & $6,5 x] 6.629$ & $-0,0 \dot{9} 5$ & 0.61 & 0,045 & 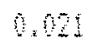 & 7.310 & 3.39 \\
\hline \multirow[t]{2}{*}{$\mathrm{BCAB}$} & $8+1.8$ & 0.69 & 0.89 & 473 & $7140 \times 6$ & $0.520,672$ & 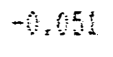 & 0,010 & 0,05 & 0.010 & 7.659 & 1,4 \\
\hline & & & & & & 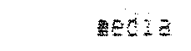 & $-0.6 Z$ & $\because+11$ & An & 6 & 24 & 56 \\
\hline
\end{tabular}


Tatela 12. Esti

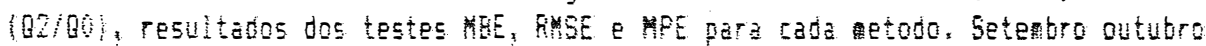

\begin{tabular}{|c|c|c|c|c|c|c|c|c|c|c|c|c|c|c|c|}
\hline dia & n & N & $n / N$ & $\mathrm{U}$ & 8 & 80 & $4 / 00$ & d1/00 & $02 / 00$ & MEEIUI) & MEE $(62)$ & BHGE(Q1) & BHGE 102 ) & MPE (Q1) & NaE $(02)$ \\
\hline$-5 e f$ & 3.8 & t & 0.32 & 0,4 & 290 & 735 & 40 & 426 & 411 & 0,019 & 0,004 & 0.019 & 0.004 & 4.631 & 0.964 \\
\hline$-9 e f$ & b. 4 & 11.7 & 0.5 & 0.76 & 36 & 780 & 0.48 & $0.53 \%$ & 0.587 & 0.050 & 0.098 & 0.050 & 0.098 & 10.177 & 19.933 \\
\hline $6-5 e ?$ & 8,3 & 11.7 & 0,71 & 0.87 & 471 & 748 & 0.63 & 0.622 & 0,655 & $-0,011$ & 0.021 & 0.015 & .021 & 1.780 & 3.396 \\
\hline $68-5 e \overline{1}$ & 9.3 & 11.8 & 0.79 & $0.94^{\circ}$ & 41 & 75 & 0.5 & 0.60 & 0.193 & 0.102 & 0.13 & 0.10 & 10 & 10.534 & 2.780 \\
\hline $7-5 \mathrm{et}$ & 8.7 & 1158 & 1, 7 & 0.90 & 38 & 75 & 0.50 & 1.63 & 0.60 & 0.125 & 1.150 & 0.21 & $15 \overline{1}$ & 24,73 & 71,12 \\
\hline $1-5 e p$ & 9 & 11.8 & $.7 t$ & 0.91 & 46 & 761 & 0,60 & 0.645 & 0.67 & 1,645 & 0.06 & 0.945 & 06 & 7.764 & 1. AbE \\
\hline $1-5 e f$ & 10. & 11.5 & 0.85 & 96 & 518 & 765 & $6 . t^{c}$ & 0.69 & 0.709 & 0.077 & 0,05 & .077 & 05 & 5.59 & 7.901 \\
\hline $12-59$ & 10.2 & 11,9 & 0.8 & 0.9 & $5 \mathrm{Bi}^{2}$ & 769 & 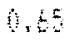 & 0.69 & 6.70 & 0,12 & bros & 0,12 & fet & 6.770 & 8.378 \\
\hline $4-5 e$ & 7.5 & 11.5 & 0.61 & 0.70 & 42 & 771 & 0,54 & 0.57 & 0.90 & 1,12 & 0.08 & 0,02 & .078 & 4.821 & 7.012 \\
\hline $4-5 e ?$ & 8.8 & 119 & 1.74 & 0.9 & A A & 778 & 0.50 & 6.65 & 0.87 & 0.070 & 1.10 & 0.07 & 10 & 12.405 & 19.976 \\
\hline $15-5=5$ & 7,7 & 11.9 & 0.65 & 0.74 & 384 & 782 & 0.59 & 0.50 & 0,57 & 0,000 & 0.685 & 109 & 08 & 24.151 & 16.825 \\
\hline $16-5 e p$ & 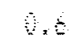 & 11,5 & 0,0 & 0.25 & 212 & 78 & 0.26 & .28 & 0.203 & 0.016 & OY & 0,016 & 013 & 5.90 & 4.95 \\
\hline $17-5 \mathrm{EF}$ & -5 & 12,0 & .5 & 0.58 & 40 & 79 & 0.5 & 0.58 & 0.477 & 0.60 & -0.042 & 0.009 & 042 & 1.680 & 8.172 \\
\hline$-5 E$ & 5.9 & 12,8 & 1.49 & 0.60 & 45 & 79 & 5,54 & 5.51 & 0,57 & -0.09 & $-0,010$ & .082 & bit & 5970 & 2,887 \\
\hline $1-580$ & $9: 2$ & 10. & 6.78 & 1.92 & 548 & 87 & 8.67 & 648 & 0.65 & -6. & 0,00 & $0.0 \mathrm{i}$ & 0.00 & 560 & $0.30 ?$ \\
\hline & 16.3 & 12 & 85 & $9 t$ & 57 & 89 & i & 0,59 & .716 & $-1,00$ & 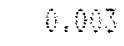 & $0.01 \%$ & me & 1.43 & 0,24 \\
\hline $20-5 e 0$ & 7,8 & 12.2 & 0.4 & 9.92 & 粋E & $82 ?$ & 0.54 & 0.58 & 0.62 & 0.64 & .192 & 0.014 & .082 & 8.187 & 15070 \\
\hline $7-5 E \%$ & 5 & 12.2 & 4.3 & 0.5 & 40 & 83 & bit & 148 & 1.499 & -1.09 & $0.0 \mathrm{~s}$ & 1.69 & .00 & 1.918 & 1.65 \\
\hline$y-5 e$ & 3.2 & 12,3 & 12 & 0.34 & 252 & 870 & 0.50 & 0,04 & 9.755 & 0.092 & 0.035 & 0.002 & 075 & 70,788 & 11.494 \\
\hline-35 & 5,5 & 12,2 & 4.77 & 0.94 & 55 & 94 & 0.6 & 6.65 & +801 & $-0,007$ & 4.01 & 07 & 03 & 1.634 & 4.65 \\
\hline$-10 t$ & 8.8 & 12.3 & 0.72 & 0.87 & 512 & 85 & 0.60 & 6,65 & $0,6=0$ & ODZ & 0.02 & 2 & $95-2$ & 3.862 & 8.57 \\
\hline B- & 4.8 & $12 . \frac{2}{4}$ & .39 & 15 & 38 & 65 & (1, 45 & 147 & 0,45 & $1, \mathrm{Bz}$ & -1.05 & 0.67 & 915 & 1.45 & 3.34 \\
\hline$b^{2}-c^{2}$ & 4.1 & 12,4 & 4.7 & 0.44 & 520 & 85 & 0.60 & $1+49$ & 1.796 & $-17 \%$ & -1.218 & $0 \times 17$ & .208 & 29.216 & 34,324 \\
\hline is-tet & 8.2 & 12 & 6.to & 0.82 & 30 & 85 & 6.61 & 1.50 & 0.62 & $-0,08$ & 1010 & 0.018 & 10 & 2.81 & 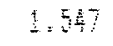 \\
\hline $\mathrm{Bt}-$ & 4.4 & 12,4 & 1.5 & 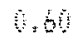 & 35 & 86 & & & 0.452 & -0.65 & 0.03 & & 36 & 5.32 & 7.768 \\
\hline Mat & 2,3 & 12,4 & 0.19 & 0.28 & 294 & 84 & 0.33 & 0.355 & 0.30 & 1.56 & -1.607 & 0.016 & 0.037 & 4.811 & 11.048 \\
\hline $09-6+t$ & 3.8 & 12.5 & 0.70 & 0,1 & 408 & 97 & 0,46 & $1, \frac{a}{4} 15$ & $1 \times 3 E$ & $-0,05$ & -1.08 & 0.05 & 0.095 & 10.880 & 18.22 \\
\hline $10-0 \mathrm{ct}$ & 11 & 325 & 8.88 & 0.9 & 620 & 80 & $0.7)$ & $1.70 \%$ & 0.13 & $1, \widehat{M}$ & 060 & 0,014 & 0.008 & 1,604 & $1=171$ \\
\hline $1-0 t$ & 9.8 & $12 \times 5$ & 0.78 & 0.92 & 55 & 884 & 0.65 & 0.660 & 0.68 & 0,105 & 0.680 & & 180 & 9.47 & 13.51 \\
\hline $2-96$ & 7.5 & 12.2 & 0.30 & 1.73 & $75 !$ & $8 \mathrm{gi}$ & 5.79 & 0.50 & 584 & $0: 170$ & 100 & 4.170 & 0.199 & $\mathrm{ESAM}$ & 51219 \\
\hline Dent & 5,3 & 2,6 & 1.42 & 0.49 & 40 & 89 & 0.4 & 1. 47 & 0.25 & 0.117 & -1.012 & 0.117 & 0.032 & D. 280 & 6.956 \\
\hline $5-5+t$ & \pm & 12.6 & 1.87 & 0.97 & 67 & 99 & 0.70 & 0.705 & 0.73 & 0,00 & 0.01 & 0.014 & 0.01 & $0 \times 55$ & $1 \times 60$ \\
\hline $15-1 t$ & 16.7 & 12,6 & 0.95 & 0.97 & bit & 89 & 0.68 & 4,69 & 0.717 & 0.006 & 1,0124 & 0.006 & 0.024 & 1.926 & 3,44 \\
\hline $17-50 t$ & $\therefore$ 青 & 12.7 & 1.27 & 0.38 & 31 & 90 & $1 \times 5$ & 0.397 & 0.75 & 0.06 & $-1,0 \mathrm{~B}$ & 0.064 & 003 & $14.0 \% 2$ & 1.996 \\
\hline$B-1+t$ & 6.7 & 12.7 & 15.5 & $4: 6$ & 48 & 907 & 0,4 & 0.20 & 4.51 & 1,08 & 1077 & 0.085 & 0.07 & 19,070 & 17.278 \\
\hline $19-0 c t$ & 9 & $12: 7$ & 0.71 & 0,87 & 58 & 910 & 0,6 & 0.621 & 6,66 & -0.016 & 0.08 & 0,01 & 0.02 & $2 \times 50$ & 4.924 \\
\hline $2-5 c t$ & $7=$ & 12.8 & 0.59 & 0.74 & 549 & 95 & 0.59 & 0.553 & 0.73 & -1.017 & -0.02 & 0,01 & 007 & 6.695 & 4.428 \\
\hline $2-n e t$ & & 12.8 & 0.2 & 0.30 & 75 & 919 & 4.58 & 0.780 & 0.360 & $-b_{1}$ & -106 & . Mb & 0.02 & 1,57 & 6.669 \\
\hline & & & & & & & & & 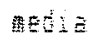 & 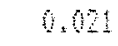 & 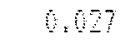 & 1,048 & 0.05 & 8.981 & 10,46 \\
\hline
\end{tabular}




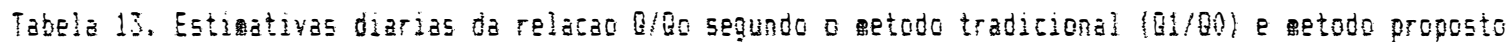

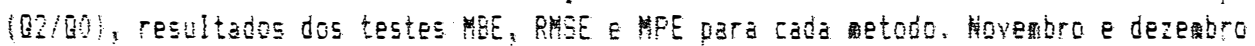

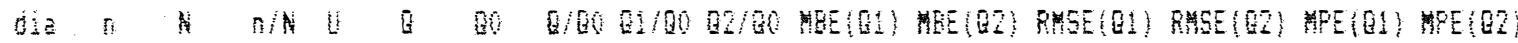

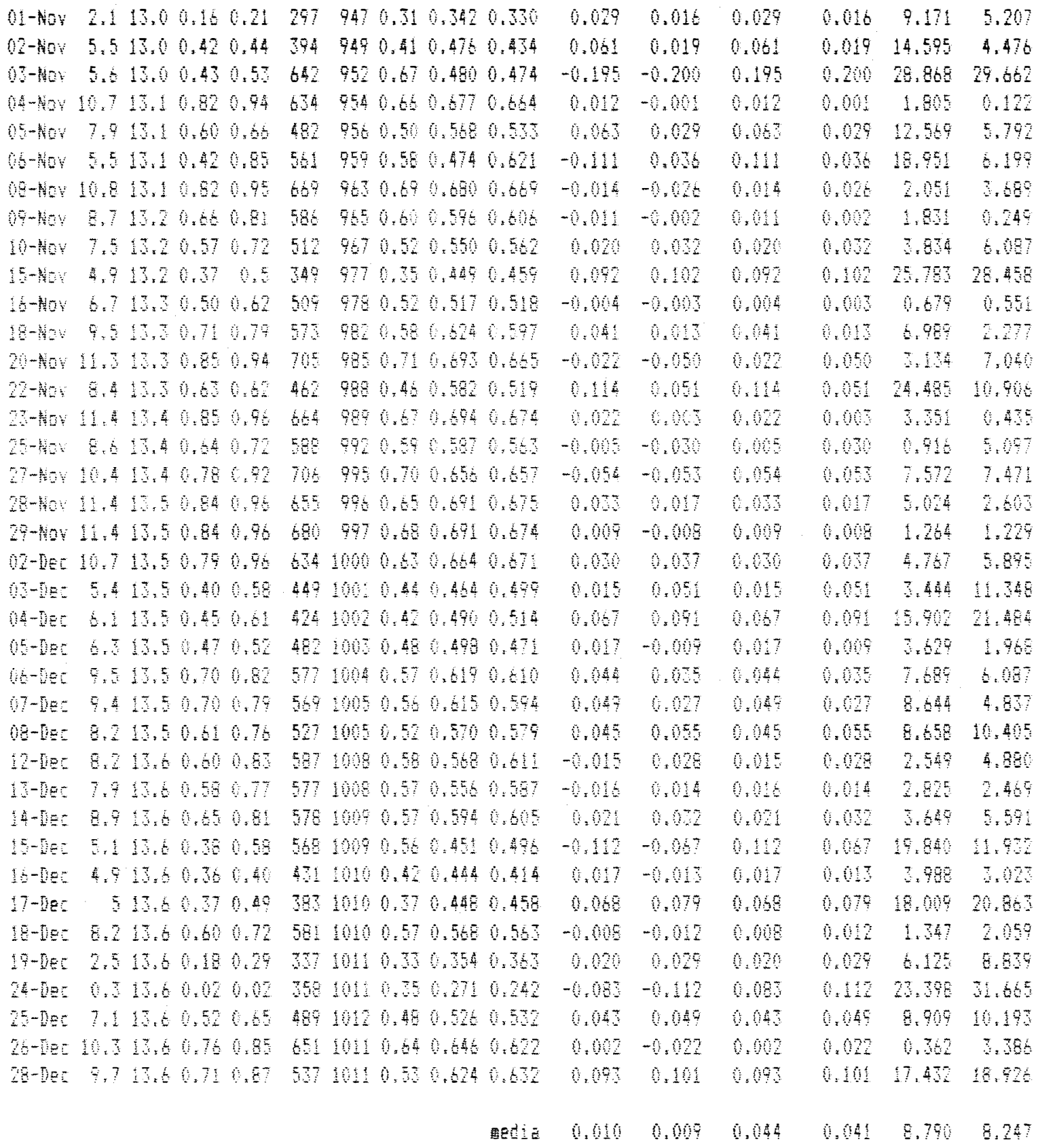




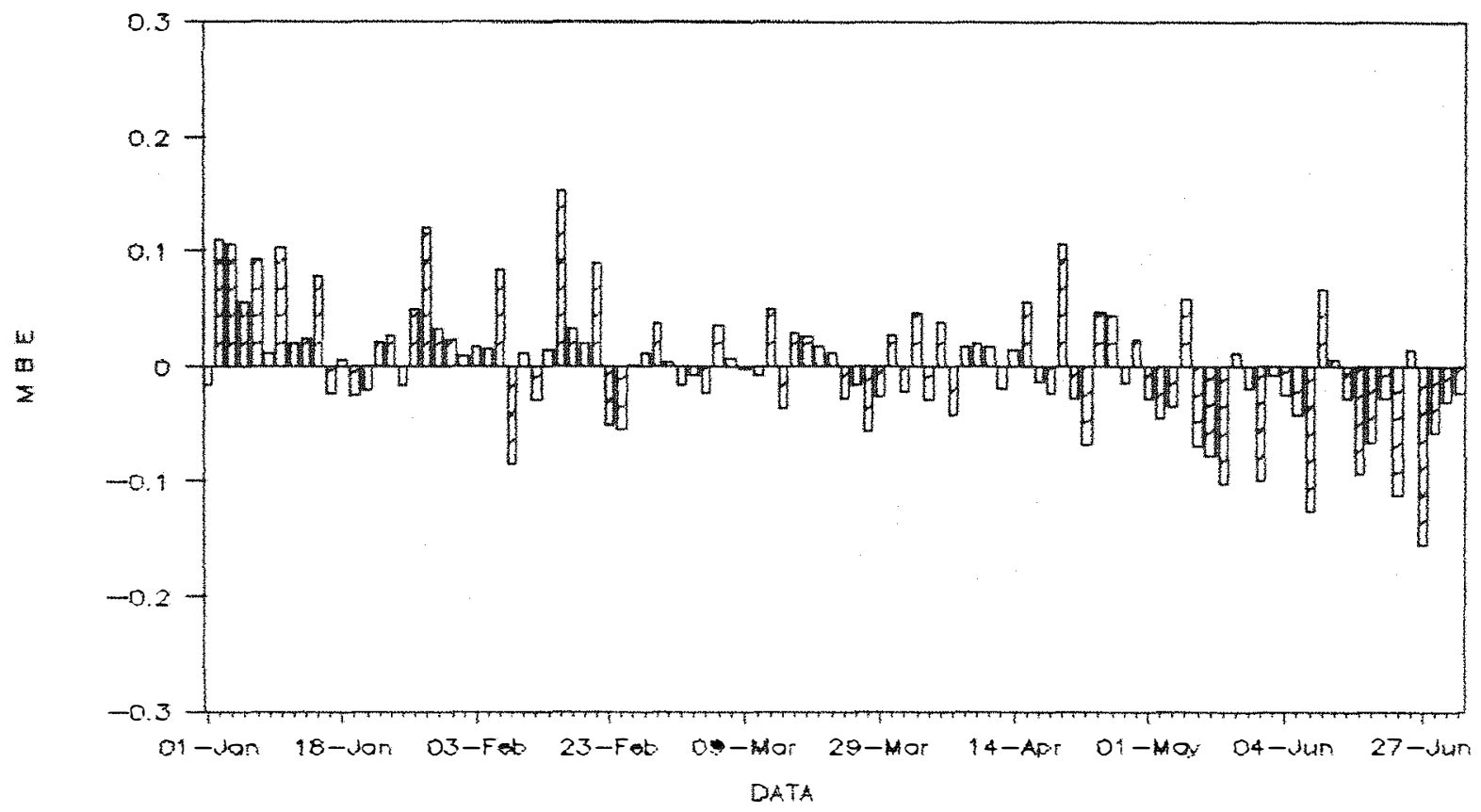

Figura 7a. Teste MBE para o metodo tradicional de janeiro a juntio.

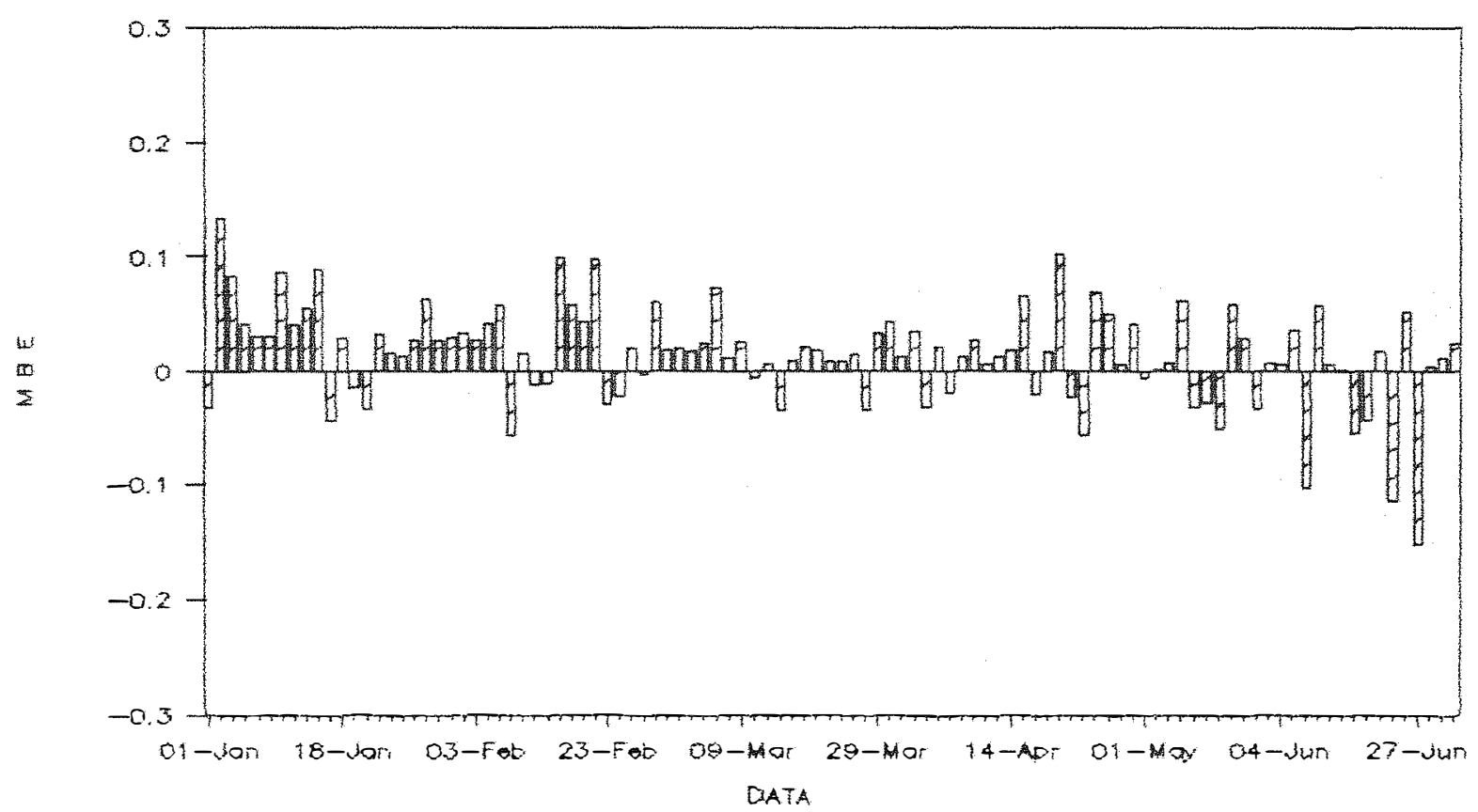

Figura 7b. Teste MBE para o metodo proposto de janeiro a juntio. 


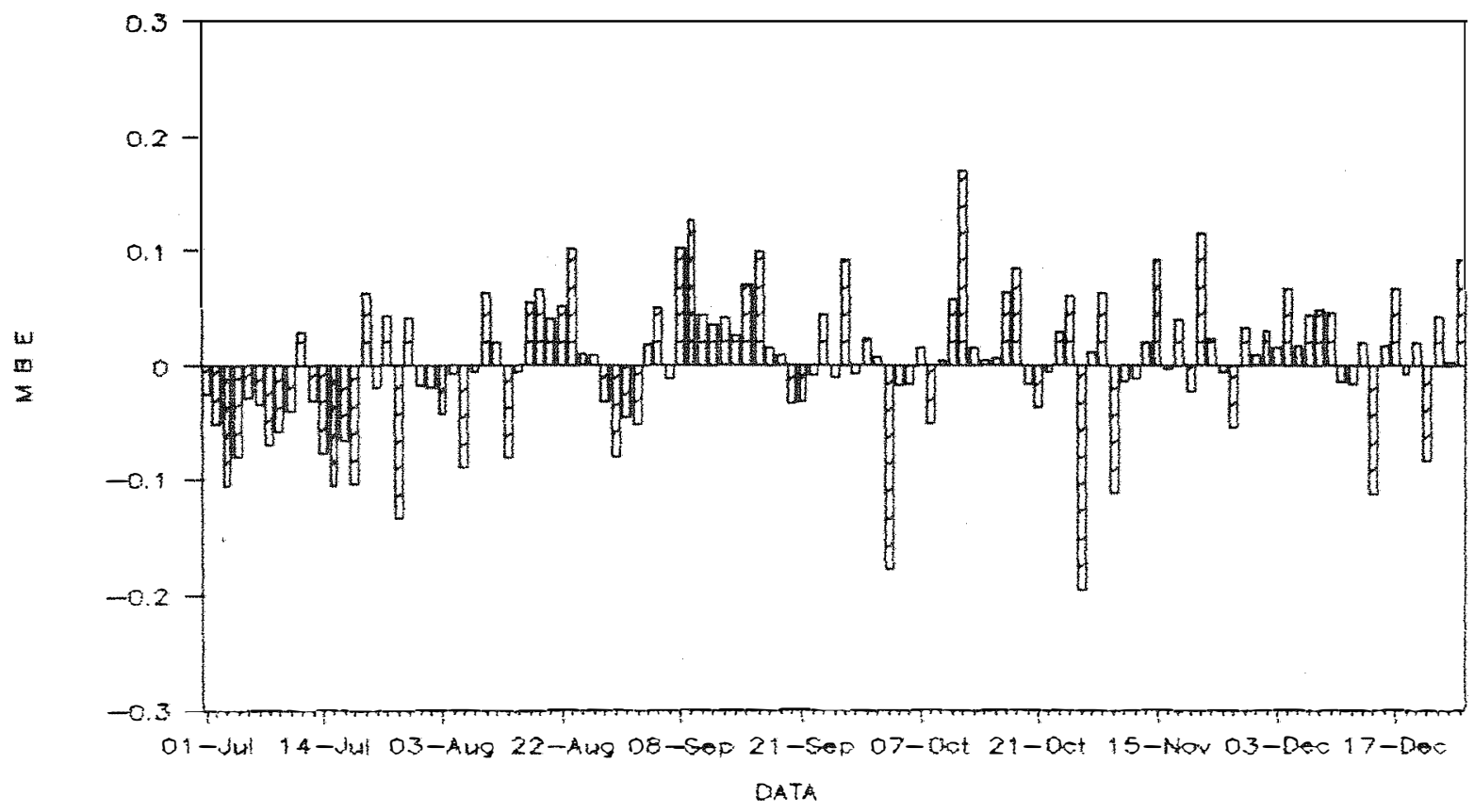

Figura 8a. Teste MBE para o metodo tradicional de julno a dezembro.

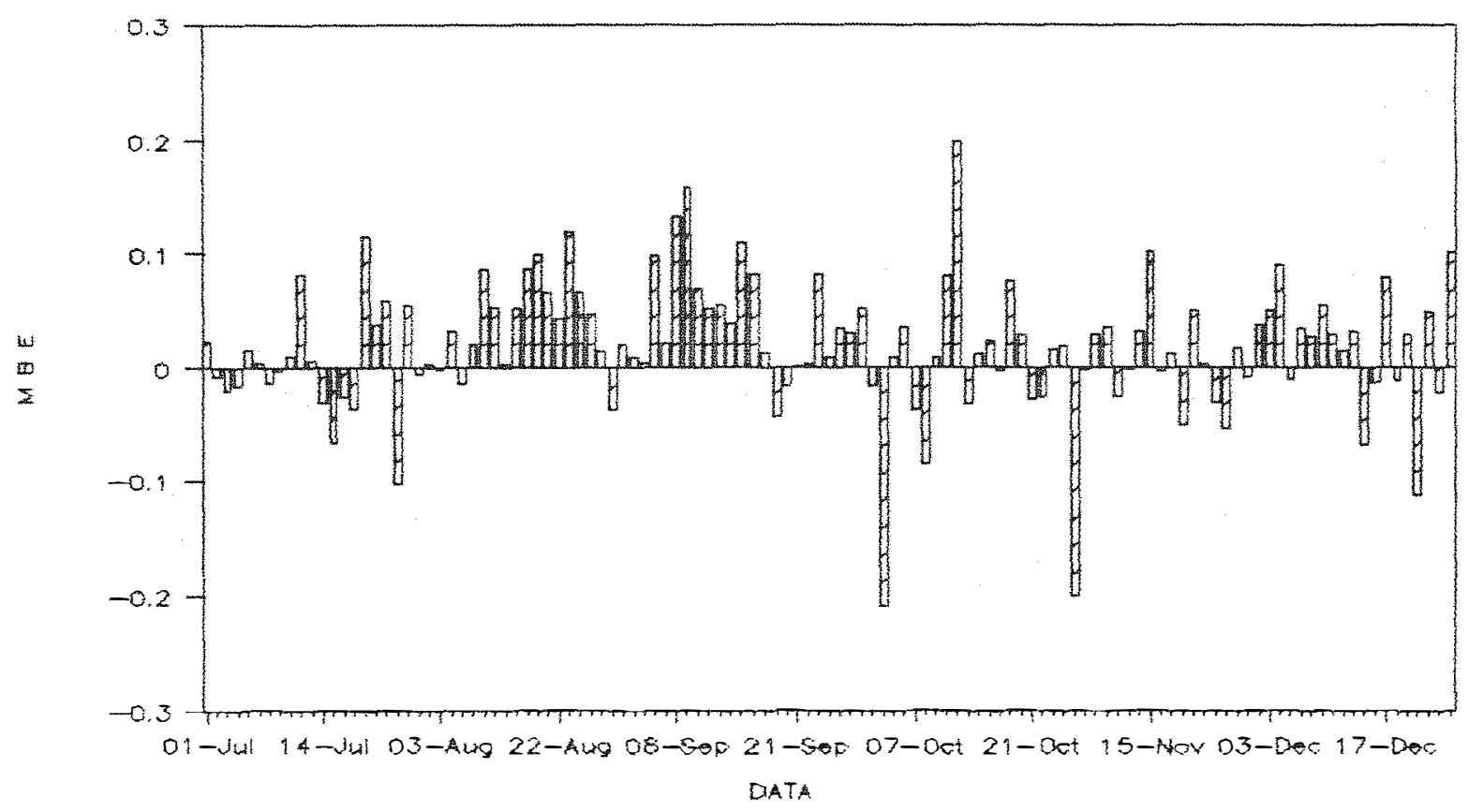

Figura 8b. Teste MBE para o metodo proposto de jultio a dezembro. 

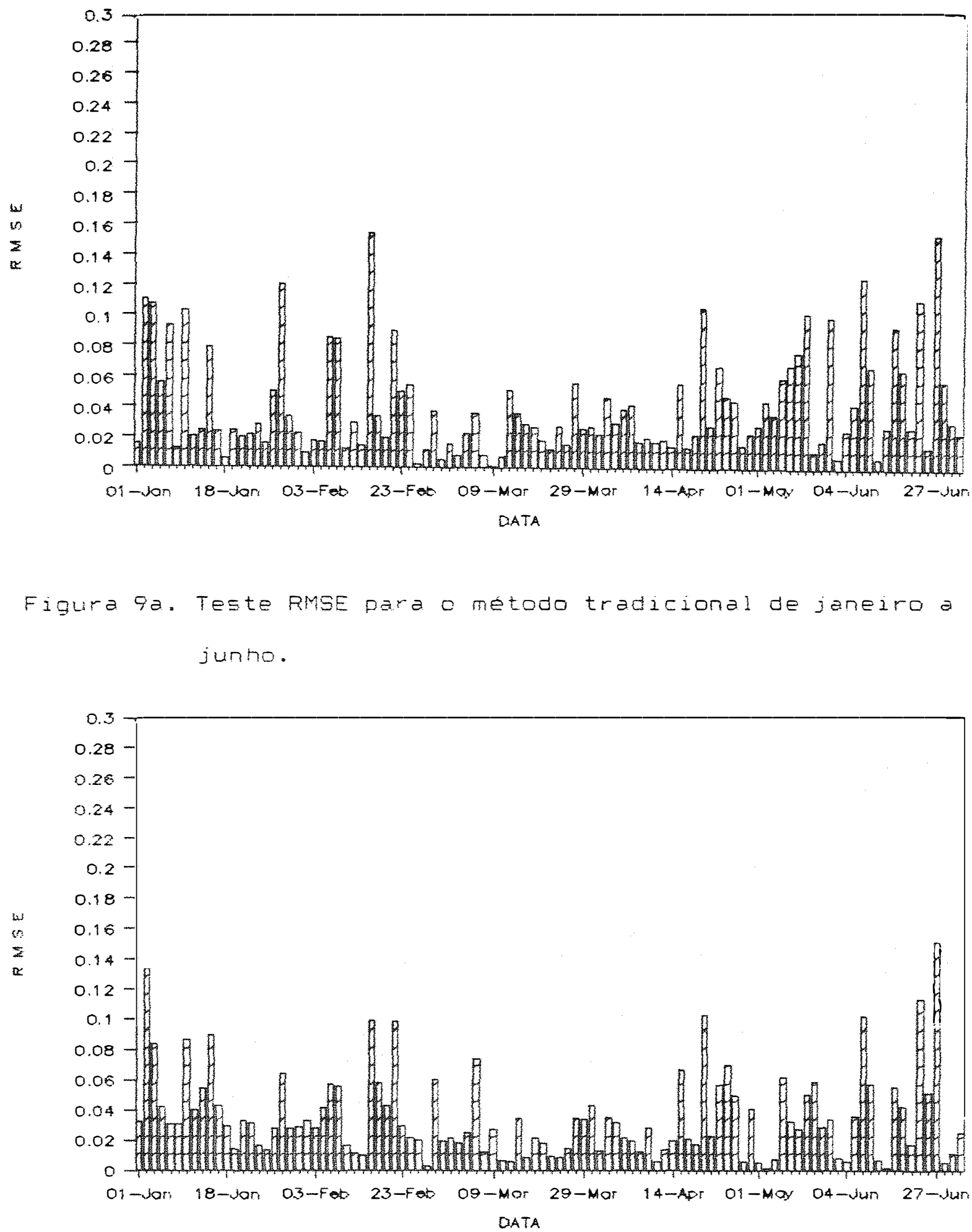

Figura 9b. Teste RMSE para o metodo proposto de janeiro a juntio. 


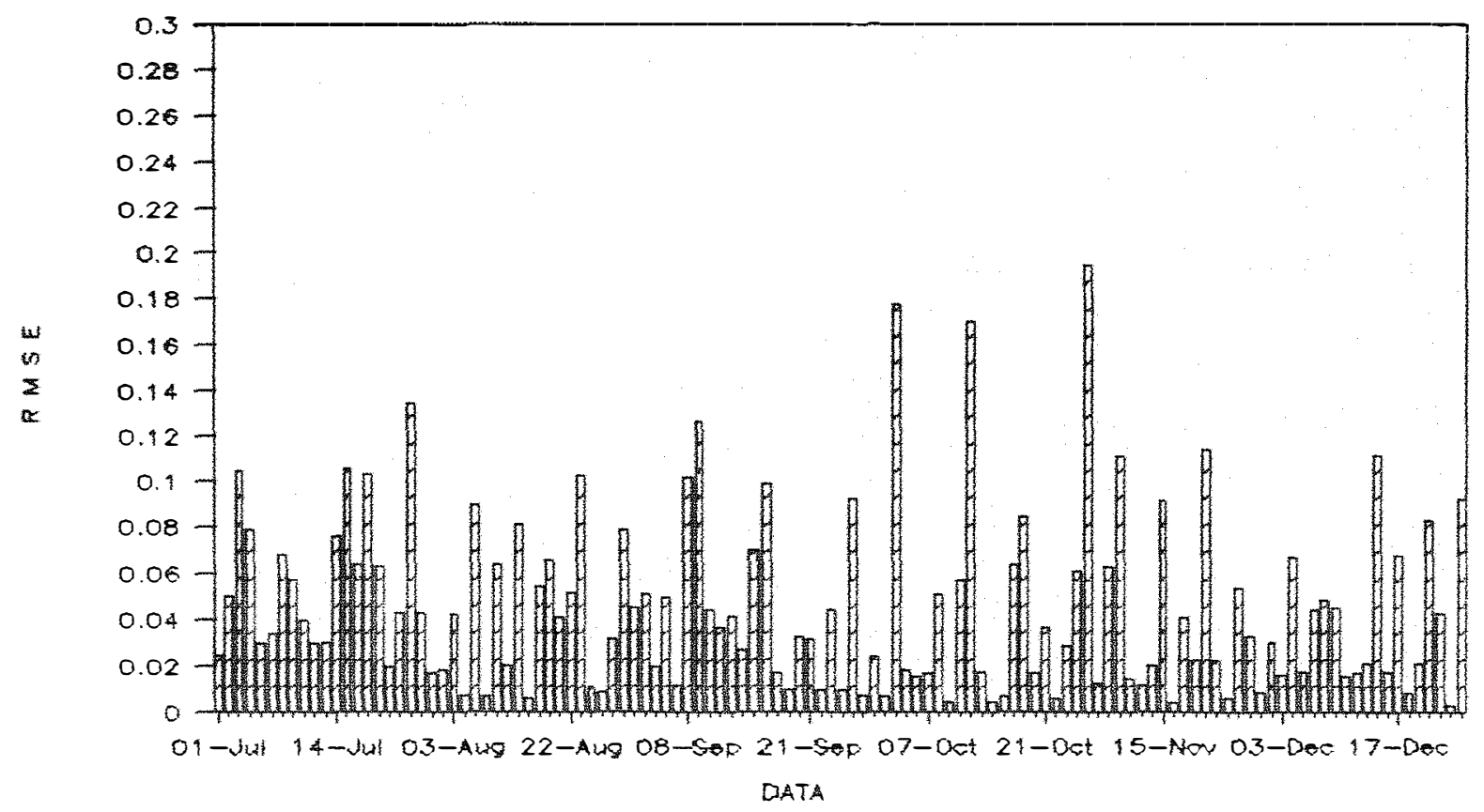

Figura 10a. Teste RMSE para o metodo tradicional de julno a dezembro.

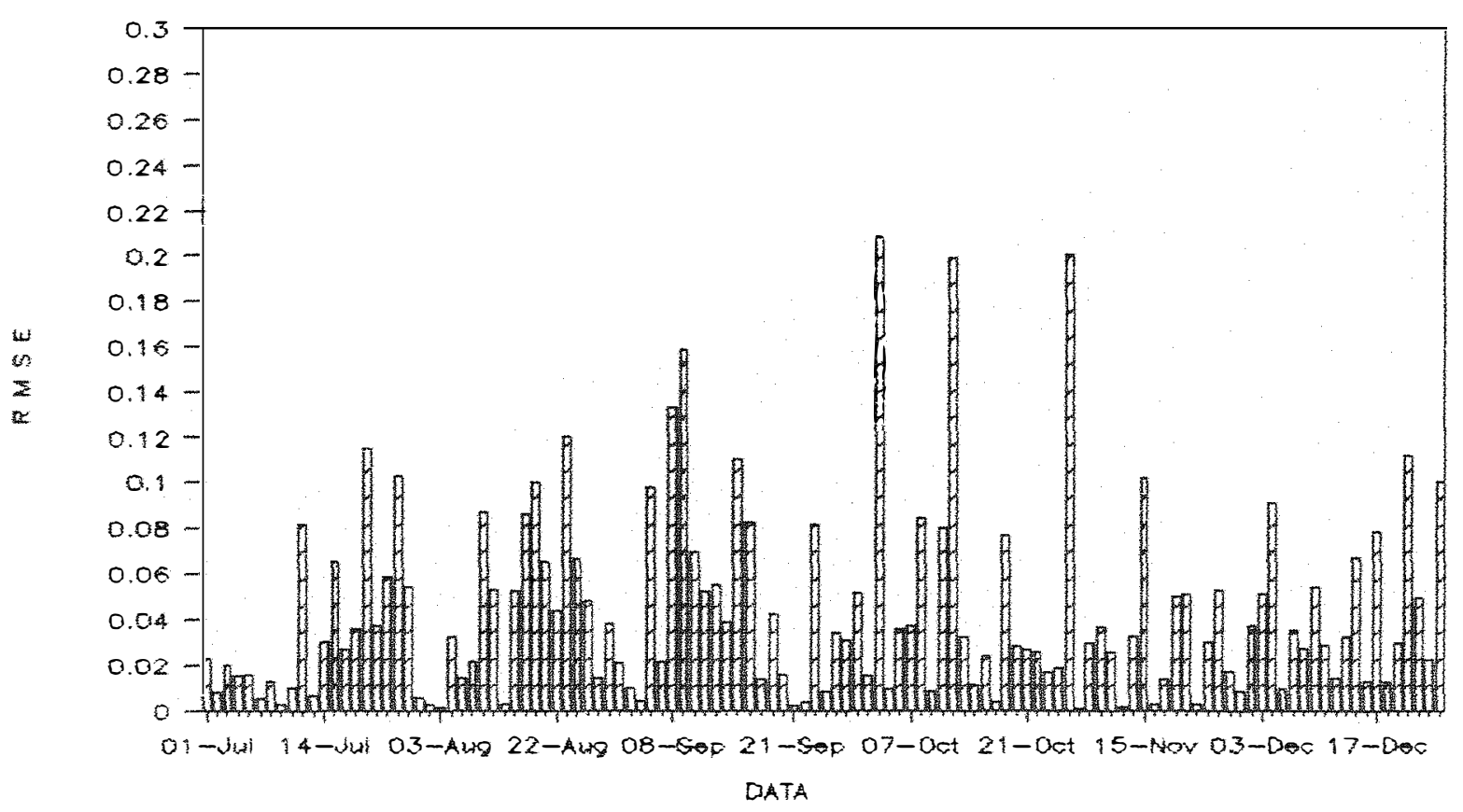

Figura 10b. Teste RMSE para o metodo proposto de julho a dezembro. 


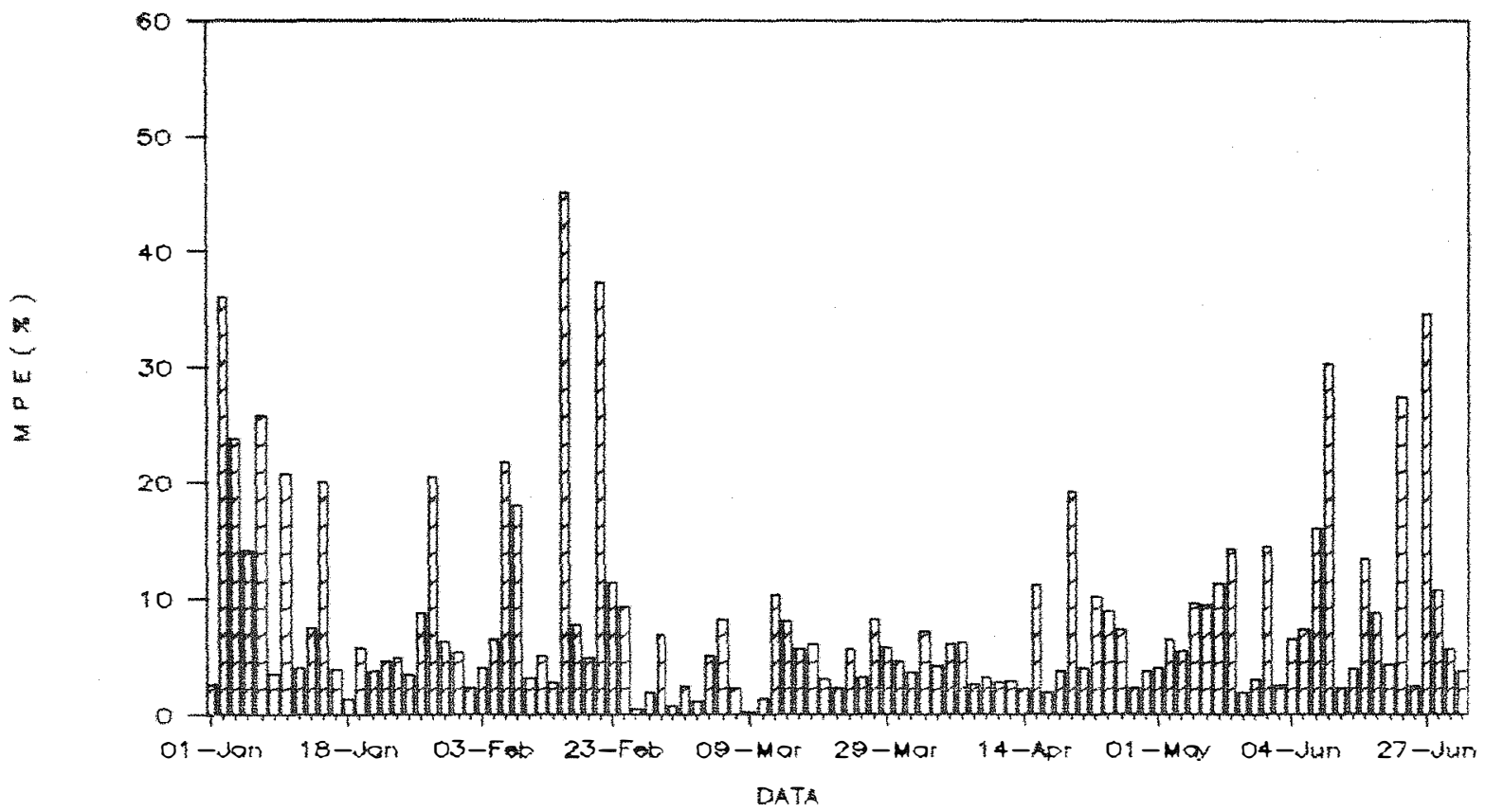

Fiqura 11a. Teste MPE para o metodo tradicional de janeiro a juntio.

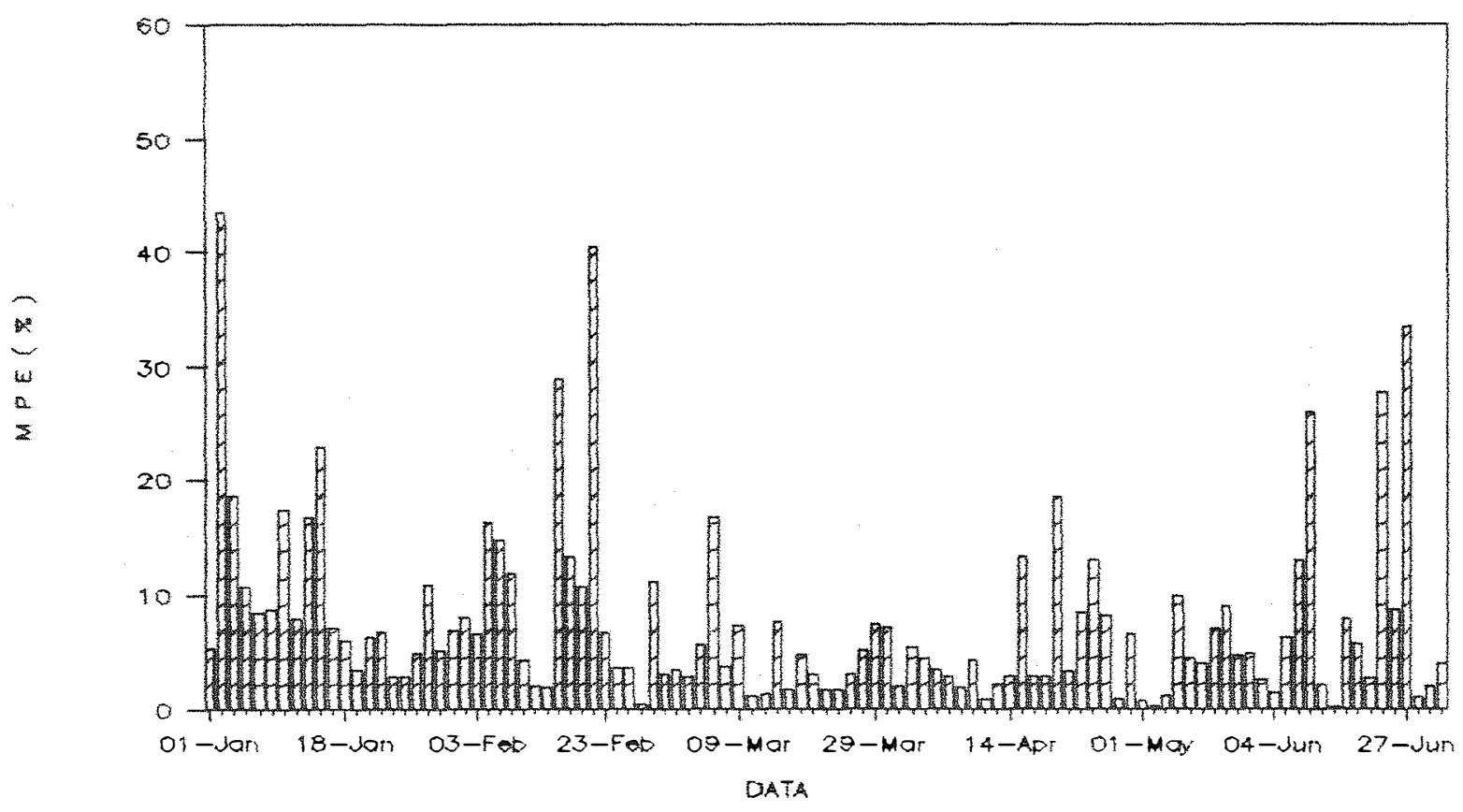

Figura 11b. Teste MPE para o método proposto de janeiro a junho. 


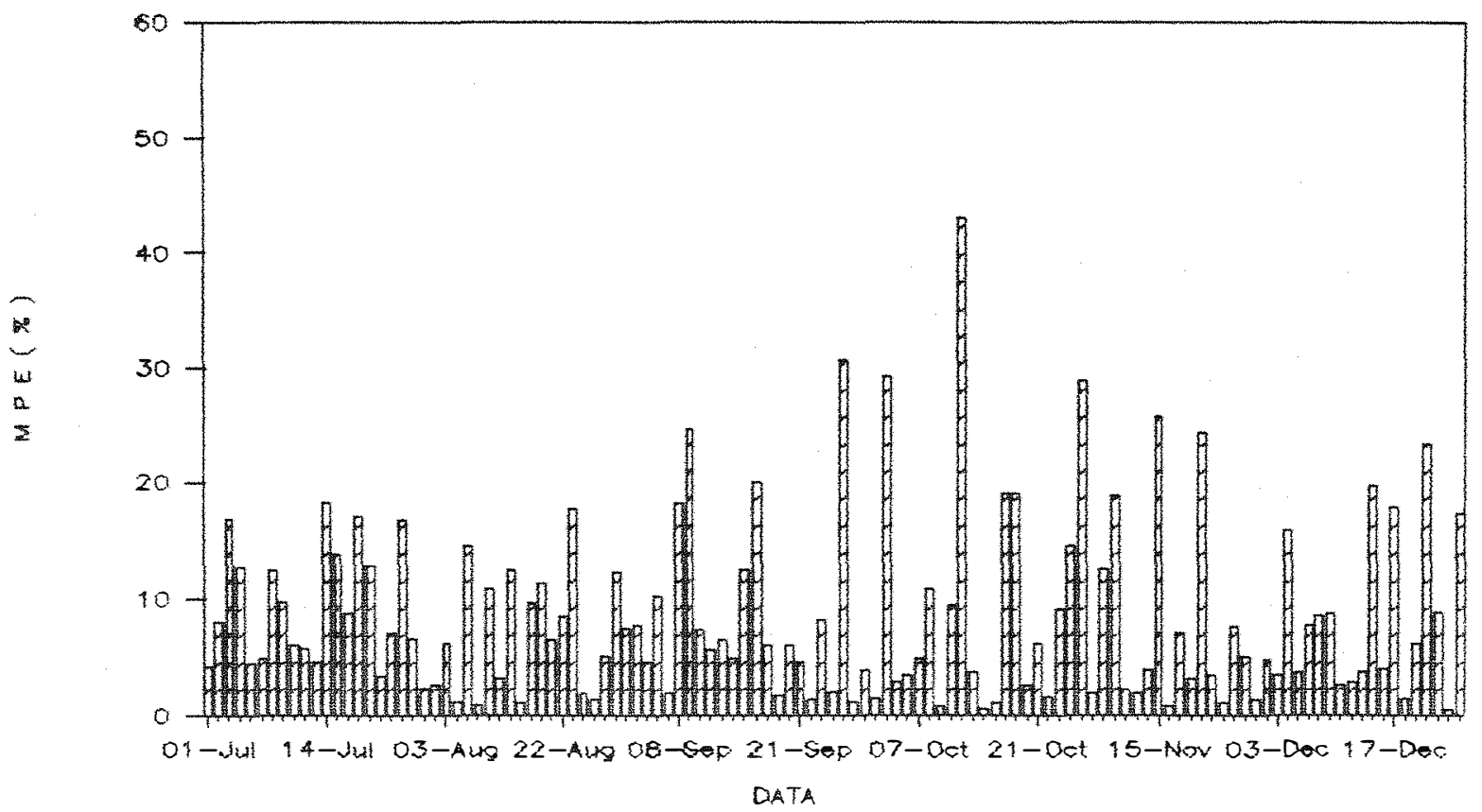

$$
\begin{aligned}
& \text { Figura 12a. Teste MPE para o metodo tradicional de jultio a } \\
& \text { dezemoro. }
\end{aligned}
$$

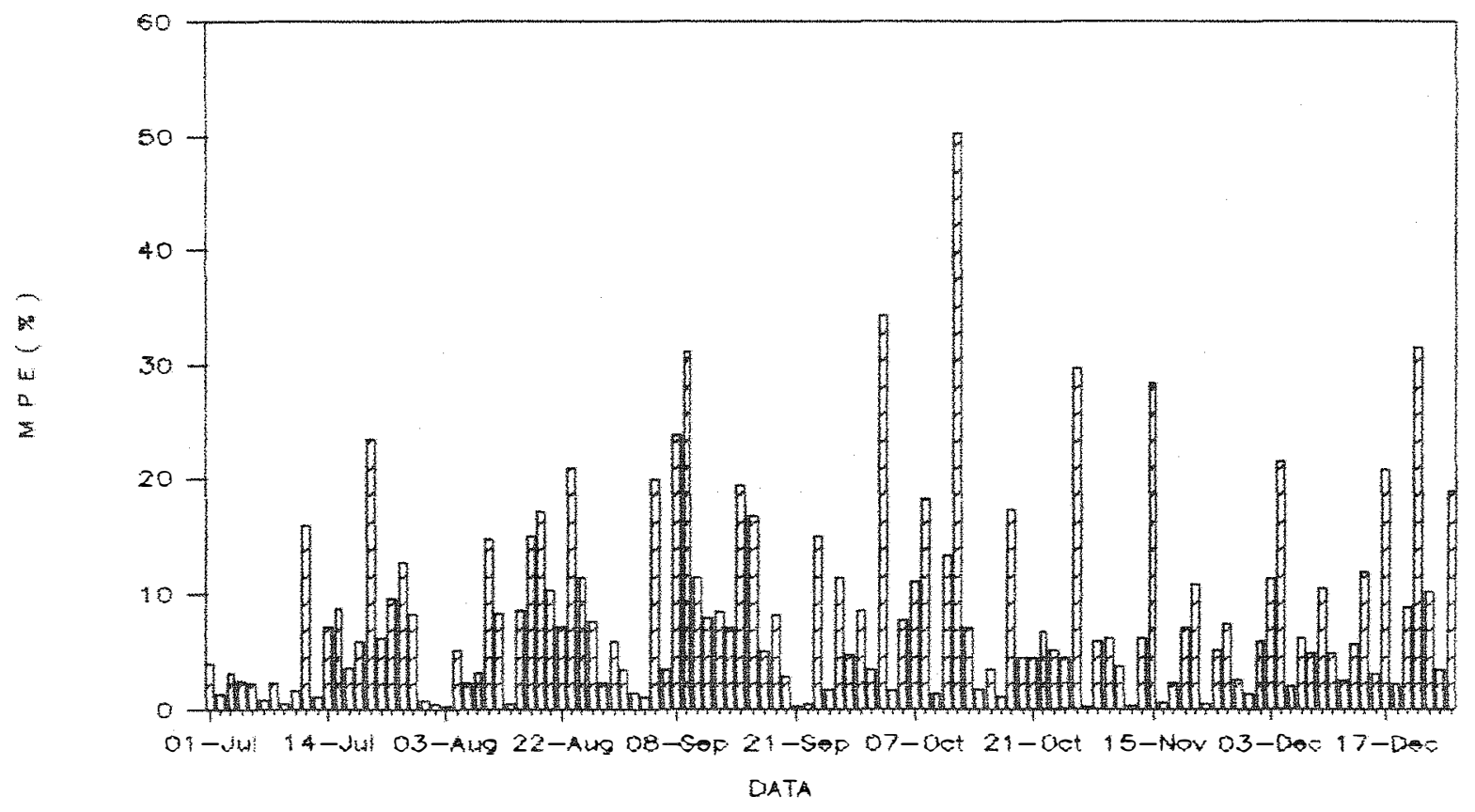

Figura 120. Teste MPE para o método proposto de julho a dezembro. 


\section{DISCUSSÃO DOS RESULtADOS}

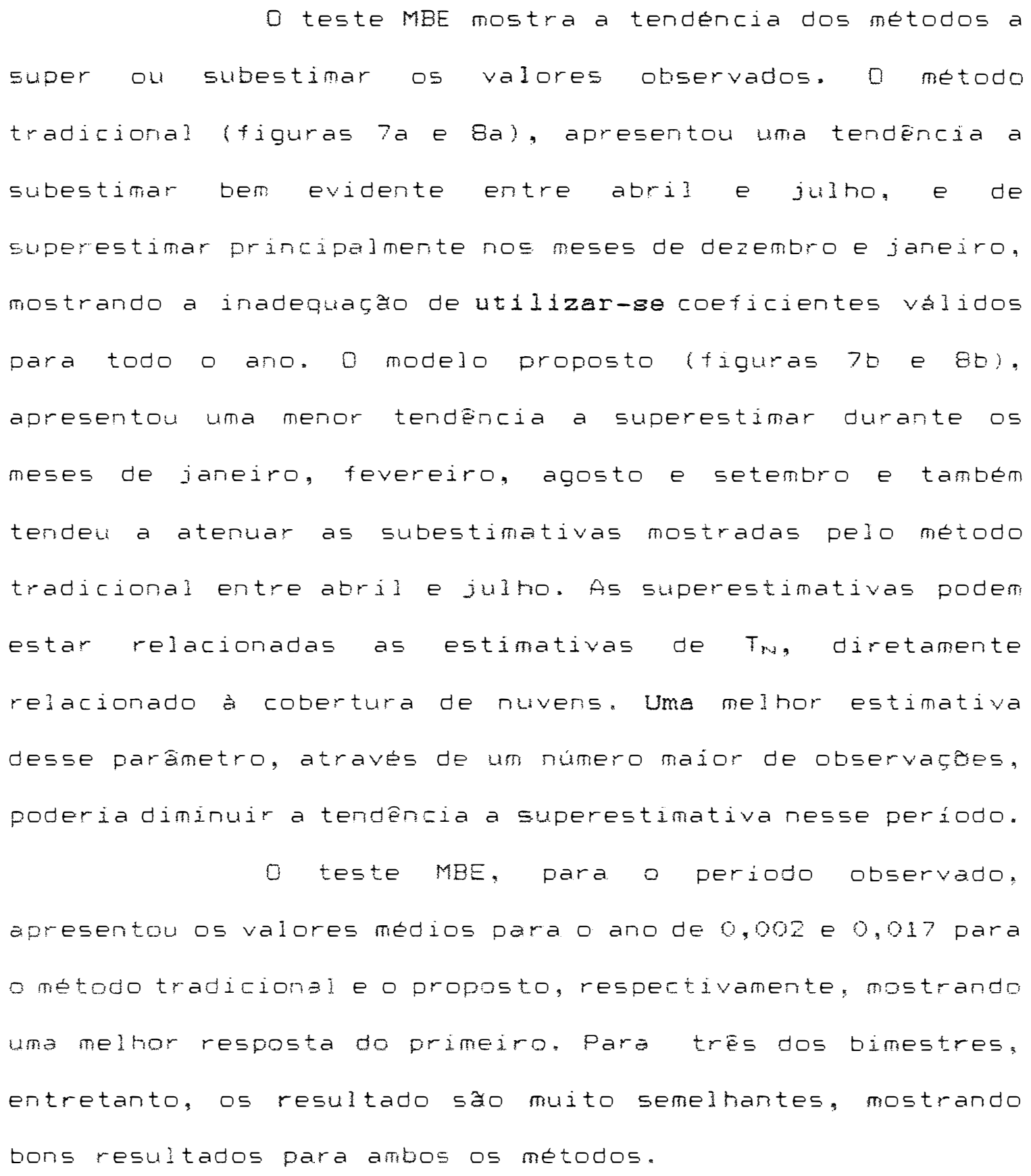


o segunto teste, RMSE, representado nas figuras (9a) a (10b), apresentou resultados muito semelnantes para os dois modelos, tanto para os bimestres ltabelas 6 e 8 a 13), como para o periodo do ano como um todo, 0,044 para o metodo tradicional e 0,040 para o metodo proposto, revelando um bom ajuste para ambos. O melnor ajuste ocorreu no mesmo periodo para os dois modelos (marso e abril) mas o modelo tradicional se afasta mais no periodo de maio a junho, enquarto para o modelo proposto isso ororre nos meses de setembro e outubro.

O Litimo teste (figuras 11 a a 12b) mostra a variagzo percentuai do valor calculado em relagăo ao observado, para o ano como um todo. O modelo proposto apresentou uma melhora de $0,5 \%$ em relagao ao metodo tradicional, 8,0\% e 8,5\% respectivamente. Adiferen 8 a media anual em favor do método proposto ocorre nos periodos de maio a agosto e novembro a fevereiro, atingindo por vezes valores proximos a $2,5 \%$

No periodo compreendido entre os meses de maio e agosto o numero de dias em que o erro na estimativa diaria supera $10 \%$ e muito maior para o metodo tradicional do que para o modelo proposto, pois o metodo tradicional apresentou um erro superior aos $10 \%$ em 23 casos dos 67 calculados, contra apenas 12 do modelo proposto. Para o periodo de setembro a abril a situaço se inverte, ocorrendo 3t casos no metodo tradicional e 44 no metodo proposto, totalizando no ano bl 
casos na método tradicional e 57 no método proposto.

O erro medio anual para o modelo proposto bem como para o método tradicional sao aceitáveis, se comparados, por exemplo, 'a magnitude do erro de planimetria dos registros de um actinografo.

o fato do metodo proposto suplantar o tradicional nas estimativas diarias no periodo seco do ano reforça a hipotese de que uma mel hor determinaça de Ta e Tiu pode diminuir o erro das estimativas proporcionadas pelo método, principalmente na epoca umida, conforme ja discutido. A respeito de $T_{A}$ e $T_{M .1}$, observou-se uma correlaça inversa entre seus valores (tabelab), com diminuiçao de TM nos meses mais secos e aumento de Ta, causado pelo decrescimo de vapor d'água da atmosfera.

O menor erro das estimativas diarias e a menor tendencia a apresentar super ou subestimativas ao longo do aro indicam que o método proposto pode ser utilizado em substituicăo ao tradicional. Uma definicăo sobre o seu mel hor desempentio em relaça ao tradicional depende de comparaça entre eles em outras situaçoes que as deste estudo, como por exemplo, outros periodos ou outros locais. Uma sugestao para estudos futuros é verificar o comportamento de ta $e$ Tru em funça da epoca do ano en diferentes locais. Nos estudos com - metodo tradicional, que se baseia em analise de regressao e cujos coeficientes das equaçoes são determinados para cada epoca do ano e local, tem-se tentado encontrar correlaçao de 


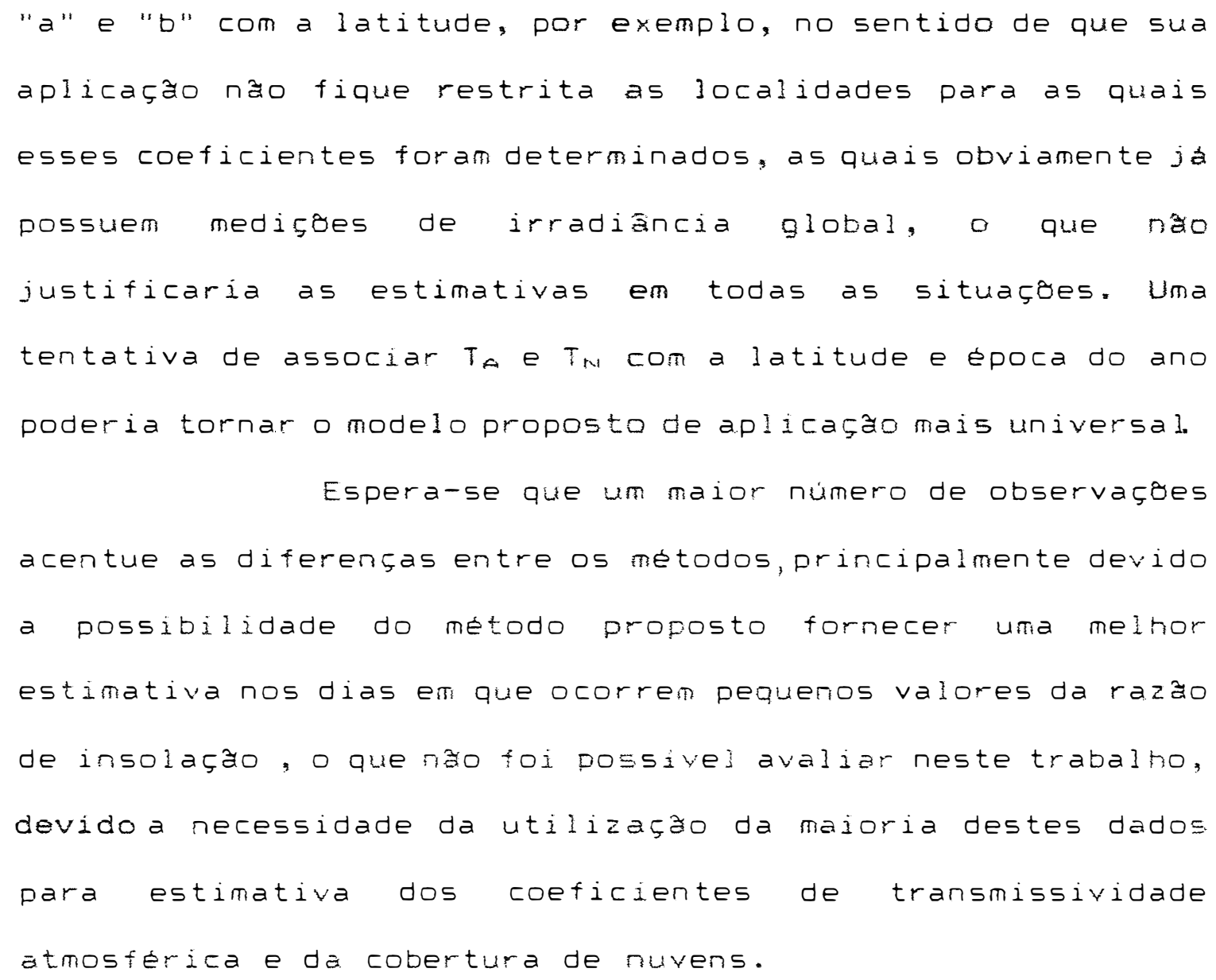




\title{
6. CONCLUSOESS E RECOMENDAÇÃO
}

\author{
(a) D metodo proposto permitiu boas \\ estimativas de irradiancia solar global ao nivel do solo. \\ (b) Para valores diários, nas condiços do \\ estudo, o modelo proposto apresentou-se ligeiramente superior \\ ao método tradicional, principalmente porque neste ultimo a \\ utilizaço de um único vajor anual para "a" e para "b" nas \\ equaças de regressao provocaram maior tendencia de super ou \\ subestimativas nas diferentes epocas do ano. \\ (c) Sugere-se estudos adicionais aos aqui \\ realizados, incluindo-se outros periodos e locais, no sentido \\ de uma melhor definicăo sobre o comportamento do metodo \\ proposto e sobre sua apiicaço de forma mais generalizada.
}




\section{REFERENCIAS BIBLI IOGRÁF ICAS}

BLACK, J.N.; BONITHON, C.W.; PRESCOTT, J.A. SOlar radiation and the duration of sunshine. Quarterly Journal of Royal Meteorological Society, London, 80(344): 231-5, 1954.

cervellini, A.; SALATI, E.; GODOY, H. Estimativa da distribuicao de energia solar no Estado de Sao faulo. Bragantia, Campinas, 25(8): 31-40, 1966.

coulson, L.K. Solar and terrestrial radiation; methods and measurements. New York. Academic Press, 1975. 3220.

DAVIES, J.A. Estimation of insolation for west Africa. Quarterly Journal of Royal Meteorological Society, London, $91(389): 359-63,1965$.

GLOVER, J. \& MCCULLOCH, 3.S.G. The empirical relation between solar radiation and hours of brigh sunshine in the High-altitude tropics. Quarterly Journal of Royal Meteorological Society, London, 84(359): 56-60, $1958 a$. GLOVER, J. \& MCCULloch, J.S.G. The empirical relation between solar radiation and hours of sunshine. Quarterly Journal of Royal Meteorological Society, London, 84(360): $172-5,1958 t$ 
GOPINATTAN, K.K. A general formula for computing the coefficients of the correlation connecting global solar radiation to sunshine duration. Solar Energy, Oxford $41(6): 499-502,1988$.

LIST, R.J., ed. Smithsonian meteorological tables. o. ed. Washington, Smithsonian Institution Press, 1984. 527p. LOPES, N.F.; GOMES, A.S.; MOTA, F.S.; GARCEZ, J.R.B.; GOEDERT, C.O.; BOING, J. Estimativa da radiagao solar durante o ciclo vegetativo dos cereais no Rio Grande do Sul. Pelotas, Instituto de Pesquise Agropecuária do Sul, 1971. 32p. (Boletim Técnico, 73).

MART INEZ-LOZANO, J.A.; TENA, F.; ONRUBIA, J.E.; DE LA RUBIA, 3. The historical evolution of the \&ngstron formula and its modification: review and bibliography. Agricultural and Forest Meteorology, Amsterdam, 33: 109-28, 1984. MATEEF, C.L. A preliminary estimate of the average insolation in Canada. Canadian Journal of Agricultural Science, Ottawa, 35(6): 579-94, 1955. MOTA, F.S. Estimativa de radiaça liquida em Pelotas, RS. Ciencia e Cultura, Såo Paulo, 28(10): 1174-8, 1976. OMETTO, J.C. Estudo das relaças entre radiaçao solar global radiaçăo liquida insolaçao. Piracicaba, 1968. 64p. (Doutorado - Escola Superior de Agricultura "Luiz de Queiroz"/USP) 
REIS, A.C.S.; COELHO, T.J.F.; ALVES, N.L.L. Estimativa da energia solar global na drea do Recife, baseada em registros de insolaçao. Pesquisa Agropecuaria Brasileira, Série Agronomia, Brasilia, $\mathbf{8}(7)$ : $177-9,1973$.

RIBEIRO, A.M.A. Estudo das relaçôes entre radiaça solar global (Qg) e razao de insolasao $(n / N)$ em algumas regides do Brasil. Piracicaba, 1980. 88p. (Mestrado-Escola Superior de Agricultura "Luiz de Queiroz" IUSP)

RIBEIRO; M.N.G.; SALATI, E.; VILLA NOVA, N.A.; DEMETRIO, C.G.B. Radiaçao solar diponivel em Manaus (AM) e suas relaçoes com a duraça do brilho soiar. Acta Amazonica, Manaus, $12(2): 339-4 t, 1982$.

RIETVELD, M.R. A new method for estimating the regression coefficients in the formula relating solar radiation to sunshine. Agriculturai Meteorology, Amsterdam, 19(3): $243-52,1978$

ROSENBERG, N.3. Microclimate; the biological environment. New York, Jonh Wiley \& Sons, 1974. 315p. SA. D.F. Alguns aspertos da energia solar em Mandacari. Boletim de Recursos Naturais da SUDENE, Recife, 11(1): $11-$ $26,1973$.

SANTOS, R.; ANDRE, R.G.B.; VOLVE, C.A. Estimativa de radiacao solar globaj em Jaboticabal, SP. Cientifica, Sao Paulo, 11(1): 31-9, 1983. 
TUBELIS, A.; NASCIMENTO, F.J.L.; FOLONI, L.L. Radiaço solar global e insolaço em Botucatu, SP, medias mensais. Botucatu Cientifica. Serie A, Botucatu, 2(1): 25-34, 1977.

WILLMOTt, C.J. On the validations of models. Physical Geograpty, Sizver Spring 2(2): 184-94, 1981. 
APENDICE 


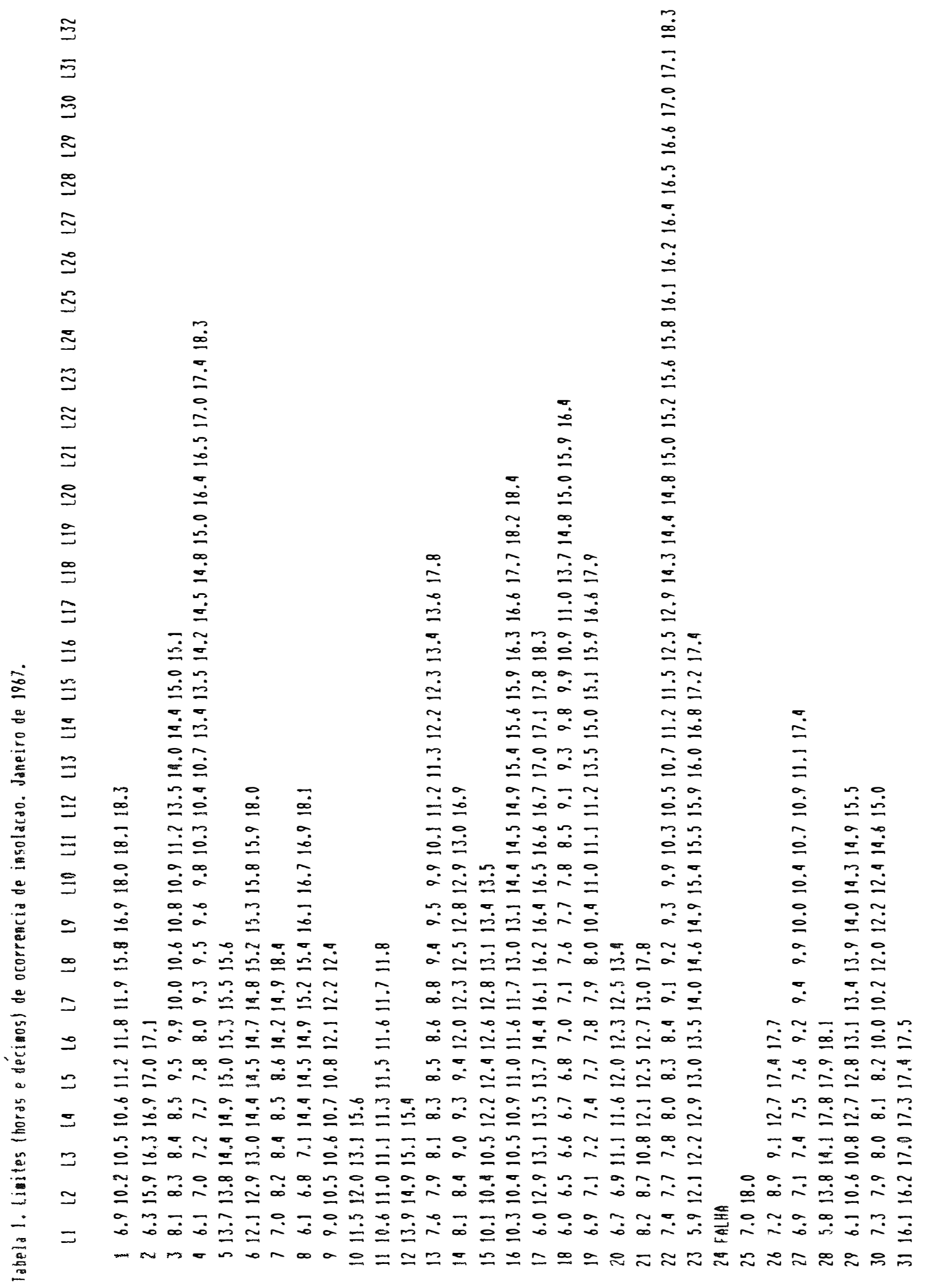




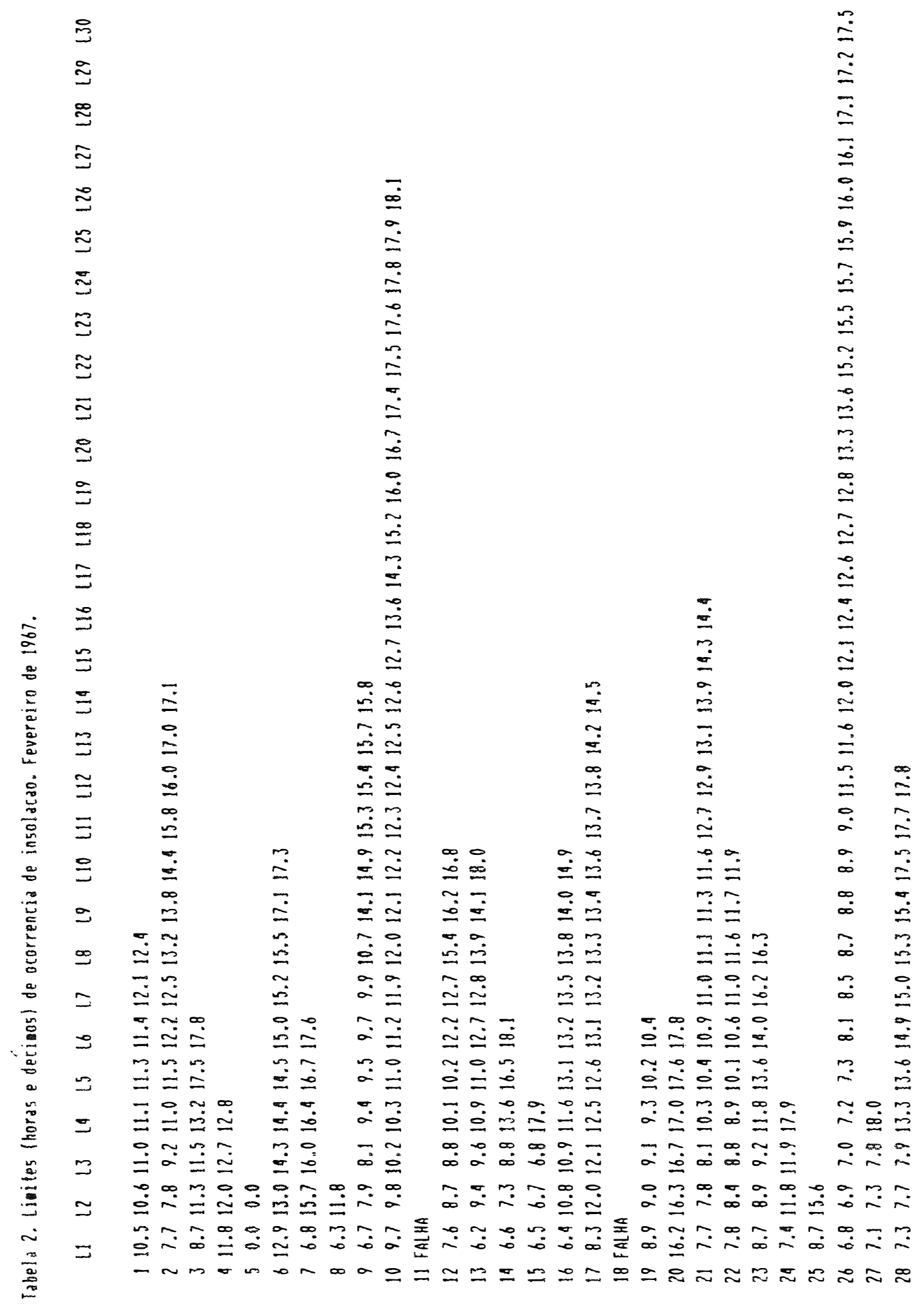




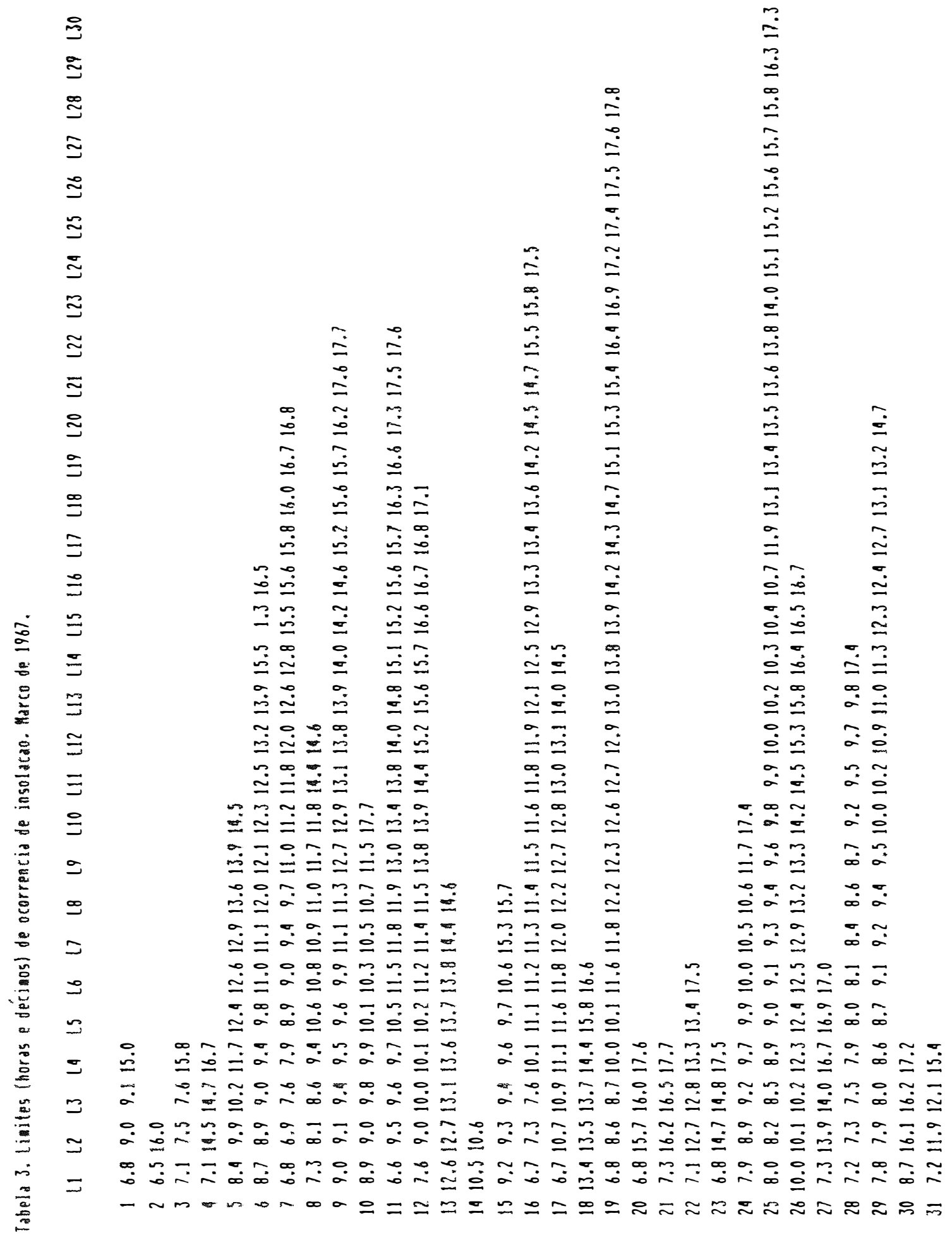




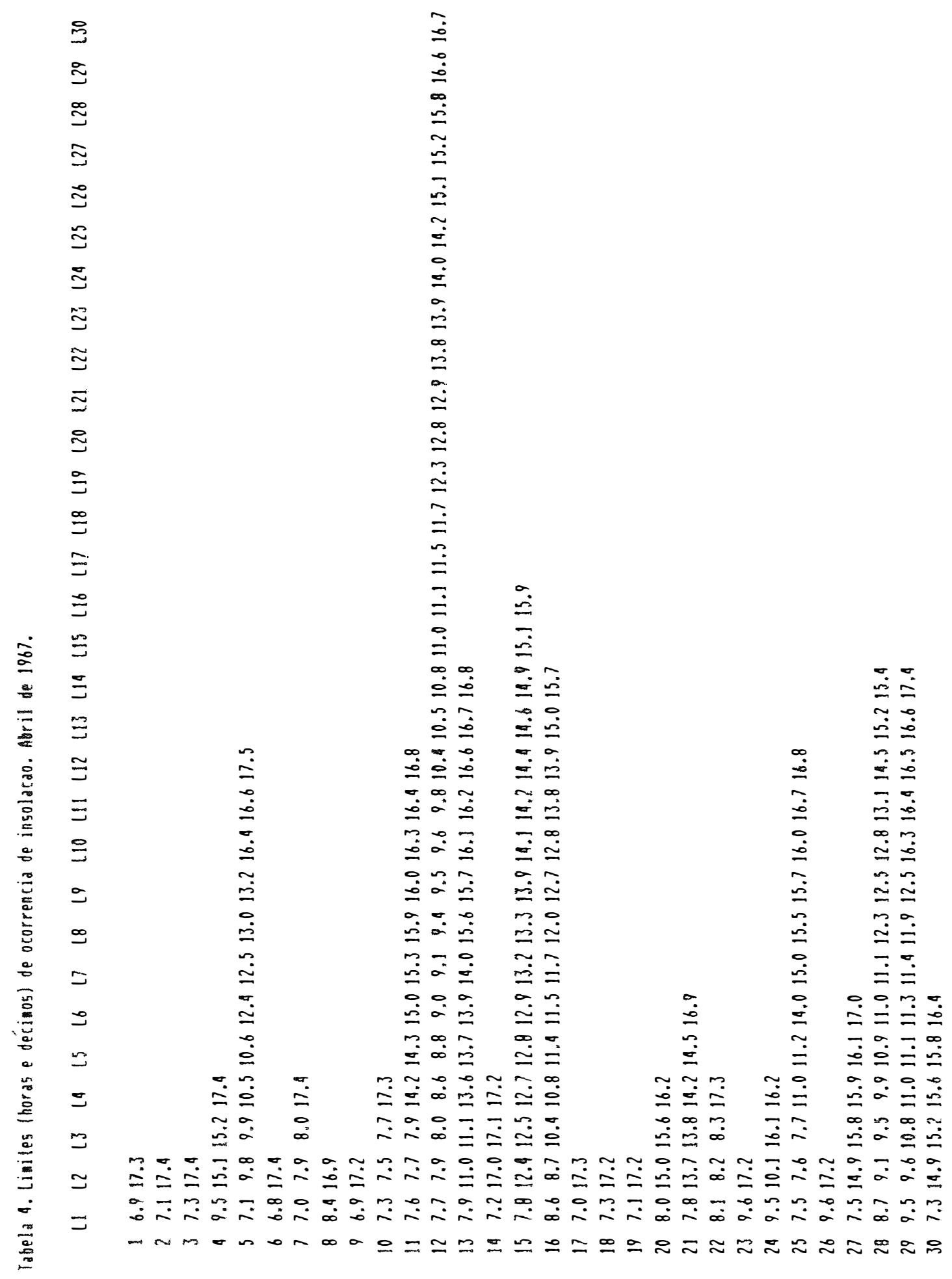




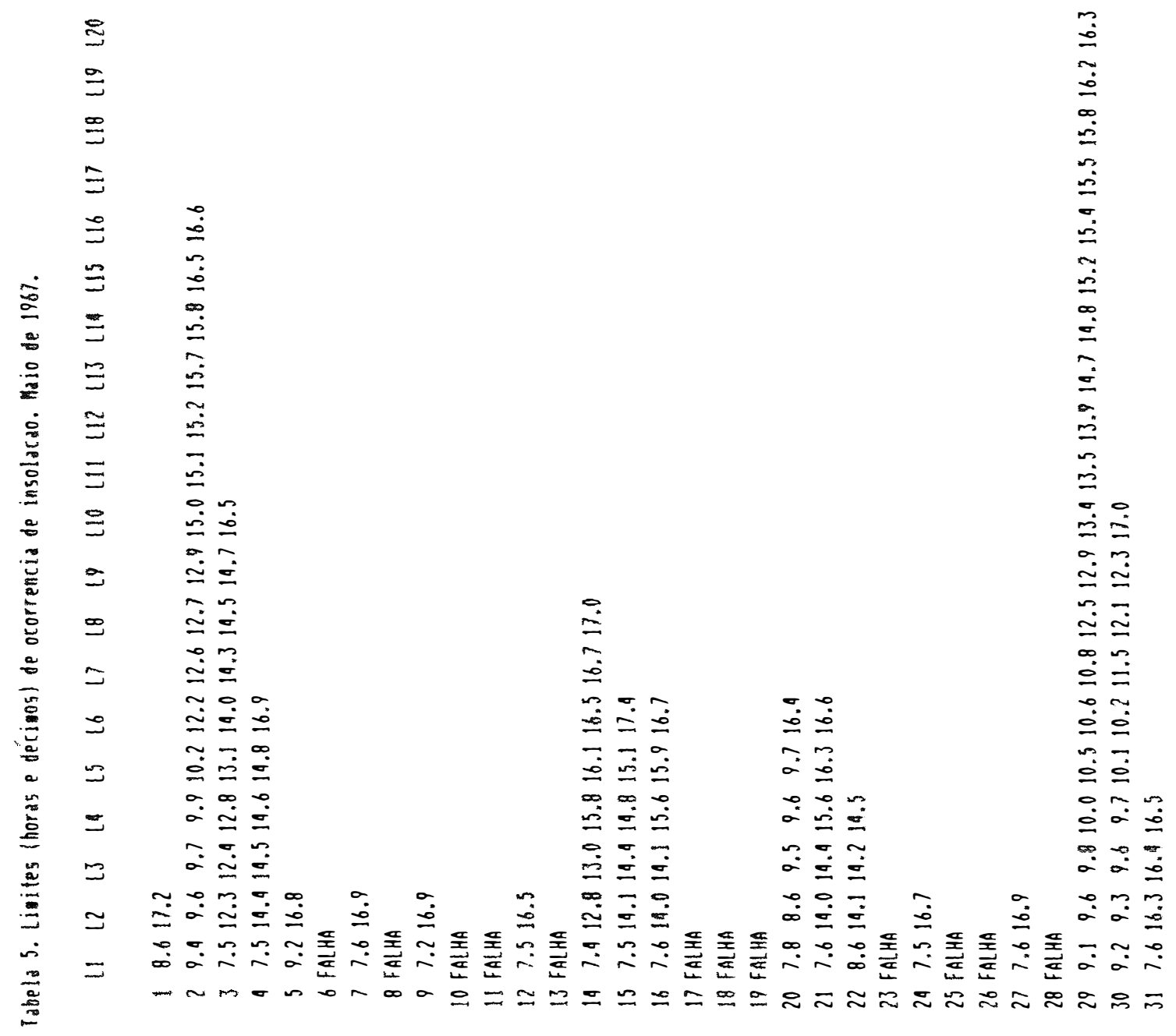




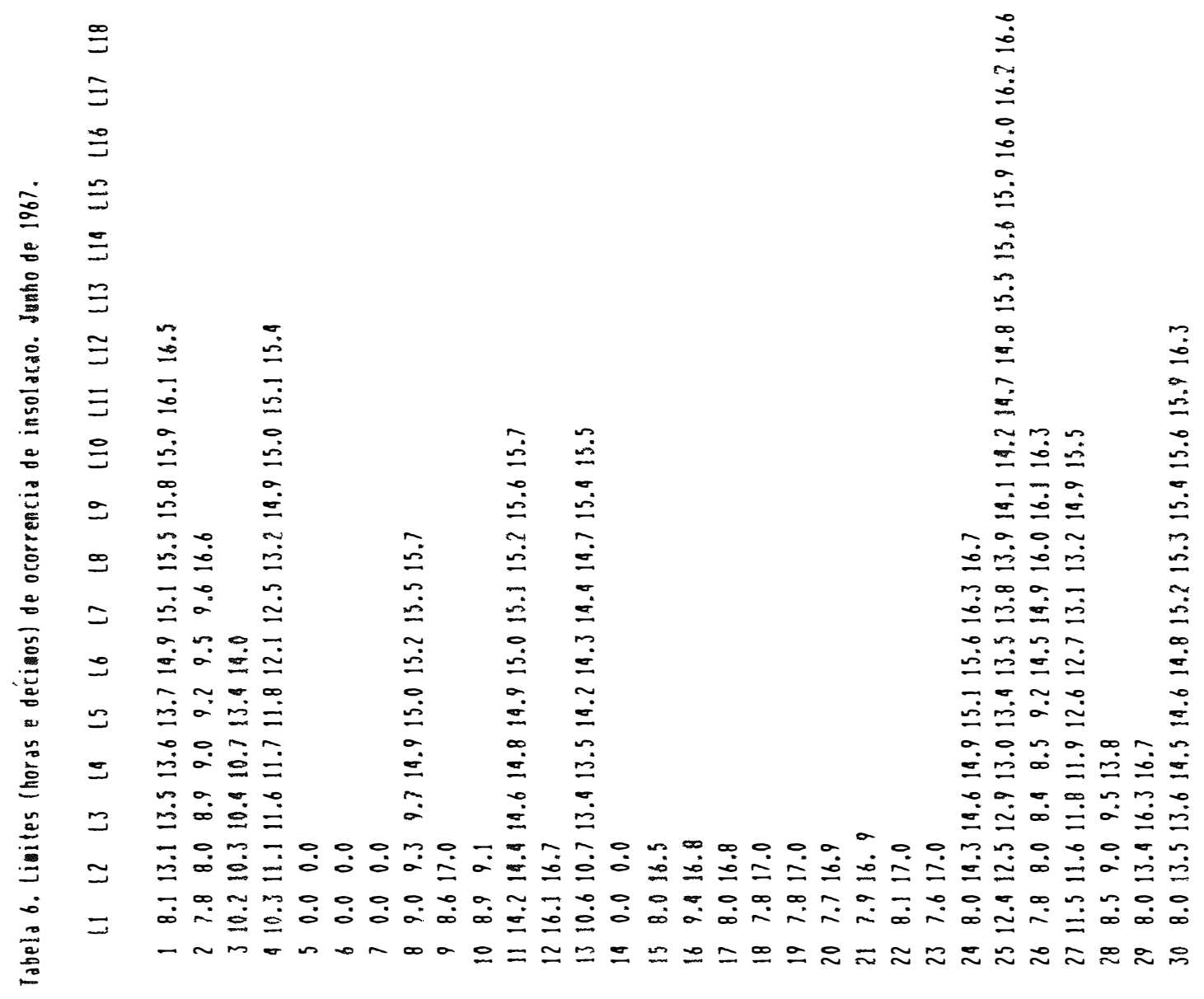




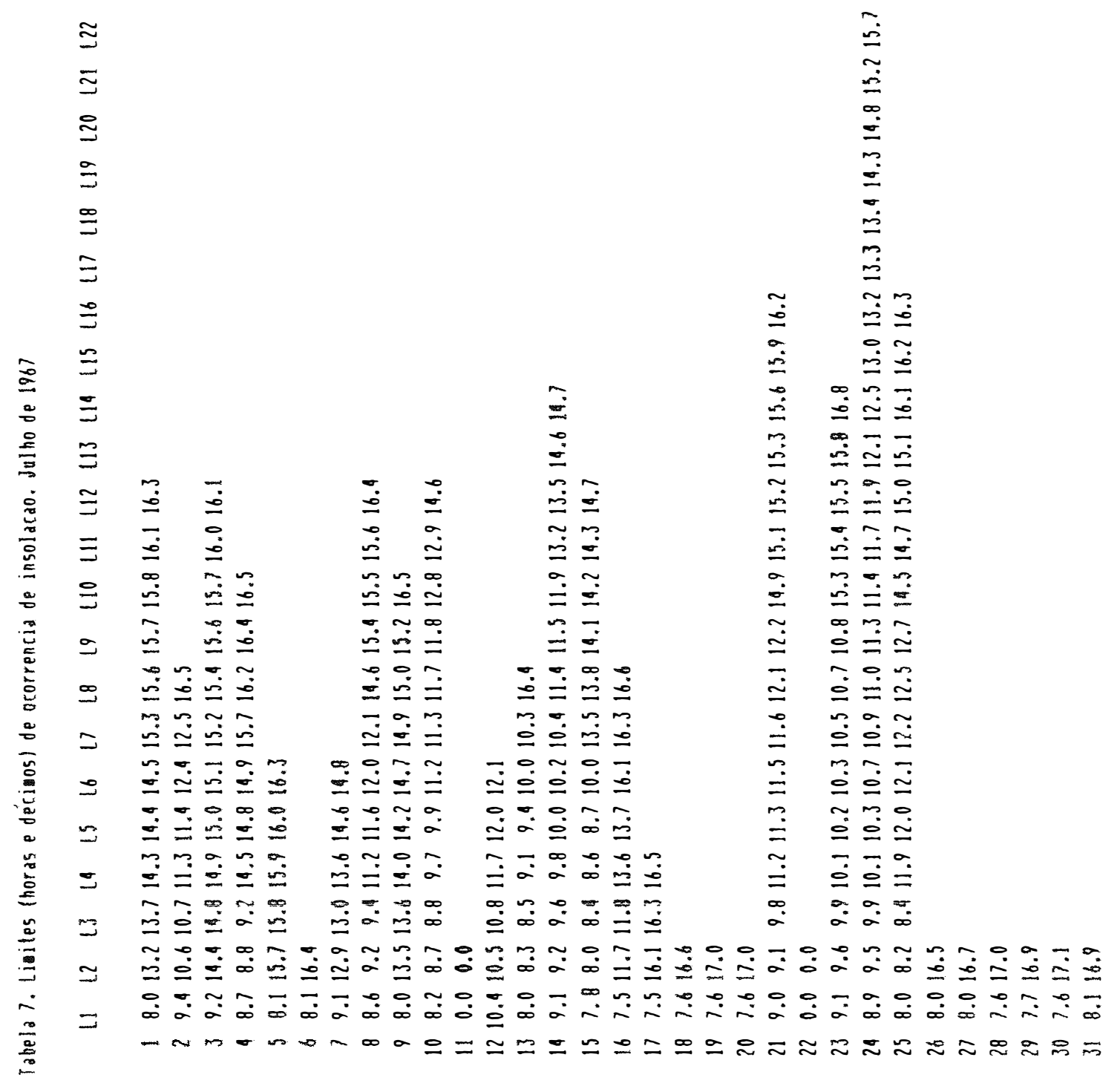




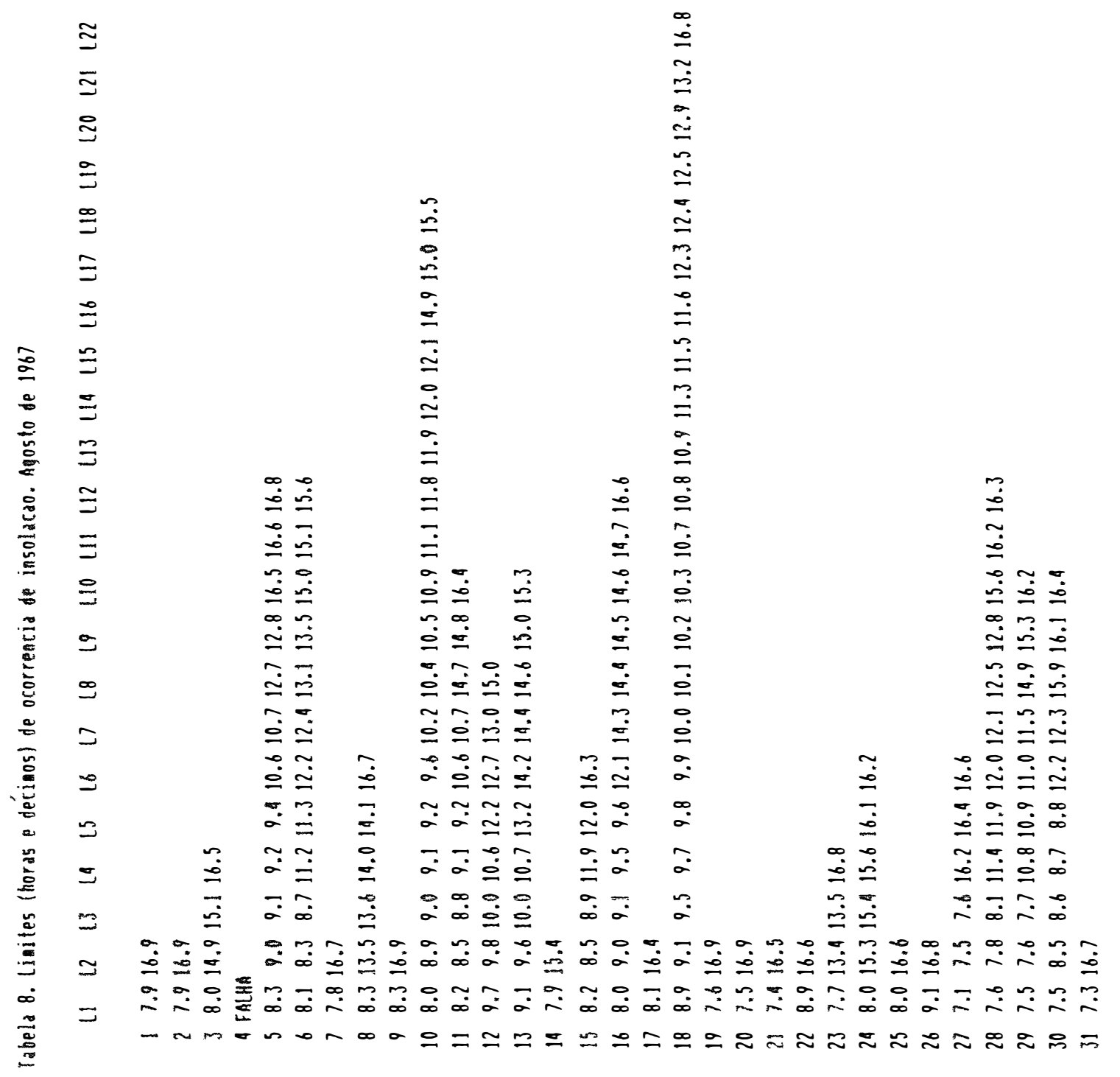




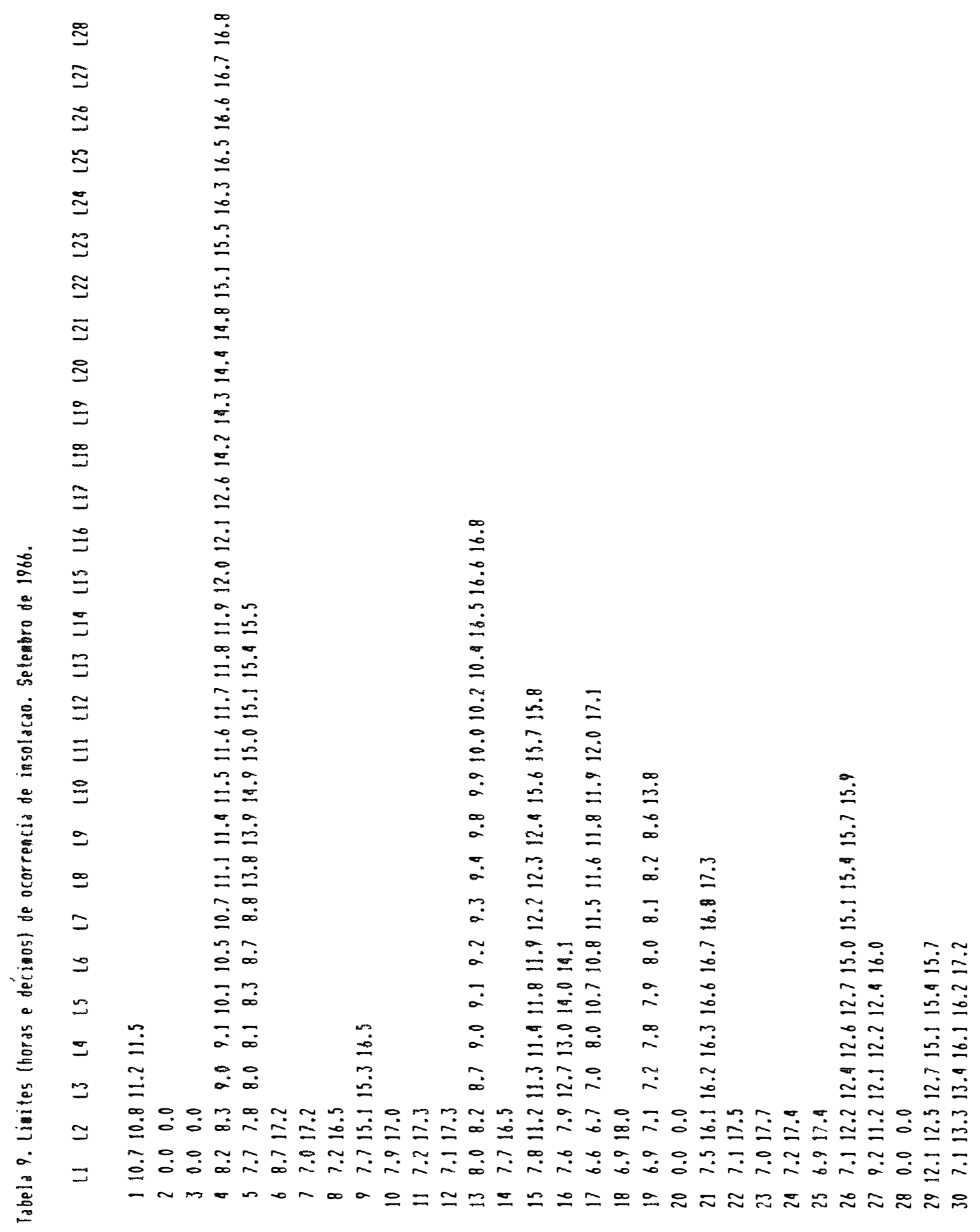




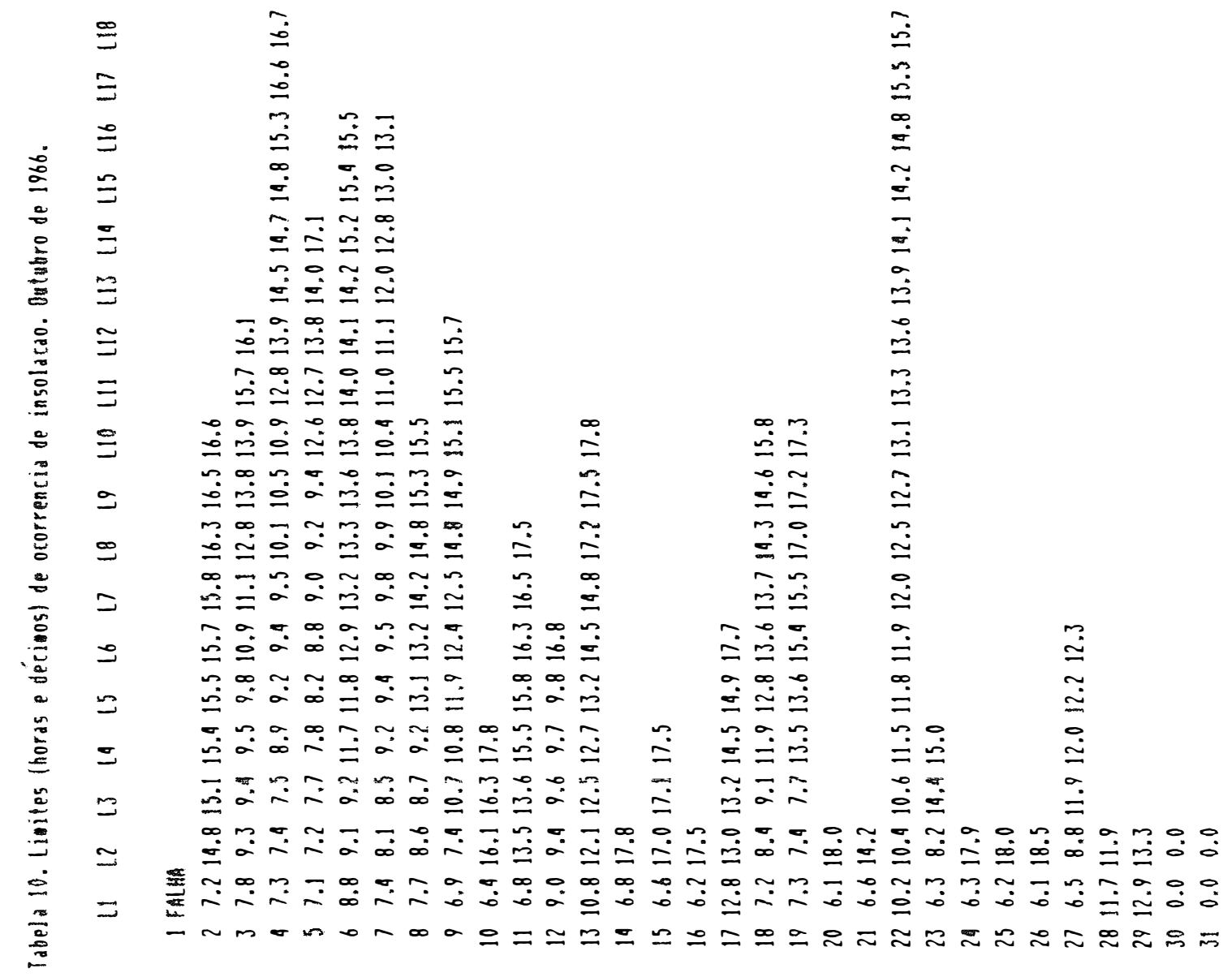




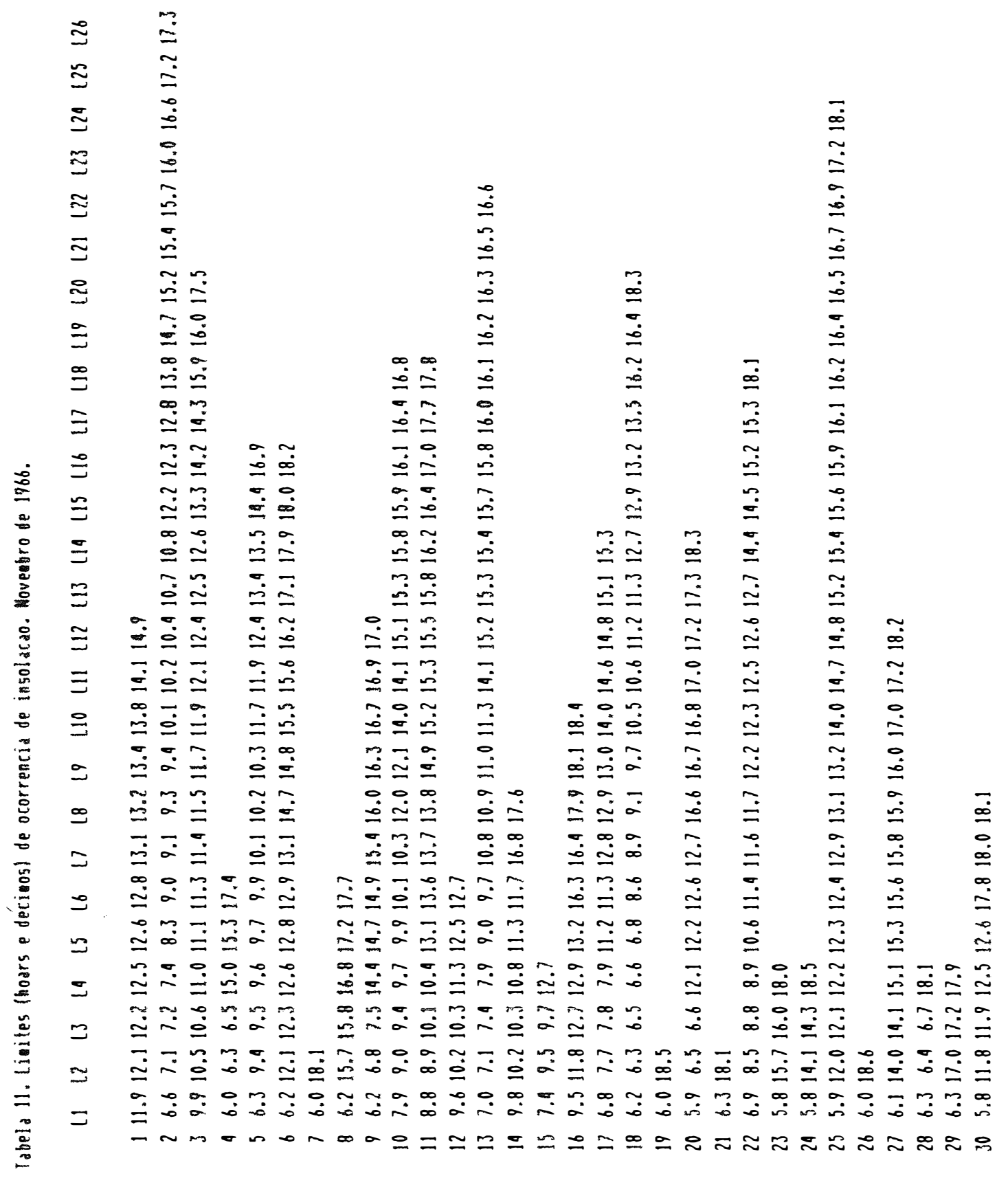




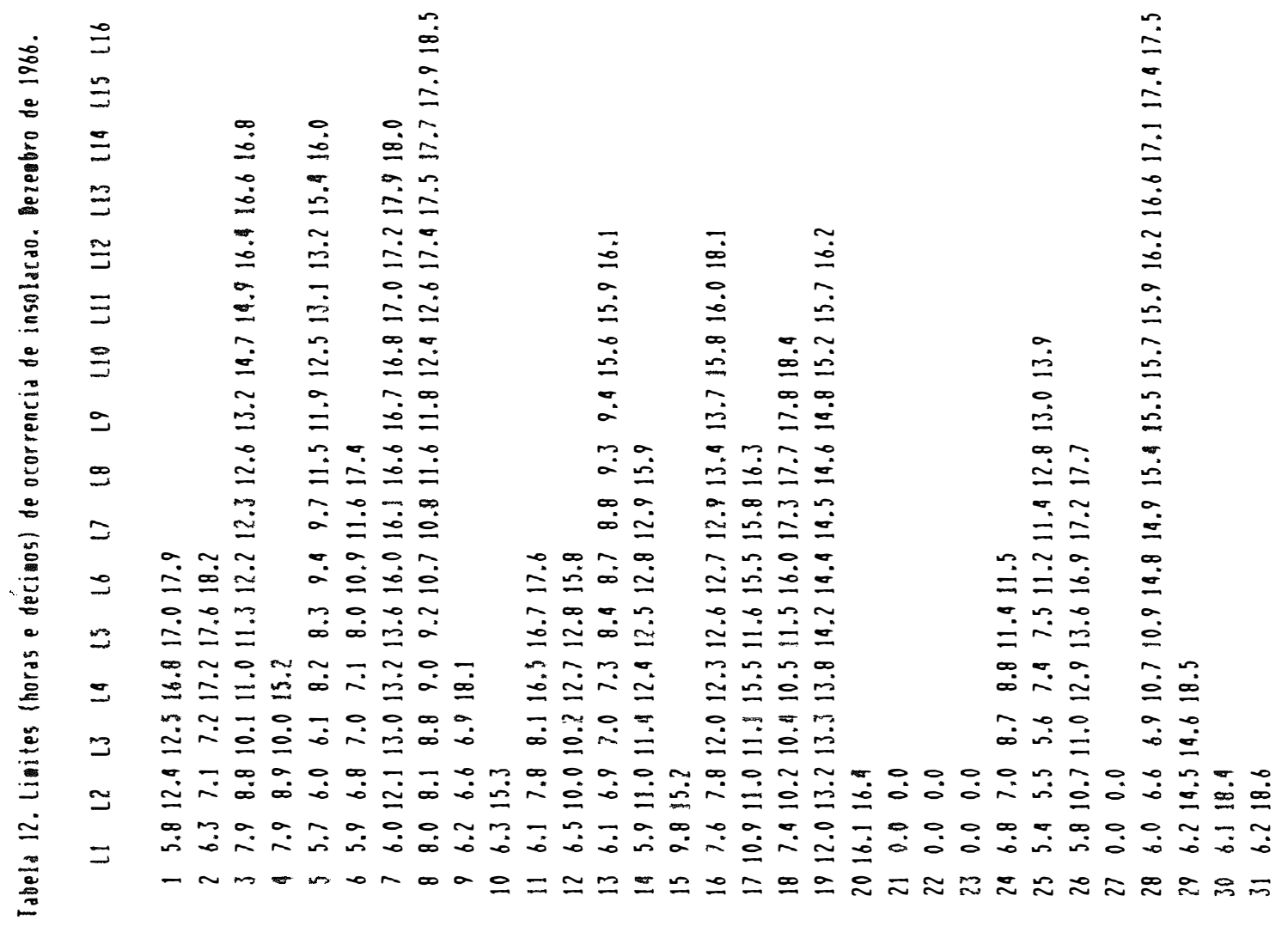

